\title{
برنامج مقترح قائم على إستراتيجية التغير المفاهيمي لتصحيح \\ التصورات البديلة للمفاهيم التاريخية وتتمية أبعاد الأمن المجتمعي \\ لاى طلاب شعبة التاريخ في كليات التربية و تأثيره على اتجاهاتهم \\ إعداد

\author{
دادماد عبد القتاح زايد \\ أستاذ المناهج و طرق تدريس التاريخ المساعد عيد الدادي \\ كلبة التربية جامعة عين شمس فلدر
}

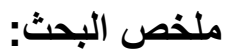

هدف هذا البحث الى التعرف على فاعلية برنامج مقترح قائم على إستر اتيجية التغير المفاهيمي

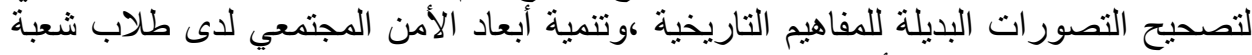

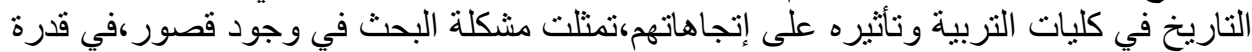

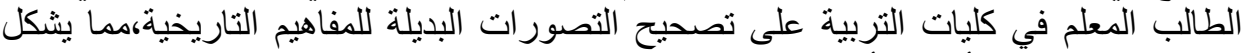

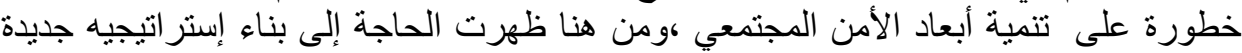

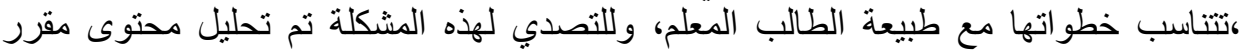

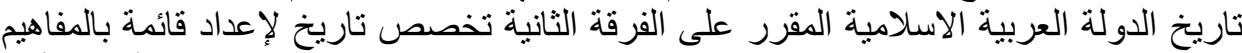

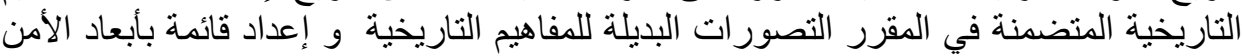

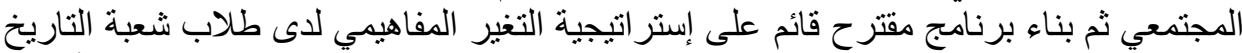

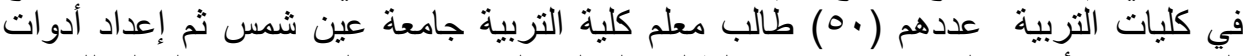

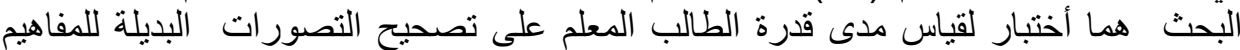

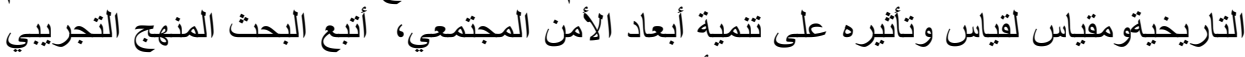

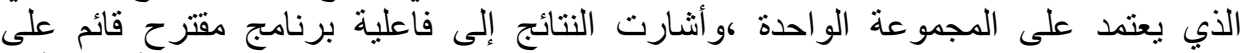

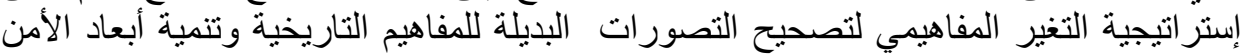
المجتمعي،ويتضح ذلك من خلال دلالة منوسطي درجات الطالب المعلم في التطبيقين القبلي

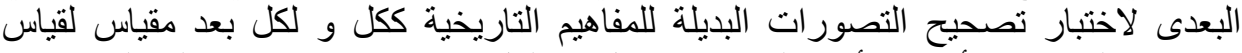

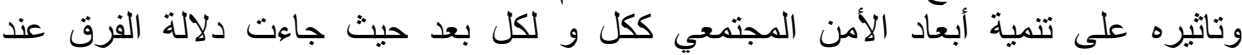

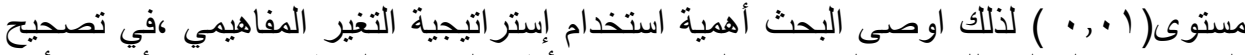

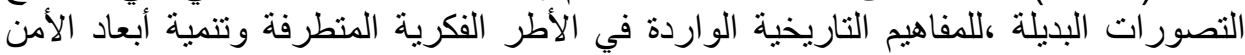
المجتمعي.

الكلمات المفتاحية:إستر اتيجية التغير المفاهيمي ـ التصور ات البديلة للمفاهيم التاريخية ـ أبعاد الأمن المجتمعي

العدد الخامس والاربعون (الجزء الثالث) ب r r r

مجلة كلية التربية- جامعة عين شمس 


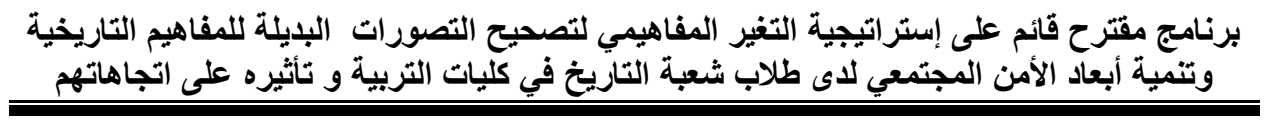

Research Summary:

The aim of this research is to identify the effectiveness of a proposed program based on a conceptual change strategy to correct alternative perceptions of historical concepts, and to develop the dimensions of societal security for students of the History Division in the faculties of education and its impact on their attitudes. Correcting alternative perceptions of historical concepts, which poses a danger to the development of the dimensions of societal security, hence the need to build a new strategy, the steps of which are commensurate with the nature of the student teacher. With the historical concepts included in the course, alternative perceptions of historical concepts, preparing a list of the dimensions of societal security, and then building a proposed program based on the conceptual change strategy for the students of the History Division in the faculties of education, numbering (50) students, teacher of the Faculty of Education, Ain Shams University, then preparing the research tools, which are a test to measure the extent The ability of the student teacher to correct alternative perceptions of historical concepts and a measure to measure and its impact on the development of security dimensions Societal, the research followed the experimental method that depends on the one group, and the results indicated the effectiveness of a proposed program based on the conceptual change strategy to correct alternative perceptions of historical concepts and develop the dimensions of social security, and this is evident through the significance of the student-teacher average scores in the two tribal and post applications to test the correction of alternative perceptions. The historical concepts as a whole and for each dimension have a scale to measure and its impact on the development of the dimensions of societal security as a whole and for each dimension, where the difference significance came at the level (0.01). Therefore, the research recommended the importance of using the conceptual change strategy, in correcting alternative perceptions, of the historical concepts contained in the extremist intellectual frameworks and the development of dimensions community security.

Keywords: Conceptual change strategy, alternative perceptions of historical concepts, dimensions of societal security

العدد الخامس والاربعون (الجزء الثالث) ا r r r r

(246)

جملة كلية التربية- جامعة عين شمس 
د/ غادة عبد الفتاح زايد

\section{برنامج مقترح قائم على إستراتيجية التغير المفاهيمي لتصحيح}

\section{التصورات البليلة للمفاهيم التاريخية وتتمية أبعاد الأمن المجتمعي}

لاى طلاب شعبة التاريخ في كليات التربية و تأثيره على اتجاهاتهم إعداد

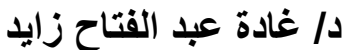

أستاذ المناهج و طرق تدريس التاريخ المساعد النيا

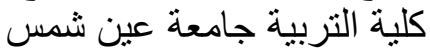

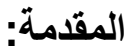

تعد البنائية من أهم النظريات التربوية الحديثة التي ظهرت في الآونة الأخيرة؛ حيث اهتمت بكيفية اكتساب المتعلم للمعرفة من خلال خطوات منظمة باستخدام نماذج و استر اتيجيات وطر ائق تدريس قائمة على أسس تربوية تجعله محور العطلية التعليمية، كما ينصب تركيزها على تتمية المفاهيم لدى المتعلم، مما يجعل التعلم ذا معنى ،و هذا يتطلب مشاركة جميع المؤسسات التربوية من أجل تحقيق ذلك ،كما أن تعديل التصورات البديلة للمفاهيم وتصوييها، أيضًا من الأهداف التربوية التي تسعى إليها

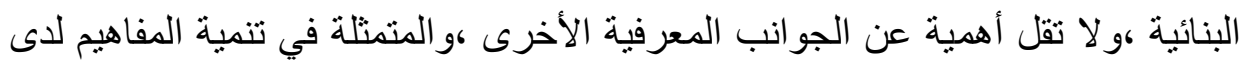

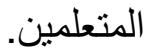
وتسهم النظرية البنائية في فهم أصول التصورات البديلة للففاهيم ،و التي تكونت لدى

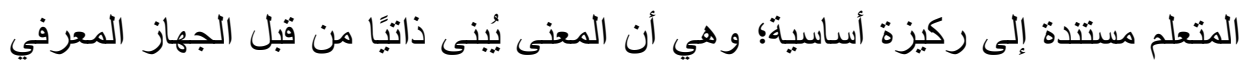
للمتعلم ويقاوم التغيير بشكل كبير؛ ولذا فالتحدي الذي يواجه الباحثين و المختصين الآن لا يقتصر على مساعدة المتعلم تعلم المفاهيم بصورة صحيحة، بل مساعدتهم على تعديل التصورات البديلة لتللك المفاهيم الموجودة بداخلهم، ولهذا قاموا بإجراء البحوث

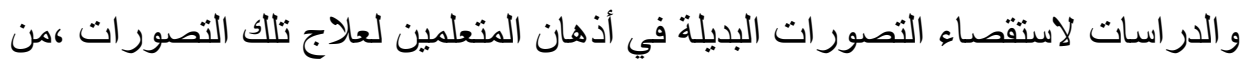

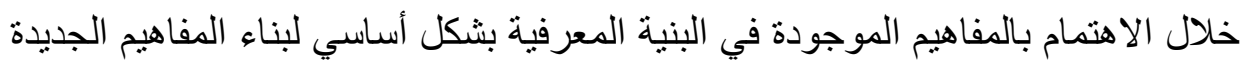

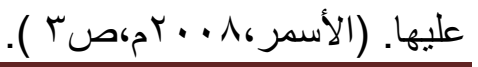

العدد الخامس والاربعون (الجزء الثالث) ا Y.r.

جملة كلية التربية- جامعة عين شثس 
برنامج مقترح قائم على إستراتيجية التغير المفاهيمي لتصحيح التصورات البايلة للمفاهيم التاريخية

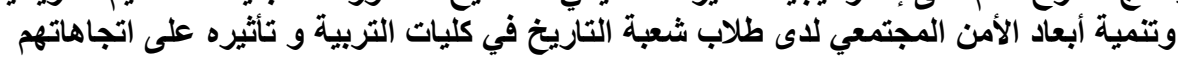

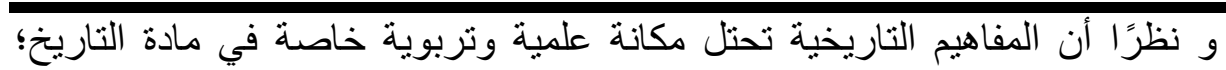
حيث تسهم في فهم المتعلمين وبعمق للمادة الدر اسية، وتعمل على ربط الحقائق التاريخية بعضها البعض، كما تزيد من البناء المعرفي المنظم للمتعلم، والذي يتم استخدامه في تفسير مواقف جديدة ،ولذلك تعد أساس المبادئ و القوانين الخاصة بعلم التاريخ ،ومكونًا مهمًا من مكونات البنية المعرفية التاريخية، وركنًا أساسيًا في تعليم وتعلم مادة التاريخ كوبالتالي يعد تصويب التصورات البديلة للمفاهيم التاريخية من القضايا التي شغلت الباحثين و المهتمين بالتربية ليكتسب المتعلم المفاهيم بطريقة

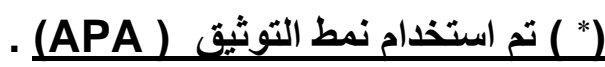

صحيحة تساعد على توظيف المعلومات القبلية لاى المتعلمين من أجل بناء فهم صحيح للمفاهيم التاريخية ؛وتفادي حدوث تصورات بديلة للمفاهيم التي يدرسها المتعلم في المر احل التعليمية المختلفة. وأكدت lane (2012)و(Pinochet,2019) أهمية تعرف التصورات البديلة للمفاهيم، وتصويبها بشكل صحيح من الأهداف الرئيسية في أثناء التدريس ، لذلك يجب بذل كثير من الجهد ليكتسب المتعلم المفاهيم ،بشكل صحيح ويعد تصويب التصورات البديلة لهذه المفاهيم من الأهمية بمكان عند تعلم الجغرافيا بشكل فعّال، وأن من أهم عناصر فهم المتعلم للمحتوى هو فهم مفاهيمه بشكل صحيح، وتصويب التصورات

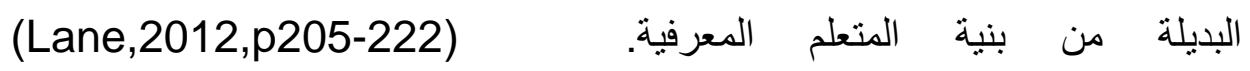

(Pinochet,2019,p32)

وأثار فتحي(10 • بم)إلى أسباب شيوع التصورات البديلة في مادة الدراسات الاجتماعية، منها: عدم وضوح المفاهيم بالكتاب المقرر، وأن معظم المفاهيم مجردة بسبب استخدام الطرق التقليدية في التدريس ،وقلة استخدام الوسائل التعليمية التي تساعد

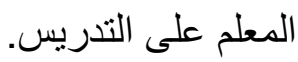

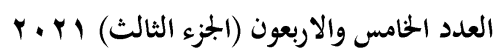

مجلة كلية التربية- جامعة عين شمس 
دادة غادة عبد الفتاح زايد

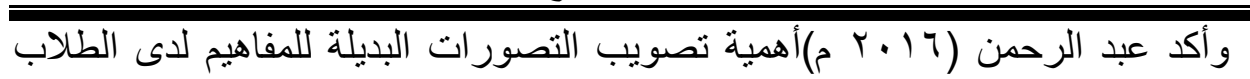
عند إعدادهم وتصميم المناهج الدراسية بمادة الدراسات الاجتماعية، وأهمية إعداد برنامج متكامل لتشخيص و تصويب المفاهيم البديلة الموجودة في البنية المعرفية لدى الطلاب.

كما أكدت دراسة Langman, Petrosino \& Persson (2018 ) أهمية الكثف المبكر عن التصورات البديلة للمفاهيم الجغرافية ، و اقتراح طر ائق وأساليب لتصحيح تللك الدفاهيم وتعديلها، وأوصت بضرورة توجيه أنظار معلمي المواد الدراسية إلى أهمية تعرف المفاهيم البديلة لدى طلابهم و تو عيتهم بخطورة التطرف داخل المدرسة. ونظرًا لأن مادة التاريخ مادة خصبة بالمفاهيم سواء المفاهيم السياسية كالخلافة و

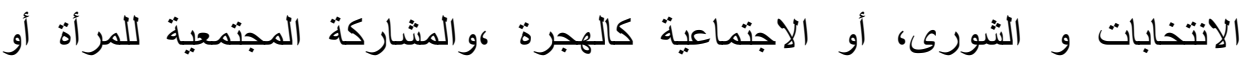
العسكرية كالجهاد و النضال من المفاهيم التاريخية، لذلك فإنها تعتبر من أساسيات العلم و المعرفة ،لكونها تزيد من قدرة الطلاب على فهم حقيقة التحديات والأحداث الإرهابية التي يتعرض لها المجتمع حتى يستطيعوا إصدار الأحكام واستيعاب ،ما يدور حولهم من أحداث وتداعيات وتفسير ها تفسيرا علميًا ومنطقيًا بعيدًا عن التطرف ،و لذا لابد من لهن تحديد متطلبات أبعاد الأمن المجتمعية ،والسياسية، والاجتماعية ،والفكرية التي تساعد الطلاب على تكوين المفاهيم الصحيحة و الاحتفاظ بها ،بدلًا من فهمها فهمًا خاطنًا للحفاظ على أمن و المجتمع واستقراره. و انطلاقا مما سبق فإن المنظومة التربوية في مجتمعنا المصري، بحاجة ماسة إلى إعادة النظر في أهدافها ومضامينها ووسائلها، لتكون هذه المنظومة أداة تطوير وتغيير بناء، لمواجهة تلك التصورات البديلة للمفاهيم التاريخية ،التي تسعي الجماعات المتطرفة لنشرها بين أبناء المجتمع، مما يتطلب أهمية نوعية الطالب بأبعاد الأمن المجتمعي ،في الأوساط التربوية وخاصة نتيجة لاضطر اب الأحداث السياسية و الاقتصادية في العالم؛ والتهديدات التي تنكل خطرًا كبيرا على المجتمعات المدنية التي تسعي للاستقرار، 
برنامج مقترح قائم على إستراتيجية التغير المفاهيمي لتصحيح التصورات البايلة للمفاهيم التاريخية وتنمية أبعاد الأمن المجتمعي للدى طلاب شعبة التتاريخ في كليات التربية و تأثيره على اتجاهاتهم

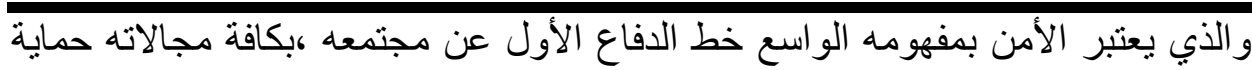
للوطن و المواطن وتوفيرًا للبيئة الاجتماعية الصالحة لإعداد مواطن حضاري ومجتمع متمدن كيرتقى بالفكر و الرؤية ويعتمد على التعايش مع الأخر.

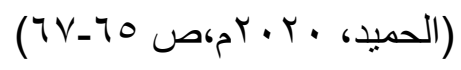
وتسعى عديد من المناهج الدراسية إلى توظيف متطلبات أبعاد الأمن المجتمي، لمواجهة مخاطر التطرف الفكري الناتج عن قصور تناول المناهج الدراسية ،ومنها مناهج العلوم الاجتماعية عامة و التاريخ خاصة ،بحكم طبيعتها تعد مسسئولة عـن تنمية السلوك الاجتماعي والأمني لــدى المتعلمين، من أجل الحفاظ على أبعاد الأمن المجتعي ،و لا يمكن يختلف اثنان على أهمية الأمن الذي يعبر عن شعور الإنسان

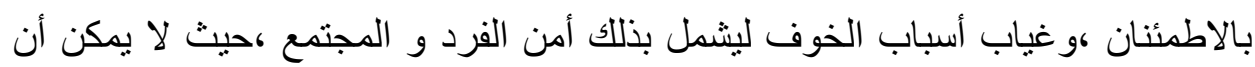
يتحقى أمن الفرد بمعزل عن أمن المجتمع.

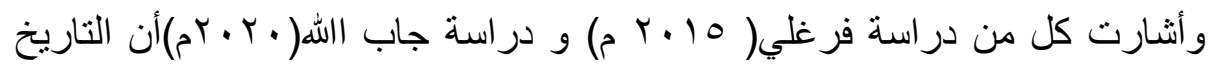

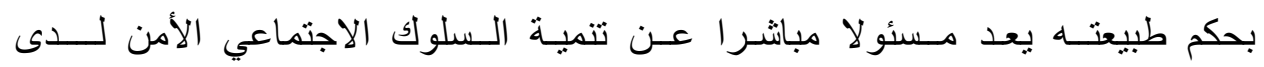

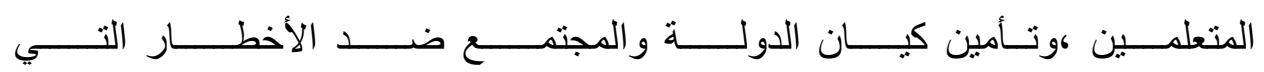

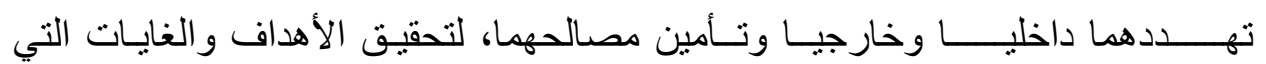
تعبر عن الرضا العام في المجتمع. ومما سبق يتضح أن تصحيح التصورات البديلة للمفاهيم التاريخية. التي قامت بنشرها جماعات العنف و التطرف، قد يؤدي إلى الإضرار بالأمن المجتمعي داخليا و خارجيا على المستوى المحلي و القومي والعالمي ،ومن ثم كان تصحيح هذا الفهم و محاربة هذا الفكر من واجبات جميع المؤسسات التعليمية في العصر الحالي أثناء التدريس ؛وذلك من فن خلال البحث عن نماذج و إستراتيجيات تدريسية جديدة ،لعلاج تللك التصورات والاهتمام بالمفاهيم الموجودة في البنية المعرفية بشكل أساسي. 
دادة غادة عبد الفتاح زايد

وتعد إستراتيجية التغير المفاهيمي من الإستراتيجيات الأكثر ارتباطًا وثثيًا بالنظرية

البنائية من ،حيث القدرة على إحداث التغير المفاهيمي للتصور ات البديلة لدى المتعلمين، ويتم ذلك من خلال استكشاف أنماط فهم التصور ات البديلة ،لدى المتعلم ثم عملية اختيار المعالجة التدريسية المناسبة، و استبدال الأفكار و التصورات البديلة بأخرى صحيحة ،بعد التأكد من عدم صحتها لديهم من خلال المناقثات ،التي تدور بين المعلم والمتعلمين ثم تقبل الفهم العلمي الصحيح ،وتتم عند تقديم الأدلة والبر اهين الدالة على صحة المفاهيم . و أنشار محمود أن إستراتيجية التغير المفاهيمي من أهم النماذج البنائية الثائعة، والتي تركز على بناء المتعلم المعلومات بنفسه، والمعرفة العلمية التي يكتسبها من خلال الخبرات التي يمر بها في البيئة التي يعيش فيها وييني فيها معارفه الجديدة، و التي تركز على إحداث تغير مفاهيمي، لدى المتعلمين للوصول إلى المفاهيم الصحيحة، بدلاً من مفاهيمهم البديلة ويؤكد على ضرورة تكامل المعرفة الجديدة ،مع المعرفة السابقة في

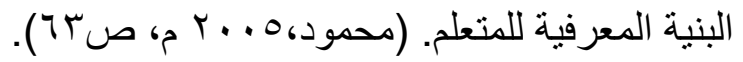

و أكد شهاب على أهية بناء المتعلم لمعرفته وتعديل البنية المعرفية، و استخدام الأمثلة و التشبيهات المختلفة " للمفاهيم و المعلومات" ،تعتمد على المشاركة للمعنى و الاتجاهات و المفاهيم و المعتقدات وتطوير ،كلٍ من النماذج و الاستر اتيجيات التدريسية المستخدمة في العملية التعليمية، وأساليب ،و إجر اءات التقويم المستخدمة من خلال العمل الجماعي

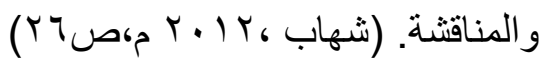

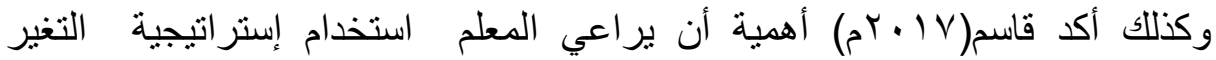
المفاهيمي ،في عرض المفاهيم الصحيحة بوضوح ،ثم تناول التصورات البديلة للمفاهيم ، والتي ثبتت في البنية المعرفية للمتعلمين في المراحل التعليمية السابقة ،من خلال تشجيعهم على البحث بأنفسهم في المصادر ،و الادلة المختلفة عن المعنى الصحيح

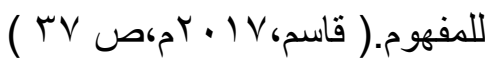


برنامج مقترح قائم على إستراتيجية التغير المفاهيمي لتصحيح التصورات البايلة للمفاهيم التاريخية وتنمية أبعاد الأمن المجتمعي لُّى طلاب شعبة التتاريخ في كليات التربية و تأثيره على اتجاهاتهم

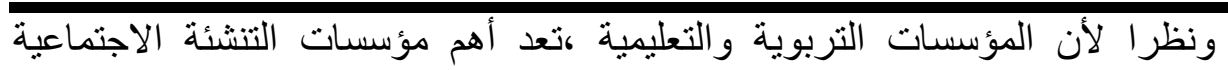
النظامية ،لذلك فهي المسؤولة عن مساعدة المتعلم علي إدراكه ،لظروف مجتمعة الأمنية العامـة للمجتمـع و مسشاركة الآخرين فـي مواجهة التطرف الذي يهدد أمن و

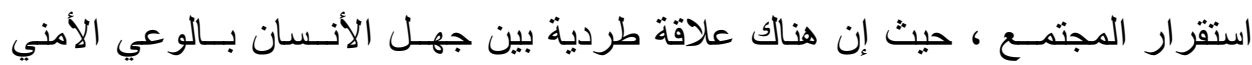
المجتمعي ،و أثره على انحر اف سلوكياته تجاه المجتمع. وتعتبر كليات التربية إحدى هذه المؤسسات التعليمية ،المنوط بها توعية الطالب المعلم ،بأهمية تنمية أبعاد الأمن المجتمعي و التعايش مع الآخر للمحافظة على كيان و استقرار المجتمع و الدولة ،من خلال تدريبهم على كافة النماذج و الاستر اتيجيات ،التي تساعدهم على تنميتها في كافة المقررات الدراسية ،لدى طلابهم بالمدرسة في أنثاء الخدمة للمحافظة على تماسك واستقرار المجتمع، حيث إن الجامعة مسئولة عن بناء شخصية الطالب المعلم ،بما يتوافق مع احتياجات المجتمع ،من خلال المقررات الدراسية وفق خطة مدروسة.

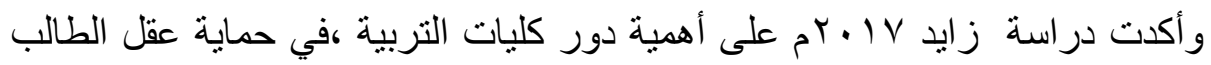
المعلم من كل تصور بديل يمثل غزو فكري للمجنم، في ظل بيئة آمنة فعنوان تقدما لأمم وفخر ها ،ومصدر أمنها واستقرار ها مر هون بسلامة عقول أفر ادها ،ونز اهة أفكار

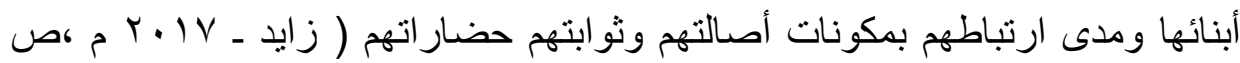
$(1.00-1 \cdot \leqslant \Lambda$ وبالرغم أن الأدبيات و الدراسات السابقة أكدت على أهمية تنمية المفاهيم التاريخية ودراستها بعمق ،و إعداد متعلم يستطيع تحديدها ومعرفة المدلول اللفظي لكل منها، وخصائصه إلا أن الجماعات المتطرفة استغلت هذه المفاهيم في جعلها زريعة ، إلى نشر التصورات البديلة والتطرف في المجتمعات البشرية ،نتيجة تناول هذه المفاهيم بشكل سطحي غير واضح ،وخاصة المتضمنة في المناهج الدراسية و منها مادة التاريخ ،و عدم التعمق في دلاتها ،و بالتالي يكتسبها المتعلم بصورة مشوهة و غير واضحة ،مما 
داد غادة عبد الفتاح زايد

يؤدي إلى نجاح الجماعات المتطرفة ،في ترسيخ تلك المفاهيم بصورة بديلة في عقول الثباب ،و استخدامها لجذبهم و التلاعب بفكر هم. ولذلك فهنالك حاجة ماسة لاستخدام استر اتيجيات تدريس حديثة، تسمح بتصحيح هذه المفاهيم للحفاظ على الأمن المجتمعي ،لديهم بصورة دقيقة ومناسبة بما يضمن بناء الصحة الفكرية ،لدى المتعلمين حيث إن الأمن المجتمي من الحاجات الأساسية كو المطالب الملحة للفرد و المجتمع . و هناك عديد من الدراسات السابقة وأكدت أن بناء المفاهيم بصورة صحيحة يواجه عديدًا من الصعوبات أبرزها المعرفة القبلية ،لدى المتعلمين فالمتعلم بيتخدم فهمه القبلي في التعامل مع المعرفة الجديدة ،فإذا كان فهمه القبلي سطحي أو غير مكتمل، فأنه قد الد الده يطور مفاهيم بديلة تختلف عن المفاهيم المقبولة في المجتمع ،و أن عدم قدرة المتعلم على

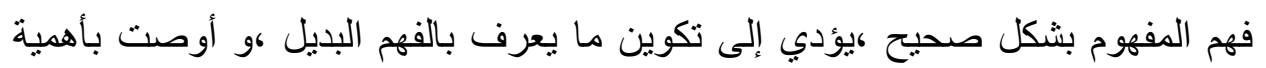
تصحيح التصورات البديلة للمفاهيم ،لدى الطلاب و ضرورة استخدام النماذج

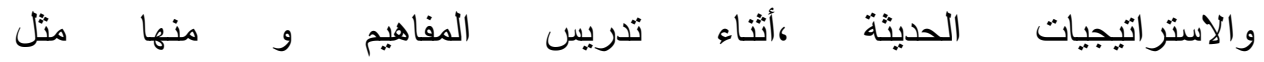

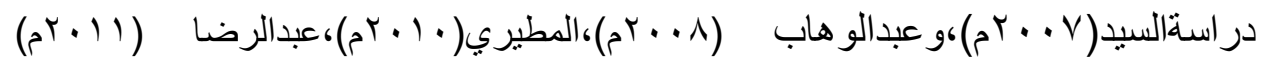

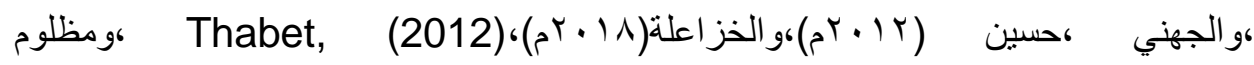

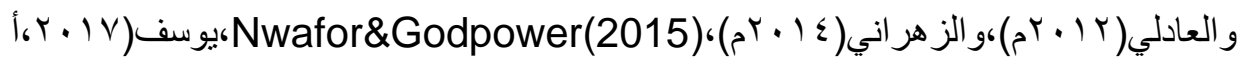

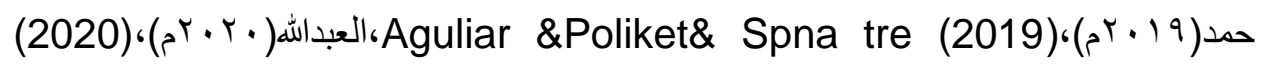

.Thomas \&Kirby وقد لاحظت الباحثة أثناء عملها كعضو هيئة تدريس ،أن الطلاب المعلمين بكلية التربية يحفظون المفاهيم حفظا أليا ،مما يجعلهم غير قادرين على التمبيز بين المفاهيم بشكل و اضح، بسبب وجود ضعف لديهم في اكتساب المفاهيم ،و عدم وصولهم إلى فهم عميق و دقيق لها ،مما يؤدي إلى عدم وعي الطلاب بالقصد الصحيح للمفاهيم التاريخية ،و التي لا تعتمد على بناء البنية المعرفية للمتعلم وخاصة مع استخدام أغلب أعضاء هيئة التدريس الطرق التقليدية ،أثناء التدريس داخل المحاضرات، قد يسبب تحدي يعوق

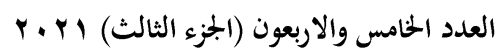

جلة كلية التربية- جامعة عين شمس 
برنامج مقترح قائم على إستراتيجية التغير المفاهيمي لتصحيح التصورات البديلة للمفاهيم التاريخية

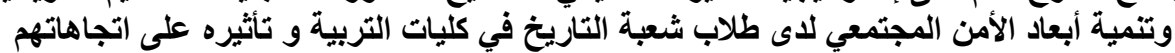

مساعدة الطالب في تصحيح التصور ات البديلة ،مما يجعله أكثر سلبية في تكوين المفاهيم

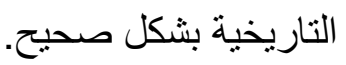

ولذا جاء البحث الحالي بهدف تصحيح التصورات البديلة للمفاهيم التاريخية ،وتتمية أبعاد الأمن المجتمي لدى الطالب المعلم في كليات التربية ، من خلال استخدام إستراتيجية مقترحة قائمة على التغير المفاهيمي كأحد أهم نماذج النظرية البنائية، والتي تناسب طبيعة تعلم المفهوم بشكل صحيح، وتعتمد على مشاركة المتعلم في تصحيح التصور ات البديلة، وبناء قدرثه المعرفية. و للتأكد من ذلك قامت الباحثة بعقد عدة لقاءات مع أساتذة المادة تخصص التاريخ ،عدد هم (0) للاستفسار عن مدى مراعاة محتوى مقرر التاريخ تقديم المفاهيم ،و التي أثنارت أنه يركز على حفظ الأحداث التاريخية ،دون التعمق في المدلول اللفظي للمفهوم. كما تم اجراء دراسة استكثافية على مجموعة من الطلاب المعلمين ،و عددهم (r. )طالب معلم لقياس مدى و عيهم بالمفاهيم المتضمنة بمادة التاريخ وا التصورات بديلة حول المفاهيم التاريخية، و مدى اهتمام المنهج الحالي بتتمية أبعاد الأمن المجتمعي ملحق( ()، وقد أنشارت النتائج إلى وجود ضعف في اكتساب الطلاب المفاهيم التاريخية ،كما أسفرت نتائج الدراسة أن محتوى المقرر لا يتعمق في توضيح المفاهيم التاريخية

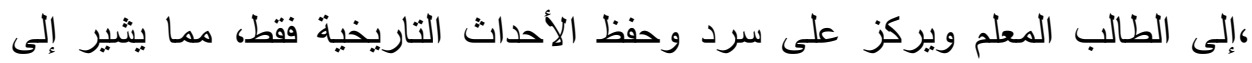
مشكلة حقيقية لاى الطالب المعلم ،مما يعوق اكتسابه المفاهيم التاريخية بشكل صحيح ،وبالتالي عدم قدرته على تصحيح التصورات البديلة للمفاهيم التاريخية الواردة ،في الأطر الفكرية المنطرفة ،مما انعكس على ضعف تمكن الطالب المعلم من أبعاد الأمن المجتمعي كو إدراكه العلاقة بينها و بين أهداف مادة التاريخ ،مما يؤثر سلبيا على اتجاهاتهم نحوها ،و في حدود علم الباحثة لا توجد دراسات تطبيقية ،تناولت تصحيح التصورات البديلة للمفاهيم التاريخية وخاصة الواردة في الأطر الفكرية المتطرفة ،لدى

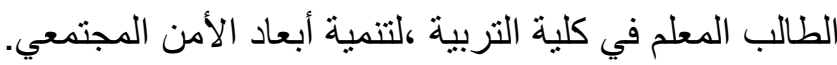

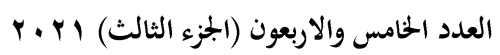

جلة كلية التربية- جامعة عين شمس 
ثَانيا مشكلة البحث: تمثلت مشكلة البحث في وجود قصور في تصحيح التصورات غات البديلة للمفاهيم التاريخية لدى الطالب المعلم في كليات التربية؛ مما يشكل خطورة على تتمية أبعاد الأمن المجتمعي ،ومن هنا ظهرت الحاجة إلى بناء إستر اتيجيه جديدة تتناسب خطو اتها مع طبيعة الطالب المعلم، وللتصدي لهذه المشكلة يحاول البحث الحالي الإجابة عن السؤال الرئيس التالي: - ماني: ما فاعلية برنامج مقترح قائم على إستراتيجية التغير المفاهيمي لتصحيح التصورات

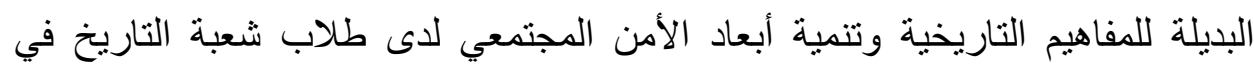

$$
\text { كليات التربية و تأثيره على اتجاهاتهم ؟ }
$$

ويتفرع من هذا السؤال الرئيس الأسئلة التالية: -

ا .ما المفاهيم التاريخية التي يجب تنميتها لدى الطالب المعلم في كلية التربية تخصص

$$
\text { التاريخ }
$$

r. ما التصورات البديلة للمفاهيم التاريخية التي يجب تصحيحها لاى الطالب المعلم في كليات التربية ؟ r. ما أبعاد الأمن المجتمعي التي يحب توافرها لدى الطالب المعلم في كلية التربية

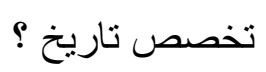
ع. ما البرنامج المقترح القائم على إستراتيجية التغير المفاهيمي لتصحيح التصورات البديلة للمفاهيم التاريخية وتتمية أبعاد الأمن المجتمعي لدى طلاب شعبة التاريخ في

$$
\text { كليات التربية؟ }
$$

ه.ما فاعلية البرنامج المقترح القائم على إستراتيجية التغير المفاهيمي لتصحيح التصورات البديلة للمفاهيم التاريخية وتتمية أبعاد الأمن المجتمعي لدى طلاب شعبة البهابة

$$
\text { التاريخ في كليات التربية؟ - ابه }
$$


برنامج مقترح قائم على إستراتيجية التغير المفاهيمي لتصحيح التصورات البايلة للمفاهيم التاريخية

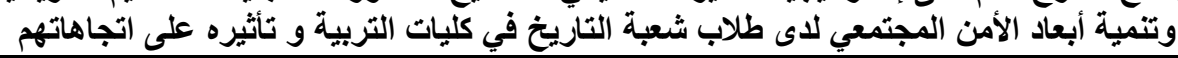

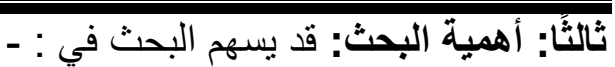

ا ـ تقديم قائمة بالمفاهيم التاريخية الواردة في المقرر ،و لها علاقة بالتصورات البديلة

للجماعات المتطرفة التي يجب نو عية الطالب المعلم بها. r. تقديم قائمة بأبعاد الأمن المجتمعي ،التي ينبغي تضمنها في مناهج التاريخ ،لدى الطالب المعلم في كلية التربية. rـ تقديم برنامج مقترح قائم على إستراتيجية التغير المفاهيمي ،لتصحيح التصورات البديلة للمفاهيم التاريخية وتتمية أبعاد الأمن المجتمعي لدى طلاب شعبة التاريخ في كليات التربية.

ع. تقديم اختبار مفاهيم تاريخية لتقويم ،مدى قدرة الطالب المعلم في كلية التربية ،على تصحيح التصورات البديلة للمفاهيم التاريخية ،لدى طلاب شعبة التاريخ في كليات التربية. ๑. مقياس لقياس اتجاهات الطالب المعلم في كلية التربية ،نحو أبعاد الأمن المجتمعي لدى طلاب شعبة التاريخ في كليات التربية. رابعًا: أهداف البحث :يهدف البحث إلى: -

1. بناء برنامج مقترح قائم على إستراتيجية التغير المفاهيمي ،لتصحيح التصورات البديلة للمفاهيم التاريخية وتتمية أبعاد الأمن المجتمعي ،لاءى طلاب شعبة التاريخ في الدير كليات التربية. r. قياس فاعلية برنامج مقترح قائم على إستراتيجية التغير المفاهيمي ،لتصحيح التصورات البديلة للمفاهيم التاريخية وتتمية أبعاد الأمن المجتمعي ،لدى طلاب شعبة بهرية التاريخ في كليات التربية. خامسًا: حدود البحث : يلتزم البحث بالحدود التالية: 1ـ اقتصر البحث الحالي على مجموعة البحث من الطلاب المعلمين ،في كلية التربية

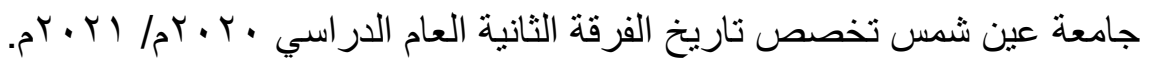


داد غادة عبد الفتاح زايد

rـ تضمن البحث تتمية بعض أبعاد الأمن المجتمعي، وهي الأمن (السياسي- الاجتماعي

$$
\text { - م-الفكري). }
$$

rـ تحديد أحد نماذج إستراتيجية التغير المفاهيمي هو نموذج بوسنر Posner ،الذي تنتبناه الباحثة لبناء البرنامج . ؟ ـ اثتمل البرنامج على تصحيح بعض التصورات البديلة للمفاهيم التاريخية المتضمنة في الأطر الفكرية للجماعات المتطرفة ولها علاقة بالمفاهيم المتضمنة في محتوى مقرر الفرقة الثانية " تاريخ الدول العربية والإسلامية". سادسًا: منهج البحث: يعتمد البحث على المناهج التالية: ا ـالمنهج الوصفي: استخدم في إعداد الدراسة النظرية ، و تحليل محتوى مقرر التاريخ الفرقة الثانية تخصص تاريخ، وإعداد أدوات البحث. r.المنهج التجريبي: استخدم في الدراسة التطبيقية لتجريب البرنامج ،وتطبيق ادوات البحث على مجموعة واحدة، لقياس فاعلية متغيرات البحث ، ورصد النتائج، وتحليلها إحصائيا، ومعالجتها.

سابعًا: فروض البحث: تم صياغة فروض البحث على النحو التالي: -

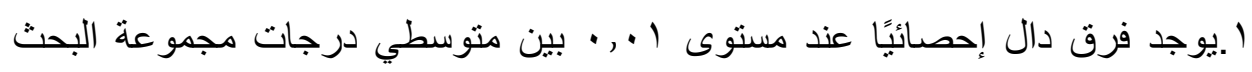

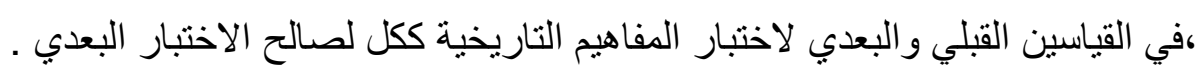

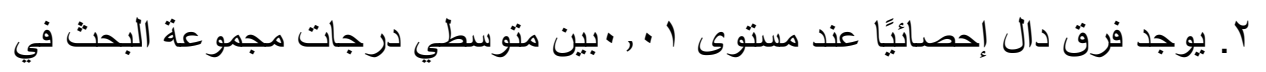
القياسين القبلي والبعدي ،لاختبار المفاهيم التاريخية لكل بعد لصالح الاختبار البعدي.

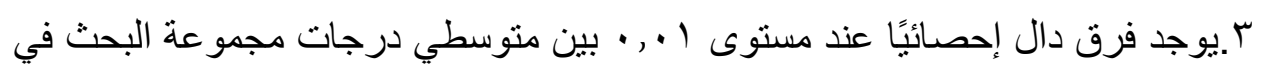
القياسين القبلي والبعدي لمقياس الاتجاهات نحو أبعاد الأمن المجتمعي ككل لصنالح المقياس البعدي. 
برنامج مقترح قائم على إستراتيجية التغير المفاهيمي لتصحيح التصورات البايلة للمفاهيم التاريخية

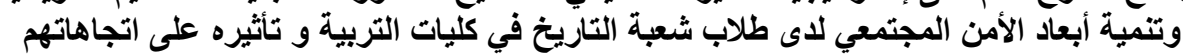

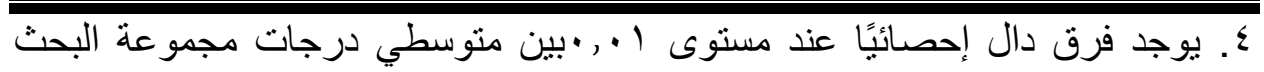
،في القياسين القبلي والبعدي ،لمقياس الاتجاهات نحو أبعاد الأمن المجتمعي لكل بعد،لصالح المقياس البعدي.

ثامنًا: إجراعات البحث: سوف يسير البحث وفقا للخطوات البهات التالية: ا ـ تحديد المفاهيم التاريخية التي لدى الطالب المعلم ،في كلية التربية تخصص التاريخ ،من خلال تحديد الوضع الراهن للمفاهيم التاريخية ،من خلال تحليل محتوى مقرر التاريخ الفرقة الثانية " تاريخ الدول العربية و الإسلامية ". باـ إعداد قائمة بالمفاهيم التاريخية المتضمنة في مقرر التاريخ الفرقة الثانية التي يمكن تتميتها لدى الطالب المعلم في كلية التربية ،بها مع نوضيح الدلالة اللفظية لكل مفهوم

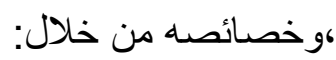
أـ الاطلاع على الأدبيات و المر اجع و الدراسات السابقة.

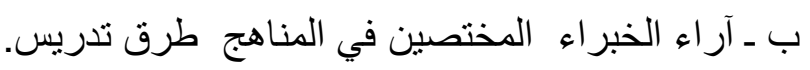
ج - طبيعة مادة التاريخ و أهدافها.

دـ تحديد خصائص الطلاب المعلمين في كلية التربية. ه ـ عرض القائمة على الخبر اء و المختصين في المناهج و طرق التدريس ،ووضعها في صورتها النهائية. rـ تحديد التصورات البديلة للمفاهيم التاريخية ،التي يجب تصحيحها والمتضمنة في الأطر الفكرية للجماعات المتطرفة ،ويجب توعية الطالب المعلم في كلية التربية تخصص تاريخ بها من خلال : ا ـ الاطلاع على الأدبيات و الدراسات السابقة العربية والأجنبية ،التي تتاولت التصور ات البديلة للمفاهيم التاريخية ،المتضمنة في الأطر الفكرية للجماعات المتطرفة. ب - وضع قائمة مبدئية التصورات البديلة للمفاهيم التاريخية ،المتضمنة في الأطر الفكرية للجماعات المتطرفة.

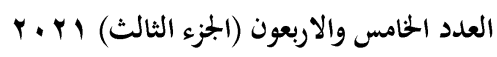

(258)

مجلة كلية التربية- جامعة عين شمس 


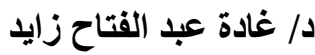

ج - عرض القائمة على خبر اء المناهج و طرق التدريس ،بهدف تحديد مدى أهمية المفاهيم التاريخية و علاقتها بالتصور ات البديلة ،لتحكيمها ووضعها في صورنها النهائية. ـ ـ تحديد قائمة بأبعاد الأمن المجتمعي ،التي ينبغي تضمنها في مناهج التاريخ ،لدى الطالب المعلم في كلية التربية وذلك من خلال: أـ آراء الخبر اءو المتخصصين في المناهج و طرق التدريس. ب ـ الاطلاع على البحوث و الدر اسات السابقة. ج- طبيعة مادة التاريخ و أهدافها. د- خصائص الطالب المعلم. هـ عرض القائمة على خبر اء المناهج وطرق التدريس. و ـ مر اجعة القائمة في ضوء ملاحظات الخبر اء ووضعها في صورنها النهائية. ه .بناء برنامج مقترح قائم على إستراتيجية التغير المفاهيمي، لتصحيح التصورات البديلة للمفاهيم التاريخية وتتمية أبعاد الأمن المجتمي، لاءى طلاب شعبة التاريخ في كليات التربية و نشتمل على كل مما يلي:

ب-تحديد أسس البرنامج المقترح. د-تحديد أهداف البرنامج المقترح.

و -تحديد الوسائل و المصادر التعليمية. أ-تحديد فلسفة البرنامج المقتر ح. ج-تحديد الإطار العام للبرنامج المقترح. ه-تحديد محتوى البرنامج المقترح.

ل-تحديد الطرق و الاستر اتيجيات التدريسية المستخدمة. س-تحديد الأنشطة التعليمية.

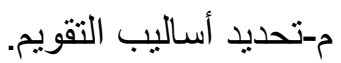
T- تحديد فاعلية برنامج مقترح قائم على إستراتيجية التغير المفاهيمي، لتصحيح التصورات البديلة للمفاهيم التاريخية وتتمية أبعاد الأمن المجتمي لدى طلاب شعبة

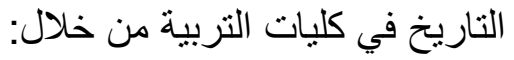


برنامج مقترح قائم على إستراتيجية التغير المفاهيمي لتصحيح التصورات البيلة للتئية المفاهيم التاريخية

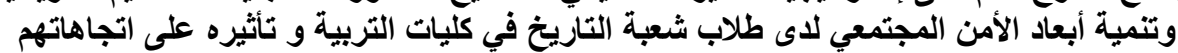

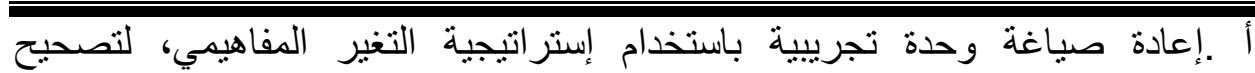
التصور ات البديلة للمفاهيم التاريخية ، وتتمية أبعاد الأمن المجتمي ،لدى الطالب المعلم

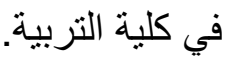
ب.إعداد كتيب الطالب المعلم كلية التربية لدراسة الوحدة المقترحة من المقرر، باستخدام إستراتيجية التغير المفاهيمي ،لتصحيح التصورات البديلة للمفاهيم التاريخية ، وتتمية أبعاد الأمن المجتمعي لاى الطالب المعلم في كلية التربية. ج.إعداد دليل إرشادي لأستاذ المادة في مقرر التاريخ لدى الطالب المعلم في كلية التربية يوضح كيفية تدريس الوحدة المقترحة ،باستخدام إستراتيجية التغير المفاهيمي ،لتصحيح التصورات البديلة للمفاهيم التاريخية ،وتنمية أبعاد الأمن المجتمعي لدى الطالب المعلم في كلية التربية. د. عرض البرنامج على مجموعة من المحكمين ،و المتخصصين في المناهج و طرق التدريس ،للتأكد من صلاحيته للتطبيق وتعديلهما في ضوء آرائهم ومقترحاتهم ووضعه في صورته النهائية. ه ـ اختيار مجموعة البحث من الطلاب المعلمين في كلية التربية ،تخصص التاريخ

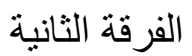
و - إعداد اختبار لقياس قدرة الطالب المعلم على تصحيح التصورات البديلة للمفاهيم

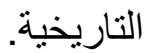
ل ـ إعداد مقياس لقياس اتجاهات لاى الطالب المعلم نحو أبعاد الأمن المجتمعي . V.قياس فاعلية برنامج مقترح قائم على إستراتيجية التغير المفاهيم، لتصحيح التصورات البديلة للمفاهيم التاريخية وتتمية أبعاد الأمن المجتمعي، لاى طلاب شعبة التاريخ في كليات التربية وتم ذللك من خلال: أ-تطبيق أدوات البحث قبليا وتثتنمل على اختبار، لتصحيح التصورات البديلة للمفاهيم التاريخية ،ومقياس لقياس الاتجاهات نحو أبعاد الأمن المتمعي قبليًا على مجمو عة البحث. 
ب-تدريس البرنامج على الوحدة المقترحة باستخدام إستر اتيجية التغير المفاهيمي. ج- تطبيق أدوات البحث بعديا وتشتمل على اختبار لتصحيح التصورات البديلة للمفاهيم التاريخية ،و مقياس لقياس الاتجاهات نحو أبعاد الأمن المجتمعي بعديًا على مجموعة البحث. ^. رصد النتائج وتحليلها ومعالجتها إحصائيا وتفسير ها.

$$
\text { 9.تقديم التوصيات و المقترحات. }
$$

Conceptual Change Strategy إستر اتيجية التغير المفاهيمي يعرف إجرائيا في البحث بأنه " الإجراءات التي يمكن استخدامها في استبدال الأفكار و التصورات البديلة ،لدى المتعلمين بأفكار وتصور ات صحيحة ،موثقة باستخدام الادلة و لإن

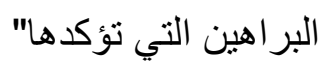

r ـ تصحيح التصور ات البديلة للمفاهيم التاريخية:

Correcting Alternative Perceptions of Historical Concepts يعرف إجرائيا في البحث بأنه " تصحيح التصورات البديلة لدى الطالب المعلم في كلية التربية عن المفاهيم التاريخية المتضمنة الأطر الفكرية المتطرفة، وتخرج عن إطار الوسطية و الاعتدالية و تمثل خطر ا يهدد استقرار ،و أمن المجتمع و استبدالها ، بالمفاهيم التاريخية الصحيحة بناء على الادلة و البر اهين موثقة ".

Dimensions of Societal Security : بـ أبعاد الأمن المجتمعيى يعرف إجرائيا في البحث بأنه (مجموعة من الإجراءات الأمنية يتفق عليها، أفراد المجتمع في المجال السياسي و الاجتماعي و الفكري ،التي يجب تو افرها لدى الطالب المعلم في ضوء معتقداته الدينية ،و عاداته ،و تقاليده لتنظيم سلوك الفرد و تحقيق الأمن و الاستقر ار داخل المجتمع). - ئ. 
برنامج مقترح قائم على إستراتيجية التغير المفاهيمي لتصحيح التصورات البيلة للتئية المفاهيم التاريخية

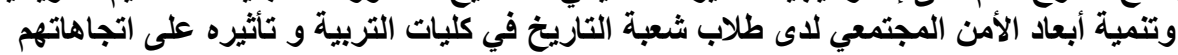

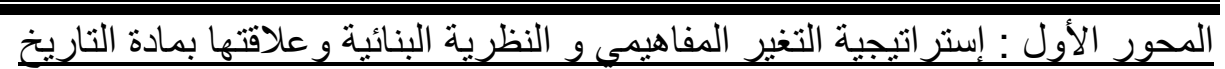
أو لاـ إستر اتيجية التغير المفاهيمي و النظرية البنائية: تمتد جذور النظرية البنائية على اسهامات بياجيه و فيجو تسكي ،والتي نادت بأهمية التعلم من أجل الفهم ،وضرورة أن يبني المتعلم معرفته بنفسه عن طريق الفهم، ثم تعريفه بأفكاره ومعتقداته الصحيحة ،التي استنتجها من تعلم الحقائق و المعلومات ،ثم تقييم تلك الأفكار والمعتقدات ،وذلك باختبار فاعليتها في تفسير الظواهر المرتبطة بها، ومن ثم التوجه لإعادة بناء تلك الأفكار ، و المعتقدات و المفاهيم في ضوء المعرفة الصحيحة. و اثتقت من النظرية البنائية عدة استراتيجيات، ومنها إستراتيجية التغير المفاهيمي ونماذجه ،حيث يتطلب أن تكون معرفة المتعلم السابقة نقية من التصورات البديلة للمفاهيم ،حتى لا تتعمق وتصبح من الصعب تغييرها ،لأنه إذا كانت المعرفة السابقة مشوشة وغير صحيحه، فإن البناء المعرفي بأكمله سيكون ضعيف، ولذلك يجب أن يكون أسلوب التدريس موجها ،نحو تكوين وصقل المفاهيم العلمية ،لدى المتعلمين و من أثنهر

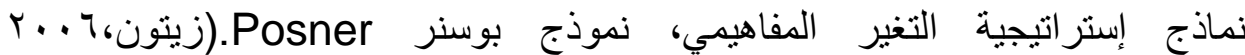

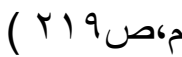

و تعتبر إستراتيجية بوسنر إحدى استراتيجيات التغير المفاهيمي،التي تتعامل مع المفهوم بهدف ايصالها،إلى الطالب بشكل صحيح مع إثارة ،ماتم إختز اله في ذهنه من نظرة سطحية أو خطا ،لهذا المفهوم بالفهم الصحيح الذي يتوافق ،مع الادلة و البراهين و المصادر أثناء التدريس. ثانيا ــ مفهوم إستر اتيجية التغير المفاهيمي: و تعددت المفاهيم التي تناولت إستر اتيجية التغير المفاهيمي كالتالي: عرفه(Stepans and Schmidt)(2006 ) أنه عملية تعلم بطريقة ذات معنى تتطلب من المتعلم أن يجمع ويعيد تنظيم أو سوء الفهم الموجود ليتمكن من استيعاب (Schmidt,D .Saigo.B.and Stepans,2006,p331).

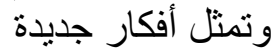


بينما يعرف الدليمي(؟ ا • بم) بأنه" عملية تغيير في البنية المفاهيمية للمتعلمين، ويقوم من خلالها المتعلم باستبدال التصور البديل ،ليحل محله التصور العلمي السليم ،من خلال

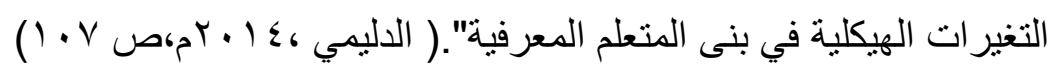

ويُعرفه قاسم(V l • r م) بأنه مجموعة من الإجراءات و الأساليب التدريسية، التي تستخدم

$$
\text { لتعديل أنماط الفهم البديل للمفاهيم واستبدالها بمفاهيم صحيحة. }
$$

و عرفه الاشقر(V V • r ) بأنه نموذج يستخدم لتصحيح التصورات البديلة ،لعرض المعتقدات الخطأ ومواجهها تمثل المفهوم و الذهاب إلى ما وراء المفهوم.( الاشقر ،

$$
\text { (OV Dapr. IV }
$$

بينما تعرفه الباحثة إجر ائيا بأنه: "الإجراءات التي يمكن استخدامها في استبدال الأفكار و التصور ات البديلة ،لدى المتعلمين بأفكار وتصورات صحيحة موثقة ،باستخدام الادلة

$$
\text { و البر اهين التي تؤكدها " }
$$

ثنالثا ـ نموذج بوسنر في التغير المفاهيمي:

استطاع بوسنر posner عام 9 ام في جامعة كورنيل بالولايات المتحدة الأمريكية من تطوير وتنفيذ نموذج يعتمد على القلسفة البنائية، ويهتم بتصويب التصورات البديلة للمفاهيم بمختلف أنواعها لدى المتعلم حول ظاهرة معينة، و إكساب المتعلم الفهم العلمي الصحيح لهذه الظاهرة، وقد اعتمد بوسنر في نموذجه على استبدال التصور العلمي السليم بالتصور البديل الذي يستقر في ذهن المتعلم ،وضرورة التكامل بين المعرفة الموجودة في البنية المعرفية للمتعلم، بهدف إحداث التعلم الفعال ذي المعنى من خلال استكثاف أنماط التصور البديل للمفاهيم لدى المتعلمين، ثم معالجة الفهم البديل باستخدام النماذج ،و الاستر اتيجيات التدريسية المناسبة وتقييم فهم المتعلم ،من خلال تنمية قدراته على تمييز التصور البديل، بتمثيله داخل شبكة المعلومات الموجودة لدى المتعلم،

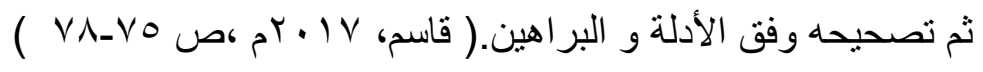


برنامج مقترح قائم على إستراتيجية التغير المفاهيمي لتصحيح التصورات البيلة للتئية المفاهيم التاريخية

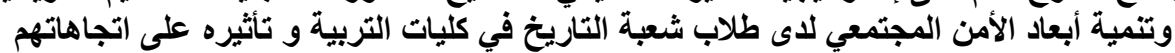

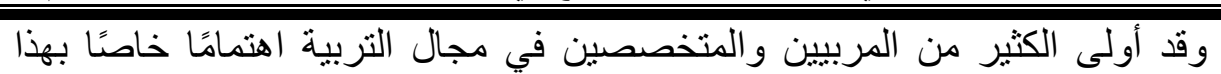
النموذج، وكذلك محاولة در استه وتطويره، وقد حددت ثلاث مر احل ضرورية لحدوث

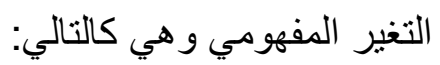
ا ـ مرحلة الوعي أو الإدر الك للمفهوم : و يتمثل في تحديد المدلول اللفظي الصحيح و خصائصه وسماته وفق الادلة والبراهين ثم عرض التصور البديل وإحساس المتعلم كبأن لديه فهمًا بديلا غير صحيح لظاهرة ما أو مفهومًا ما.

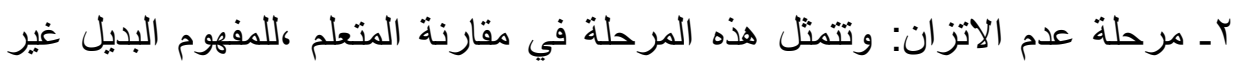

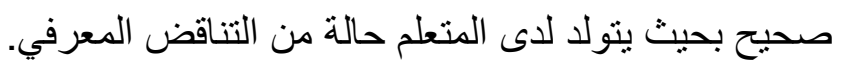
بـ تكوين المفهوم :وتتمثل هذه المرحلة في تشكيل المفهوم الصحيح ، وطرد المفهوم البديل من البنية المعرفية للمتعلم، ومن المفترض أن تتم عملية التغير المفهومي داخل غرفة الدر اسة وفق تكيف المادة التعليمية مع الفهم السابق للمتعلمين، والأخذ في الاعتبار المفاهيم البديلة. (langman,2018,p15).

و انطلاقا مما سبق يتضح أن إستر اتيجية التغير المفاهيمي وفق نموذج بوسنر تعتمد على التى استبدال التصور الصحيح ،بتصور بديل ثبت في ذهن المتعلم، وتمر عملية الاستبدال هذه بمرحلتين ،الأولى يتم الكثف عن التصورات البديلة عند المتعلم ،والثانية يتم استخدام إستراتيجية تدريسية مناسبة ، وذلك من خلال عملية الموائمة بين التصور البديل ،و المعلومات الموجودة في ذهن المتعلم، ثم إحلال المدلول اللفظي الصحيح للمفهوم. خامسا ـ شروط حدوث التغير المفاهيمى لدى المتعلم: أجمعت عديد من الدراسات و البحوث مثل دراسة مصطفى و محمد (9 . . بم)،وقاسم

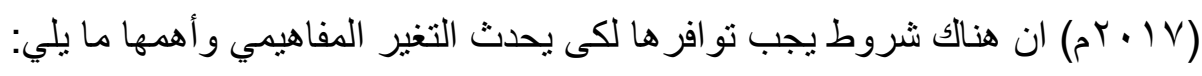
1 ـ شعور المتعلم و عدم رضاه بتلك التصور ات البديل للمفاهيم التي في ذهنه. r - تقديم المفاهيم الجديدة للمتعلم بشكل و اضح، وذا معنى. 
د/ غادة عبد الفتاح زايد

بـ افتناع المتعلم بالمفاهيم المقدمة حديثا، وشعوره بالرضا عنها لكونها متر ابطة وغير متناقضة مع غير ها من المفاهيم الأخرى.

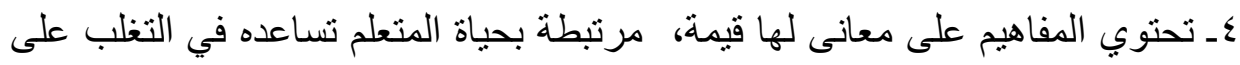
الصعوبات التي تو اجهه على المستوى الفردي او المجتمعي. سادساـ استخدام استر اتيجية التغير المفاهيمى في تدريس المفاهيم التاريخية: تؤكد عديد من الأدبيات والدراسات السابقة أهمية استراتيجية التغير المفاهيمي بناء على مبادئ بوسنر (Poser) في إحداث التغير المفاهيمي:كأحد النماذج البنائية، والذي يختص بتصويب التصورات البديلة بمختلف أنواعها، ومحاولة تثبيت المفاهيم الصحيحة بدلًا منها ،وتتبنى الباحثة (نموذج بوسنر )لأسباب أهمها:

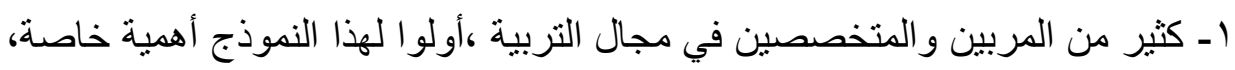

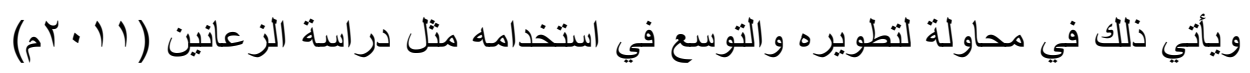

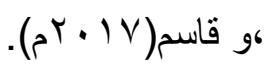

r- قلة البحوث والدراسات العربية والأجنبية ،في حدود علم الباحثة لإحداث التغير المفاهيمي ،و تصحيح التصور ات البديلة بصفة خاصة في مادة التاريخ. rـ تضمن عملية التغير المفاهيمي مجمو عة من المراحل المهمة التي تساعد المتعلم على كلى اكتساب طرق فعالة للتعبير عن المفاهيم المتضمنة فيه. ـ-يعتبر من أكثر النماذج التدريسية المعنية بتصويب التصورات البديلة للمفاهيم في مختلف المواد الدر اسية الأخرى. 0ـ الاعتماد على إستر اتيجية التغير المفاهيمي عند بناء مر احل الإستراتيجية من حيث أهدافها، وخطو اتها، ومر احلها لتحقيق الأهداف المنشودة منها. 7ـ الاهتمام بالمعرفة القبلية للمتعلم و الإفادة منها، في اكتساب المفاهيم بشكل صحيح من خلال ربط المعرفة السابقة باللاحقة. 
برنامج مقترح قائم على إستراتيجية التغير المفاهيمي لتصحيح التصورات البايلة للمفاهيم التاريخية

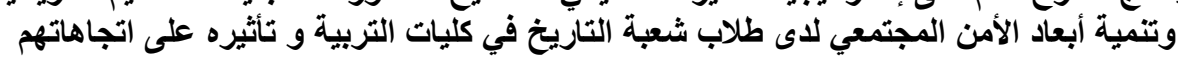

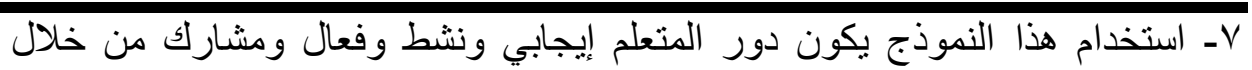
استخدام الوسائل التعليمية، والأنشطة طرق التقويم المستخدمة ، والعناية بالدور الفعال

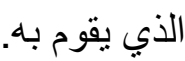

ᄉ- مناسبة خطوات ومر احل هذه الإستر اتيجية المقترحة مع طبيعة المفاهيم التاريخية ، وطرق تعلمها بشكل صحيح.

9- انتماء هذا النموذج باستراتيجياته للفلسفة البنائية، والتي أوضح التربويون فاعليتها

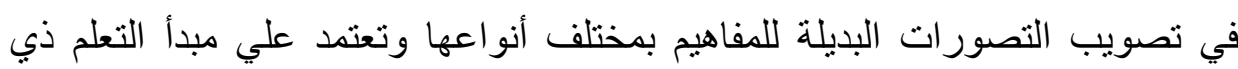
المعنى.. انطلاقا مما سبق يعتبر نموذج بوسنر أحد نماذج استراتيجية التغير المفاهيمي التي يمكن ان تساعد المتعلم في تصويب التصورات البديلة للمفاهيم الصحيحة علميًا التي لها فلسفاتها و تعتمد عليها النظرية البنائية في تصحيح المفاهيم، للإفادة منها في بناء البيئة التعليمية المناسبة ،لتصحيح المفاهيم التاريخية و تحقيق الأهداف التعليمية، حيث أنها تساعد المتعلم من البحث عن المعلومات والخبر ات ،بطريقة مشوقة وجذابة ونشطة؛ مما يجعل التعلم ذا معنى. و هناك عديد من الأدبيات و الدراسات السابقة ،أكدت على أهمية استخدام إستراتيجية التغير المفاهيمي في تصحيح المفاهيم البديلة ،لدى الطلاب في مختلف المواد الدراسية

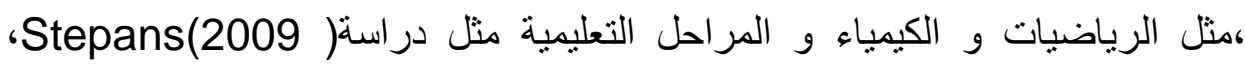

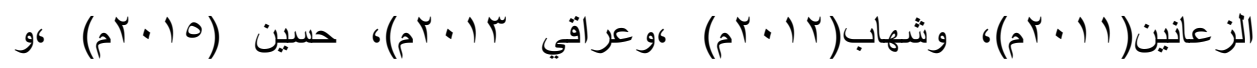

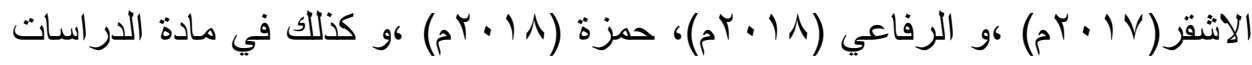

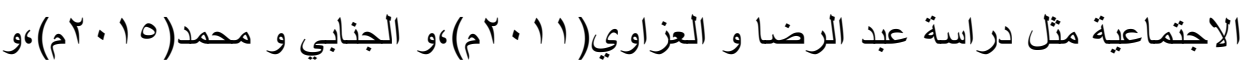
تنوعت الدراسات والأدبيات ،التي أوصت بأهمية استخدام نموذج بوسنر في أثناء تطبيق

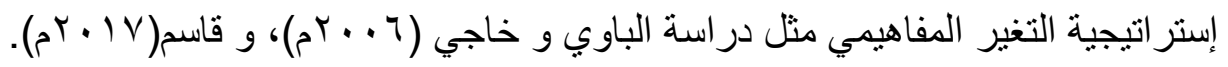


د/ التادة عبد الفتاح زايد

المحور الثانى البنائية و تصحيح التصورات البديلة للمفاهيم التاريخية:

أو لا نشأة النظرية البنائية وتصحيح التصور ات البديلة:

النظرية البنائية هي إحدى نظريات التعلم للرائد التربوي جان بياجيه التي تتمركز حول المتعلم ودوره في بناء معرفته بنفسه ،وذلك من خلال خبراته السابقة وما يقدم إليه في بيئة التعلم، وما ير اه في حياته الو اقعية، مما يجعل تعلمه مستمر اً وذا معنى ،و تعتمد على أن المعنى يينى ذاتيًا من قبل البنية المعرفية للمتعلم نفسه ،وليس من المعلم ثم يتم تشكيل المفاهيم عند المتعلم ،وهي عملية نشطة تتطلب منه جهدًا عقليًا ،لبناء المعرفة

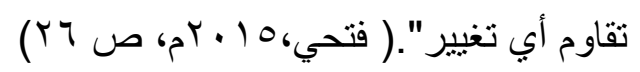

وأنثار زيتون أن نظرية التعلم البنائية تنادي ،بأهمية فهم وايجابية المتعلم أثناء التعلم لكي يبني معرفته بنفسه ،و توظيف عقله لتكوين خبرات جديدة ليصبح التعلم ذو معنى بالنسبة له ،ويرى أن البنية المعرفية السابقة المتكونة ،لدى المتعلم تقاوم التغيير بدرجة كبيرة ،لذلك يهتم التدريس البنائي بالتصورات البديلة ،وضرورة تصوييها أثناء التعليم و التعلم ،ويقول فرانسيس بيكون فيلسوف العلوم التجريبية (أن استعمال المصطلحات

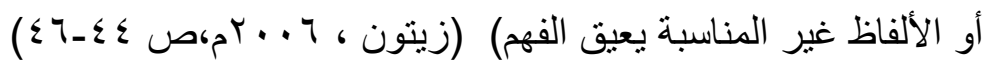
و أكد كل من الزهراني(§ ( • ب ) ) أن تصحيح التصورات البديلة يعتمد على النظرية البنائية ، وفق ضوابط تساعد المتعلم على تكوين المفاهيم ،بصورة صحيحة وضبط العلاقات بين الظواهر بدلا من استقبالها عن طريث التلقين ،وتؤكد أن المتعلم يبني معلوماته داخليا متأثرا بالبيئة المحيطة به ،و المتعلم يقوم بصناعة المعنى الثخصي الذاتي الناتج عن المفهوم ،بناء على معرقته و إدر اكه لها بصورة صحيحه ، و بذللك يتم بناء الفكر الذي يشمل كلٍ من البنية المعرفية والعمليات العقلية لدى المتعلم.

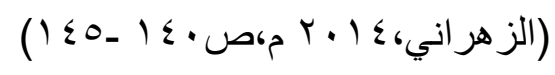

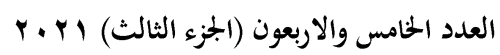

(267)

جلة كلية التربية- جامعة عين شمس 
برنامج مقترح قائم على إستراتيجية التغير المفاهيمي لتصحيح التصورات البيلة للتئية المفاهيم التاريخية وتنمية أبعاد الأمن المجتمعي لأى طلاب شعبة التاريخ في كليات التربية و تأثيره على اتجاهاتهري

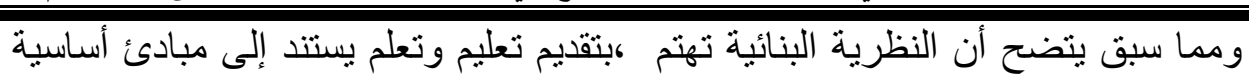
،تساعد على اكتساب المتعلم المفاهيم بصورة أكثر فهما و عمقا ،لمعرفة الدلالة اللفظية لكل مفهوم و الخصائص المشتركة الخاصة به ،بحيث تساعد المتعلم على تسهيل عملية تعلم المفاهيم الجديدة ،و بذلك فأن المعلم مطالب بالكثف عن البنية المفاهيمية لطلابه، وإزالة ما فيها من أخطاء تعوق عملية تعلمهم تمنحه الوعي والقدرة ،على تصحيح التصورات البديلة ،مما ينعكس على خبراته و تساعده على اتخاذ القرار وفق بنية مفاهيمية صحيحة . ثانيا مفهوم: تصحيح التصور ات البديلة للمفاهيم التناريخية ا ـ تصحيح التصور ات البديلة:

أطلق عديد من التربويين والمهتمين بعمليتي التعليم والتعلم على التصورات البديلة للمفاهيم في مختلف المجالات مسميات مختلفة، وهذا يرجع إلى أهميتها الكبيرة في تدريس المفاهيم ،في مختلف المناهج الدراسية في جميع المراحل التعليمية، وقد أُطلقت عديد من المسميات ومنها:( التصورات القبلية ـ التصور ات الخاطئةــ الاستدلال العفوي

ويعرفها Chi \& Roscoe بأنها وضع المفاهيم بعيدًا عن سياقها الصحيح ،ضمن فئة أو مجمو عة مغلقة، وبالتالي يتم التغير المفاهيمي ،من خلال إعادتها إلى موقعها الأصلي بهاي

الصحيح.(Chi \& Roscoe,2002,p4)

في حين يعرفها شحاتة و النجار بأنها ما لدى المتعلم من تصورات و أفكار في بنيته المعرفية عن بعض المفاهيم ؛ ولا تتفق مع التفسيرات العلمية الصحيحة.(شحاتة و

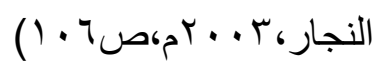

و عرفه أبو هو لا و المطيري بأنه التفسير غير المقبول علميًا لبعض المفاهيم من قبل المتعلمين، وذلك بعد مرور هم بنشاط تعليمي معين.(ابو هو لا و المطيري, V . . بم، ص ع (). 
بينما يعرفها(زيتون) بأنها نوع من المعرفة الساذجة التي يكتسبها المتعلم ،من خلال

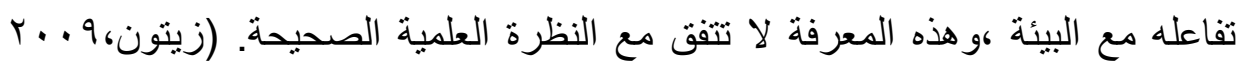

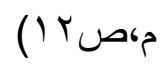
و عرفه المطيري بأنه الأفكار و التصورات التي تتكون لدى المتعلم ،التي تكون مخالفة

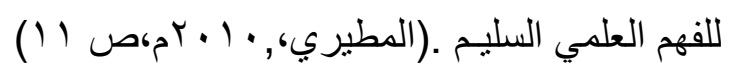
ويشير عراقى أنه المفهوم الذي يحمل تصورات غير مطابقة لوجهه النظر العلمية

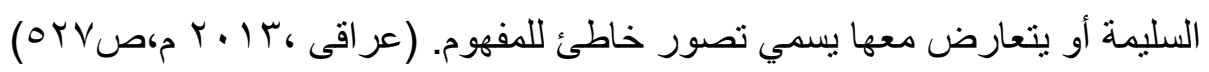
وتعرف(رجب) بأنها" أفكار أو أراء أو معتقدات أو مفاهيم غير دقيقة ،أو غير علمية

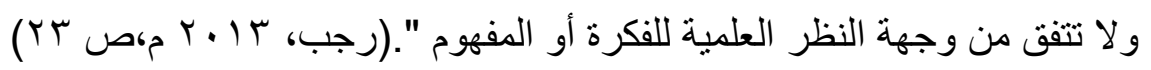
rـ تعريف المفاهيم التاريخية: تعددت تعريفات المفهوم بشكل عام، ومن أهم التعريفات ما يلي: يعرف Merrill\&Tennyson بأنه" مجموعة من الأشياء أو الأحداث أو الرموز،التي

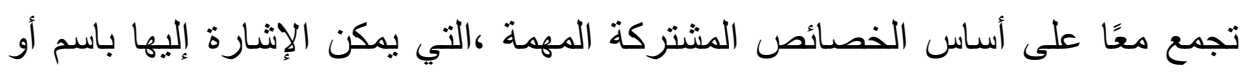

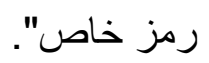

\section{( Merrill\&Tennyson,2006,p12)}

تعرفه الباحثة اجر ائيا بأنه" معلومات تاريخية يعبر عنها المتعلم بمفاهيم محددة، يثترك فيه مجمو عة من الصفات و الخصائص المتشابهة". وعرفته الباحثة تصحيح التصورات البديلة للمفاهيم التاريخية إجرائيا بأنه: " تصحيح التصورات البديلة لاى الطالب المعلم عن المفاهيم التاريخية ،المتضمنة الأطر الفكرية المنطرفة ،وتخرج عن اطار الوسطية و الاعتدالية و تمثل خطر ا يهدد استقرار ،و أمن المجتمع و استبدالها ، بالمفاهيم التاريخية الصحيحة بناء على الادلة و البر اهين موثقة " و يتسم مفهوم تصحيح التصورات البديلة للمفاهيم التاريخية من السمات وهي كما يلي:- 
برنامج مقترح قائم على إستراتيجية التغير المفاهيمي لتصحيح التصورات البايلة للمفاهيم التاريخية

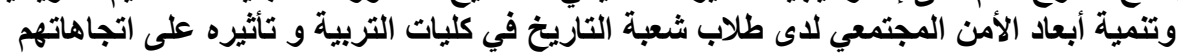

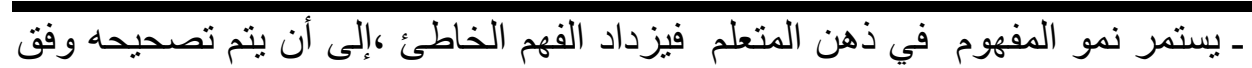
تفسير علمي، بناء على الادلة و البراهين التي تتبت صحتها ـ تتعارض المفاهيم التي يحصل عليها المتعلم السابقة و اللاحقة اذا لم يتم تصحيحها قد يجعله في حالة عدم اتزان معرفي ـ تتضمن البنية المعرفية للمتعلم عديد من المعارف والمفاهيم ، لابد من توعيته بها بصورة و اضحة وثرية ثنالثاـ أهمية تصحيح التصور وات البديلة للمفاهيم التاريخية: اجمعت عديد من الدراسات و البحوث السابقة ،على أهمية الكثف عن التصورات البديلة للمفاهيم في مختلف التخصصات مثل دراسة ابو سعيد و حسين (9 . . ب بمعبد

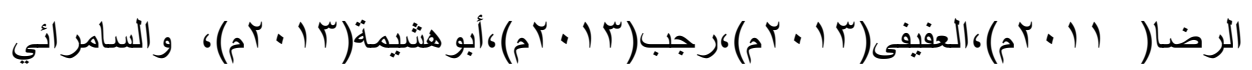

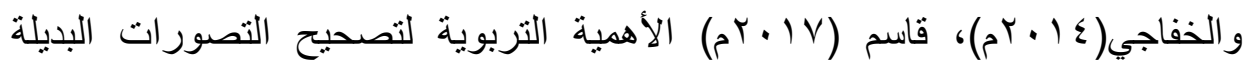
للمفاهيم التاريخية لدى المتعلم فيما يلي: ا ـ التحـرر مـن بعض المفاهيم التصور ات البديلة والغامضهة، التي يمكن أن يينى عليها كثير من الآراءو الافكار ،تؤثر على ردود افعالهم تجاه المواقف الحياتية.

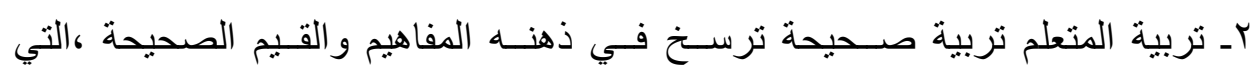
تساعده على التسامح واحتر ام الاختلاف و الو لاء و الانتماء للوطن.

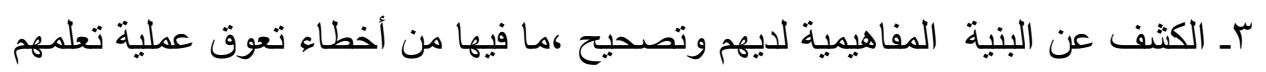
و محاورتهم و توجيه8ح. عـ تتمية المفاهيم التاريخية و القدرة على تحديد صفاتها، وخصائصها، لتساعده على لتى الوصول إلى تعميمات دقيقة و أكثر تعميمًا. هـ مر اجعة المفاهيم التي ينم تعلمها مر اجعة علمية صحيحة الوقوف على أهم مصدادر تكوين التصور ات البديلة، وأهم أسبابها، وكيفية التغلب عليها. 
د/ غادة عبد الفتاح زايد

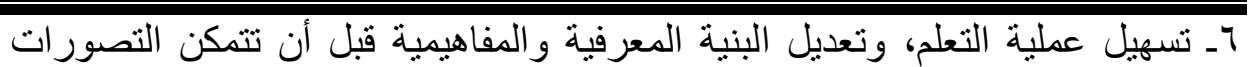

البديلة منها، فتتنـابك وتتعقد ويصعب تصويبها. Vـ الكثف عن التصورات البديلة للمفاهيم التاريخية و تكوين مفاهيم صحيحة يستطيع من خلالها تكوين رؤية و اضحة، وثباته في البنية المعرفية للمتعلم ^ـ استخدام الترتيب الهرمي الصحيح في تعليم المفاهيم التاريخية الصحيحة، والتمييز بين الأمثلة المنتمية و الأمثلة غير المنتمية والدمج بينهما 9ـ إدراك العلاقة بين المفاهيم التاريخية الموجودة في البنية المعرفية لديه و التصورات التهيه البديلة لها في شكل إيجابي ذو معنى. مما سبق يتضح أهمية تعرف التصور ات البديلة ،للمفاهيم التاريخية كما أن تشخيصها وتصحيحها ،يُعد من أهم أهداف التعلم الرئيسة ،التي تهتم بها الدراسة الحالية لتصحيح التصور ات البديلة ،بما فيها من معاني ومفاهيم توجد ،لدى الطالب المعلم في كلية التربية تجاه بعض المفاهيم التاريخية ،التي يخالف مدلولها اللفظي المفاهيم الصحيحة الموثقة ،و اتفق عليها و المؤرخون في هذا المجال. رابعا- أنواع التصور ات البديلة للمفاهيم التاريخية: اجمعت عديد من الأدبيات و الدراسات السابقة ،أن للتصور ات البديلة للمفاهيم التاريخية،

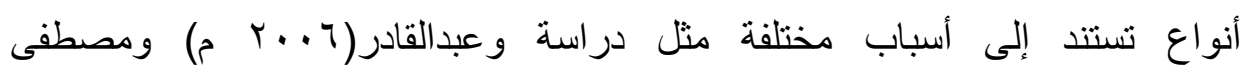

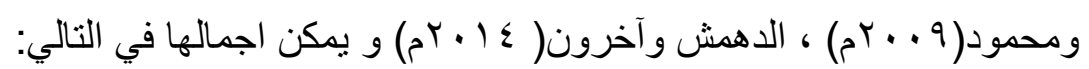

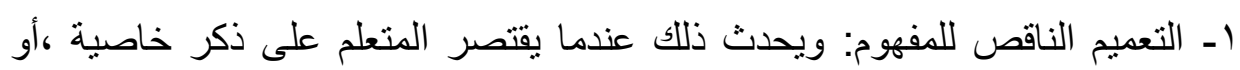
أكثر دون باقي الخصائص عن المفهوم. r- الإفراط في تعميم المفهوم ويحدث عندما يتم ذكر الخصائص الرئيسية، ويتم اعتبار الخصائص الفر عية منها. rـ الخلط بين المفاهيم المتقاربة في الألفاظ ويحدث عند عدم قدرة المتعلم على التفرقة بين بعض المفاهيم المتثابهة.

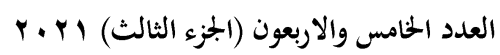

جلة كلية التربية- جامعة عين شثس 
برنامج مقترح قائم على إستراتيجية التغير المفاهيمي لتصحيح التصورات البيلة للتئية المفاهيم التاريخية

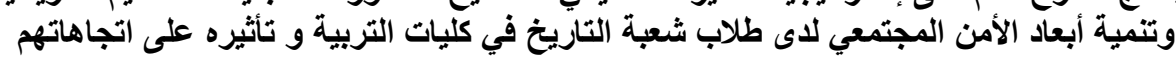

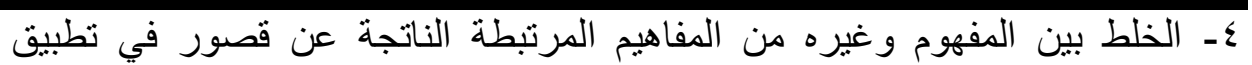

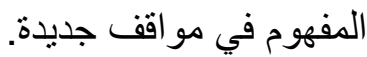
0ـ الفهم الغير صحيح للمفاهيم الثابتة في الجانب المعرفي للمتعلم، و المخالفة للتفسيرات

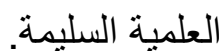

مما سبق تستنتج الباحثة أن الأساليب السابقة ،تتكامل مع بعضها البعض في العمل على الكثف ،على كيفية تصحيح التصورات البديلة للمفاهيم والمتواجدة في البنية المعرفية للمتعلم. خامساـ مصادر تكون التصور ات البديلة: أجمعت عديد من الأدبيات و الدراسات السابقة ،أن هنالك مصادر ينتج عنها التصورات

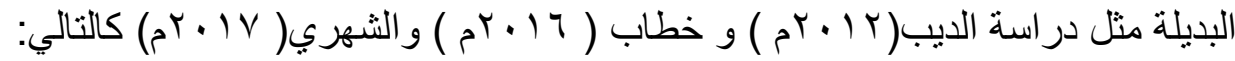
اـ المعلم : حيث إن بعض المعلمين ينقصهم الفهم العميق للمادة العلمية ،و بالتالي لا يعطون المتعلم ما يثبع رغباته للمعرفة ،فتقتصر المادة على عرض المعلومات بصورة سطحية ،الامر الذي يحدث عند تعريف المتعلم التصور البديل.

r ـ البيئة المحيطة: حيث إن هذه البيئة إذا كثر بها غير المتعلمين فهم يعطون تفسيرات خطأ ،لبعض الأحداث التي سرعان ما يقبلها المتعلم و يتكون لديهم تصور بديل يصعب تصويبه.

rـ عو امل داخلية معلقة بالمتعلم : كنموه العقلي العام وكذلك مدى استعداده ،للتعلم ووجود دافعية لديه للتعلم و الاهتمام.

عـ أساليب تدريس المفاهيم التقليدية: حيث تفتقر لاستخدام الخبرات المباشرة و المو اقف ،التي تساعد على ربط الماضي و الحاضر والمستقبل موضحا أوجه التشابه و

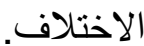

0ـ وسائل الإعلام : تسهم وسائل الإعلام المقروءة و المسموعة و المرئية ،في نشر التصور البديل لدى المتعلمين من خلال تقديم بعض البرامج و الأفلام. 
د/ غادة عبد الفتاح زايا

\section{سادسا-العلاقة بين استر اتيجية التغير المفاهيمى وتصحيح التصور غات البديلة للمفاهيح التاريخية الواردة لدى الجماعات المنطرفة:}

و تعتبر مادة التاريخ من المواد الدراسية ،التي تحتوى على كثير من المفاهيم ،يجب

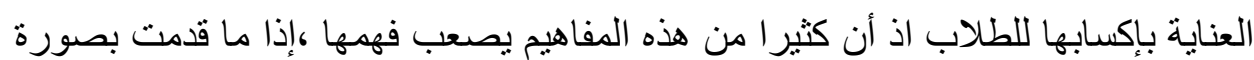
مجردة الامر الذي يثير ،إلى إمكانية تكوين بعض أنماط الفهم البديل حول هذه المفاهيم ،كما أن تزويدهم بأكبر كمية من المعلومات و المفاهيم ،وقلة الاهتمام بربطها يشكل

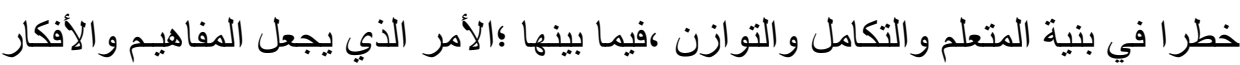

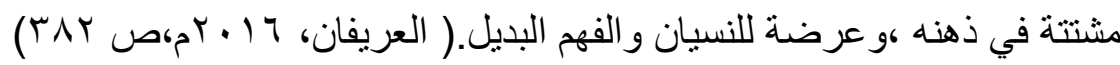
و هناك علاقة بين استراتيجية التغير المفاهيمي للمفاهيم التاريخية وبين ،ما يتم تتاوله في العصر الحالي من تصورات بديلة لدي الجماعات المنطرفة، للتأثير على الاجيال القادمة ،و خاصة الثباب مستغلين عدم تمييز هم بين المفاهيم بشكل واضح خاصة ،تلك التي تتقارب من الناحية اللفظية ،وقد يرجع سبب ذلك إلى ضعف في اكتساب المفاهيم ،و عدم وصولهم إلى فهم عميق ودقيق لها، مما يؤدي إلى تكوين تصورات بديلة لديهم حول عديد من المفاهيم الواردة ،في كتب التاريخ أثناء الدراسة ،مما يجعلهم فريسة لأي فكر متطرف خاطئ تتبناه الجماعات المتطرفة من أجل تهديد أمن و استقر ار المجتمع، بحيث تساعدهم على التصدي وتصحيح التصورات البديلة ،للمفاهيم التاريخية في الأطر

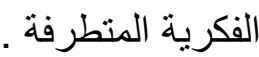

و قد تبنت الجماعات المتطرفة استخدام التصورات البديلة ،للمفاهيم التاريخية من أجل نشر التعصب في الرأي ،ومحاولة التأثير على عقول الطلاب في مختلف المراحل الدراسية ،و خاصة الثباب و استحداثهم فتاوى شاذه مثل تكفير الحكام و المجتمعات المسلمة ،ووجوب الهجرة من البلاد الإسلامية و رفض مبدأ التعايش السلمي ،الذي قرره الإسلام بين مختلف الشعوب هجرتهم من المجتمعات المسلمة ،و اتخاذهم البراري و الصحاري سكنا لهم بذريعة ،أن المتمعات المسلمة مجتمعات جاهلية تجب الهجرة منها

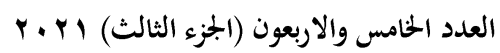

(273)
مجلة كلية التربية- جامعة عين شمس 
برنامج مقترح قائم على إستراتيجية التغير المفاهيمي لتصحيح التصورات البيلة للتئية المفاهيم التاريخية

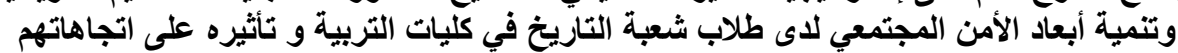

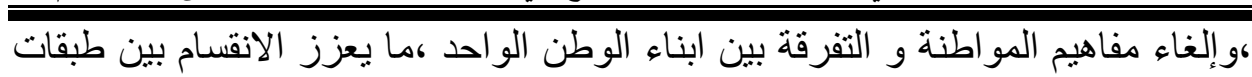
المجتمع و المساهمة ،في ظهور الارهاب الفكري في العصر الحاضر. (جاب الله،

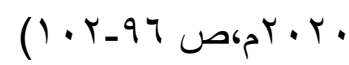

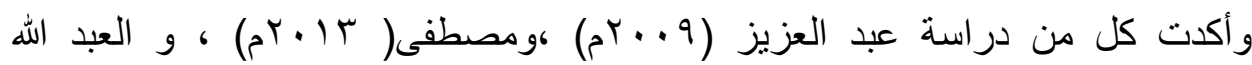

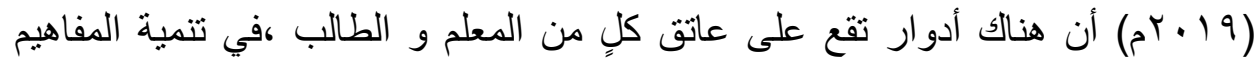
التاريخية بشكل صحيح وفق المصادر و الأدلة ،حيث إن المعلم هو المسئول عن تصحيح أخطاء المفاهيم الواردة ،و خاصة الأطر الفكرية المتطرفة ،في البنية المعرفية للطالب وتعزيز المفهوم الصحيح ،لديه من خلال معلوماته التي يقدمها له، والطرق والوسائل والاستر اتيجيات اللازمة لإحداث هذا التعلم بشكل فعال، أما الطالب فنمو المفاهيم ،لديه يساعده على فهم طبيعة المادة بشكل صحيح. ومما سبق يتضح أن المشكلة الحقيقية ليست في تعلم المفهوم فقط ،و إنما في التغير المفاهيمي و التصور البديل للمفهوم التاريخي ،الناتج عن إعطاء حقائق كثيرة غير مترابطة ،لا يستطيع ربط المعلومات ذات العلاقات ببعضها ،أدى إلى حدوث التصور إنى البديل للمفاهيم التاريخية ،ولذلك يعد العمل على مراجعتها من الأمور المهمة ،لتكوين

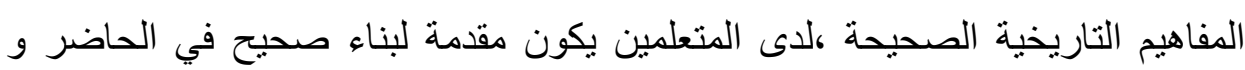

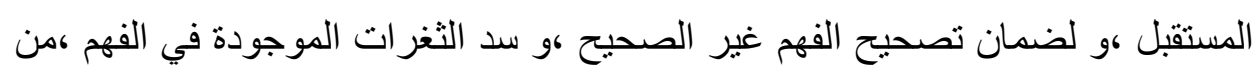
خلال توعية الطلاب بمتطلبات أبعاد الأمن المجتمعي ،لتصحيح المفاهيم التاريخية التصورات البديلة.

و هناك عديد من الدراسات السابقة التي أكدت أهمية تصحيح التصورات البديلة

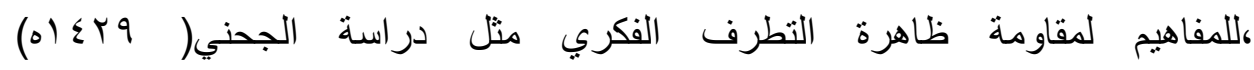

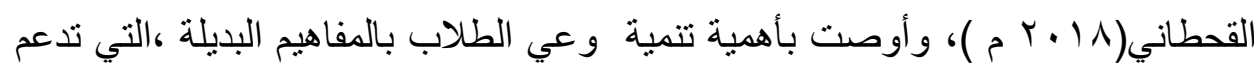
بناء شخصية تتسم بالأطر الفكرية الإيجابية ،التي تضمن بناء المواطن القادر على تمييز

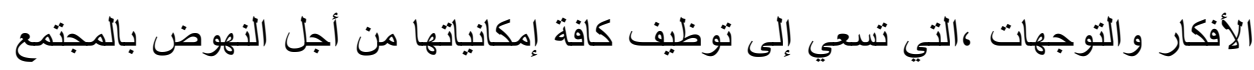

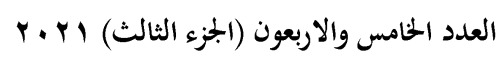

جلة كلية التربية- جامعة عين شمس 
د/ غادة عبد الفتاح زايد

،بينما در اسات أخرى أشنارت إلى أهمية تصحيح المفاهيم البديلة في مختلف التخصصات زيلات

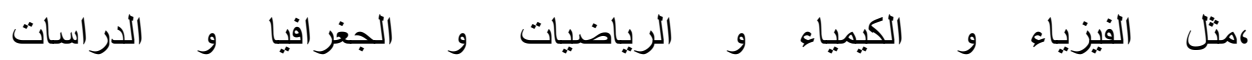

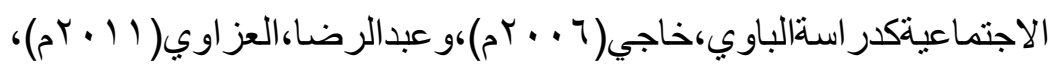

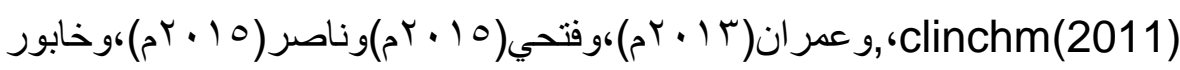

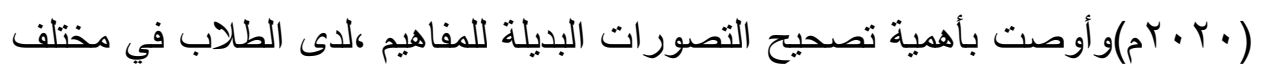
المراحل التعليمية ،و كذلك أهمية استخدام استراتيجيات التدريس الحديثة ،في تصويب التصور ات البديلة للمفاهيم . المحور الثالث: تنمية أبعاد الأمن المجتمعي لدى الطالب المعلم بكلية التربية تخصص تاريخ:

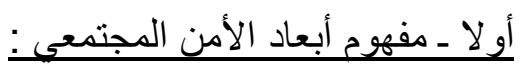
يعد مصطلح الأمن المجتمعي من المصطلحات المعاصرة، وتعددت تعاريفه في الأدبيات و الدراسات السابقة كما يلي:

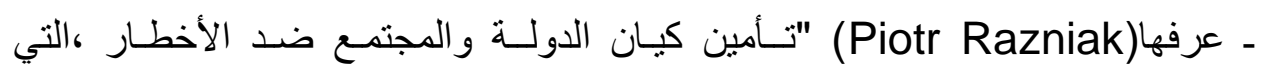
تهددهما داخليـا وخارجيـا وتأمين مصالحهما، وتهيئة الظروف المناسبة اقتصاديا ،واجتماعيـا لتحقيق الأهداف والغايـات ،التي تعبر عن الرضا العام في المجتمع .

( Piotr, 2012)

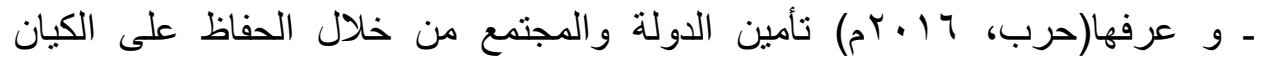
التعليمي في الدولة ،يكون من خلال مواجهة الأخطار الداخلية والخارجية ،وتــــأمين منين

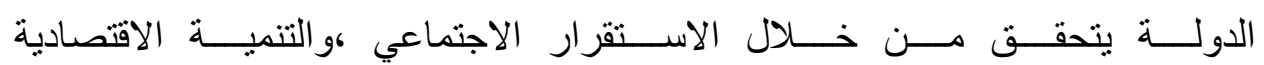

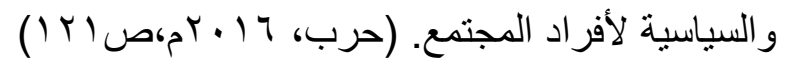
ـ بينما عرفها فرغلي(10 • rم)حالــة الاسـتقرار التـي ينبغـي أن تسود المجتمع في جوانبه المختلفة، وإحداث التماسك الاجتماعي ،في ظل نظــام متناسـق للمعتقـدات

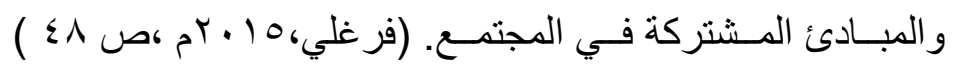


برنامج مقترح قائم على إستراتيجية التغير المفاهيمي لتصحيح التصورات البيلية للمفاهيم التئيم التاريخية وتنمية أبعاد الأمن المجتمعي لأى طلاب شعبة التاريخ في كليات التربية و تأثيره على اتجاهاتهري

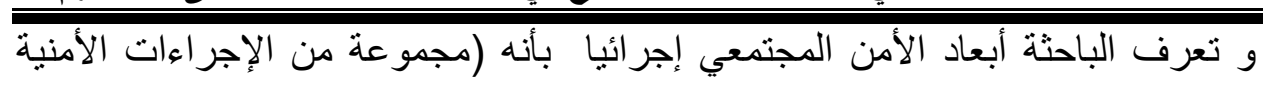

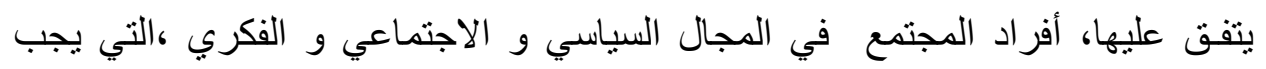
تو افرها لدى الطالب المعلم في ضوء معتقداته الدينية ،و عاداته ،و تقاليده لتنظيم سلوك

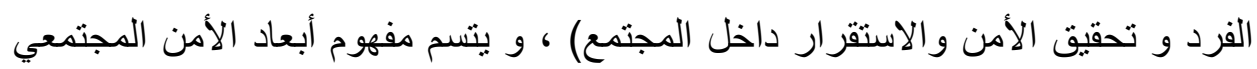
بمجمو عة من السمات و هي: ـ ارتبط مفهوم الأمن بالإجراءات الأمنية ،التي بتفق عليها افراد المجتمع في جميع المجالات ،لدى المجتمع للنهوض بالدولة وفق معتقداته الدينية ،و عاداته ،و تقاليده ،و بون تنعكس على سلوكه ـ الثمول الأمني لكل ما يحقق استقرار الدولة في مختلف المجالات مثل المجال السياسي و الفكري و الاجتماعي. ـ السعي إلى تامين كيان الدولة و المجتمع ،من الأخطار لتحقيق الأهداف و الغايات التي

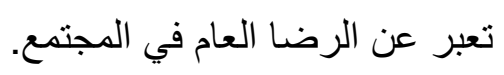
ثانيا دور كليات التربية في الحفاظ على أبعاد الأمن المجتمعي لدى الطالب المعلد: و تعد المرحلة الجامعية إحدى تللك المؤسسات المجتمعية التربوية الرئيسية ،تسعي لبناء

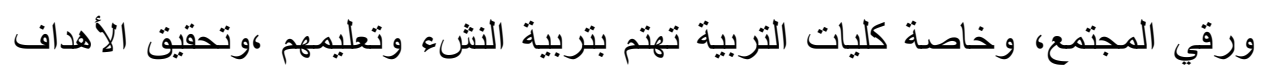
التربوية و التعليمية ومسؤلياتها ،وتزويد الطالب المعلم بالمفاهيم و الثوابت التاريخية ،التي تساعده في الحفاظ على أبعاد الأمن المجتمعي ،و مواجهة ظاهرة التطرف الفكري ،التي تهدد الأمن و تتمية الوعي الأمني المجتمعي لديه حتى يتمكن من تتميتها لاى طلابه في أثناء تدريس المقررات الدراسية عند التحاقه بالعمل. و هناك عديد من الدراسات و البحوث السابقة ،أكدت على أهمية دور كليات التربية ،في لئه تنمية أبعاد الأمن المجتمي والحفاظ على استثرار المجتمع ،مثل دراسة الريعي

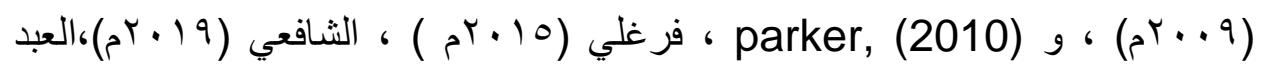


دادة غادة عبد الفتاح زايد

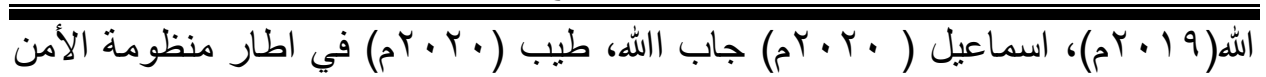
،حيث تساعد الطالب المعلم على كل مما يلي: ا ـ تنظيم اللقـاءات العلميــة التـي تهـتم بتحقيـق أبعاد الأمن المجتمعـي كو امدادهم بنشرات تربوية و قرارات مواجهة الفكر المتطرف ،و تعزيز روح المواطنة لديهم. r- تبصير هم بكيفية التعامل الصحيح مع وسائل ،و مصادر تكنولوجيا المعلومات تعرض صور ،مختلفة للتطرف الفكري لتحصينهم و حمايتهم منها. rـ مساعدتهم على فهم وتفسير الأحداث التاريخية بو اقعية وموضوعية ،و التمكن من وصن رصد و إدر الك عدد من الحقائق في الحاضر و التنبؤ بالمستقبل.

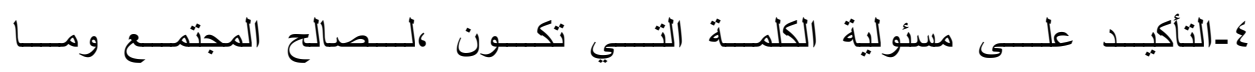
يتبعـــاه مـــن أفعال. هـ الحفاظ على الوحدة و الهوية الثقافية للأمة وأصالتها وقيمها، للارتقـــاء و الــسمو

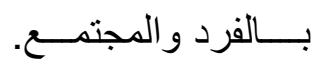
7- فهـم المـشكلات التــي تواجـهـ المجتمـع ومواجهتها ،عقائسديا، وروحيـا، وفكريـا، وسياسـيا ، واجتماعيـا، و التعرف مـن خلالهها على مـن هـو، ومـاذا يريـد،

$$
\text { ومساذا يـر اد منه. }
$$

V- فهم الواقع الاجتماعي السياسي وطبيعة النظـام القـائم ،في مجتمعهم واعطائهم فرصــة ،التعبير عـن آرائهم وتوجهـاتهم إز اء المشكلات التـي تحيط بهر.

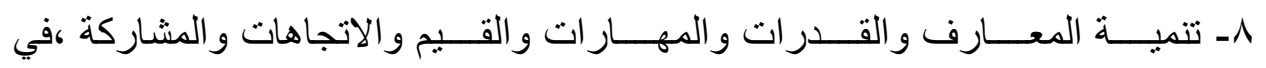
خدمة المجتمع ومعرفة الحقوق و الواجبات. 9- التحـرر مـن بعض المفـاهيم التصورات البديلة والغامضة عن عن الكثير من المشكلات ،التي يعيشونها ويتفاعلون معها. 
برنامج مقترح قائم على إستراتيجية التغير المفاهيمي لتصحيح التصورات البايلة للمفاهيم التاريخية

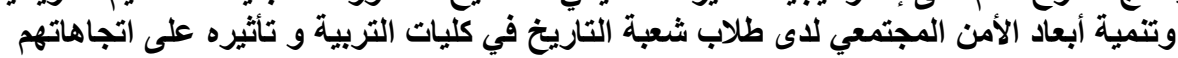

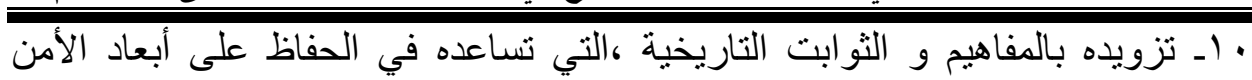
المجتمعي ترســخ فـي ذهنـهـ المفاهيم والقـيم الصحيحة ،التي تساعده على التسامح والانتماء للوطن.

ثالثاعلاقة تصحيح التصور ات البديلة للمفاهيم التاريخية بتنمية أبعاد الأمن المجتمعي: و يعتبر تصحيح التصورات البديلة للمفاهيم التاريخية ،أمر ا ضروريا للحفاظ على أبعاد

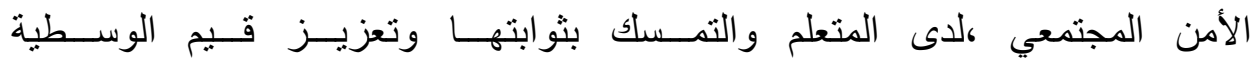

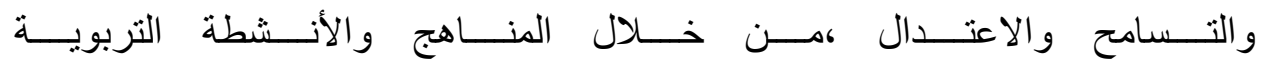
و التعليمية،والتأكيد على القيم الإنسانية والجمالية فيه وتشجيعهم على البحث والدراسة

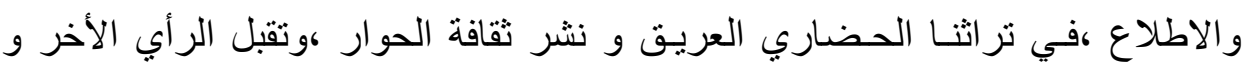
الو لاء و الانتماء و المواطنة في المؤسسات التعليمية ،وتو عيـــتهم وتحــــين أفكار هم لمواجهــة آثـــار التطرف من خلاء تنمية أبعاد الأمن المجتمعي.

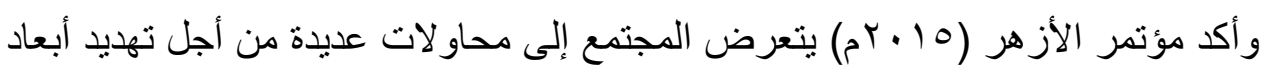
الأمن المجتمعي ،من خلال الخلط و التلاعب بين الحقائق و المفاهيم التاريخية ،في مادة التاريخ الإسلامي والتيارات السياسية المختلفة ،و التخفي وراء الثعار ات الدينية للتأثثير على ولى الناس،و كسب تعاطفهم من قبل الجماعات المتطرفة لتحقيق أغر اض ،و مطامع شخصية تبني على أساس افكار متعصبة معادية للأوطان ،و البشرية مستغلة قلة وعي الطلاب في مختلف المراحل ،و خاصة في مرحلة الثباب ،مما جعلهم ارضا خصبة لاستقبال الفكر المنطرف ،مع أن الإسلام وجميع الأديان السماوية ،تنادي التسامح و التعايش مع الآخر و

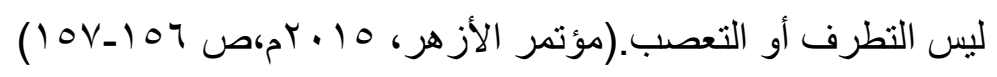
- وتسهم مادة التاريخ في تحقيـــق متطلبات أبعاد الأمن المجتمعـــي وتتمثل فيما يلي: اـ الأمن السياسي: و تتضمن التأكيد على أهمية العمل على الترابط بين السلطة

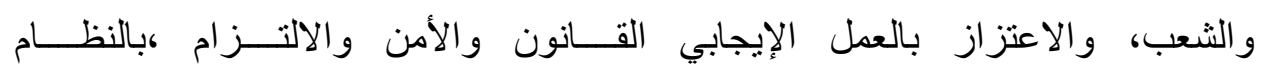

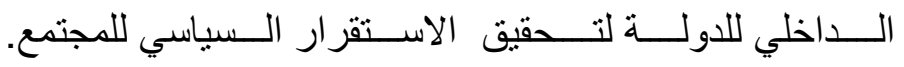

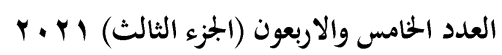

جلة كلية التربية- جامعة عين شمس 
rـ الأمن الاجتماعي: وتتضمن التأكيد على أهمية التمسك الاجتماعي ،بالقيم والمعتقدات في الماضي التي تعبر عن الحاضر ومستقبل الأمة ،و تتسم بالأصالة و الحث على المشاركة ،في حل المشكلات الاجتماعية ،التي تهدد أمنه و استقرارهو الحرص على المحافظة عليه. rـ ـ الأمن الفكري: وتتضمن التأكيد على أهمية الهوية الثقافية ،التي تشكل الضابط الفكري للفرد والمجتمع ،و دور الأمن الفكري في نشر المعرفة وتتمية الوعي ،لاى الأفراد بطبيعة الانحر اف الفكري، و توضيح أن الأمن الفكري مسئولية كل فرد حتى لونى وأن تعلق بذاته.

و مما سبق تتضح العلاقة بين اهمية تصحيح التصور ات البديلة للمفاهيم التاريخية،و تنمية أبعاد الأمن المجتمعي لدى المتعلم، مثل الأمن( السياسي ـ الاجتماعي ـ الفكري)،للحفاظ

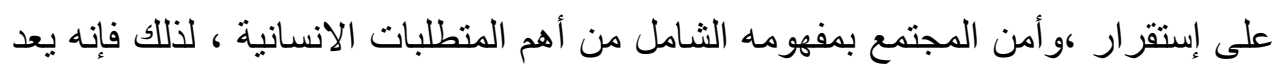
تحقيقه مسئولية جميع المؤسسات التعليمية لتحصين الفرد والمجتمع،ضد أي غزو فكري لمالها من أثر ايجابي في تتشئة الاجيال ،وبناء الحضارة وحماية الفكر و صيانة المعتقدات ،كما أنها وسيلة الامم لتحقيق أهدافه والمحافظة ،على كيان المجتمع بل تتعدى ادوارها ايضا ،إلى رصدالتصور ات البديلة لدى الطلاب وتعديلها بل ،و إدر اك تطلعاتهم وطموحاتهم وتوجيهها الوجهة الصحيحة ،بما يتناسب مع امكاناتهم وبناء شخصية تتسم بالأطر الفكرية الصحيحة ،التي تضمن بناء المواطن القادر على تمييز الافكار والتوجهات ،التي تسعي إلى نوظيف كافة|مكانياتها من أجل النهوض بالمجتمع. و هناك العديد من الأدبيات و الدراسات السابقة، أثنارت إلى أهمية توظيف أبعاد الأمن المجتمي في تحقيق أهداف المتمع ،مثل دراسة كمال (

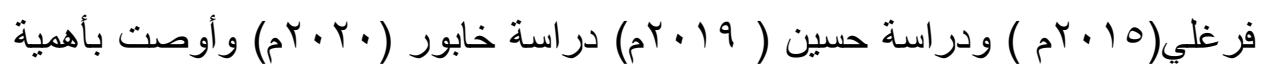
تضمين بر امج إعداد المعلم ،على قيم الأمن الفكري لدعم الاستقرار في المجتمع ،و تدريبهم أثناء الخدمة على تخطيط و تنفيذ أنشطة لتنمية قيم الأمن الفكري ،وترسيخ 
برنامج مقترح قائم على إستراتيجية التغير المفاهيمي لتصحيح التصورات البيلة للتئية المفاهيم التاريخية

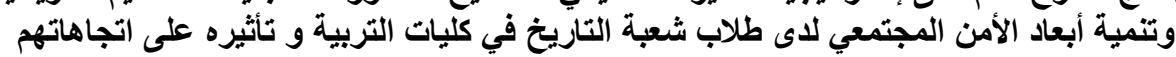

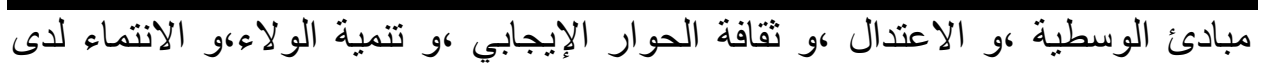
الطلاب في جميع المراحل التعليمية و خاصة المرحلة الجامعية ، للحفاظ على أمن واستقرار المجتمع ،وهناك دراسات أشثارت إلى أهمية تنمية أبعاد الأمن المجتمعي في

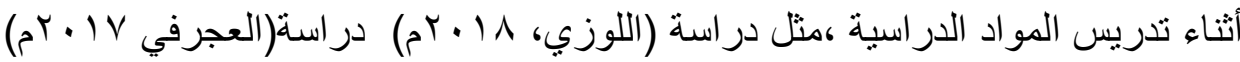
،أكدت على أن التطرف الفكري بمثل خطورة كبيرة على أبعاد الأمن المجتمي ،و أهمية مو اجهته *ولقد أفادت الباحثة من الإطار النظري، والدراسات السابقة الأدبيات المتعلقة في بناء ، برنامج مقترح قائم على إستر اتيجية التغير المفاهيمي ،لتصحيح التصورات البديلة للمفاهيم التاريخية وتتمية أبعاد الأمن المجتمعي ،لدى طلاب شعبة التاريخ في كليات التربية. المحور الر ابع : بناء برنامج مقتر ح قائح على إستر اتيجية التغير المفاهيمي ،لتصحيح التصورات البديلة للمفاهيم التاريخية وتتمية أبعاد الأمن المجتمى لدى طلاب شعبة التاريخ في كليات التربية، و تأثثره على اتجاهاتهم و يتضمن كل مما يلي: أو لا إعداد القائمة:

1 ـ تحديد الهدف من بناء القائمة:يستهدف بناء القائمة تحديد:أـ المفاهيم التاريخية التي لدى الطالب المعلم في كلية التربية تخصص التاريخ. ب. التصورات البديلة للمفاهيم التاريخية ،التي يجب تصحيحها لدى الطالب المعلم في

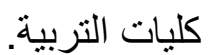
ج ـأبعاد الأمن المجتمعي التي يحب توافرها،لدى الطالب المعلم في كلية التربية تخصص ناريخ. r - دراسة مصادر بناء قائمة : تم من خلال دراسة الأدبيات والبحوث و الدراسات السابقة ،وطبيعة اهداف مادة التاريخ وخصائص الطالب المعلم في كلية التربية،و ضبطها وفق أراء الخبراء والمتخصصين ملحق (Y) في ميدان مناهج وطرائق مادة

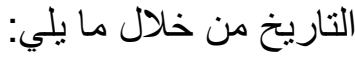


دالمادة عبد الفتاح زايد

أ ـ لتحديد المفاهيم التاريخية التي لدى الطالب المعلم ،في كلية التربية تخصص التاريخ ،قامت الباحثة بتحليل محتوى مقرر الفرقة الثانية " تاريخ الدولة الإسلامية و العربية"

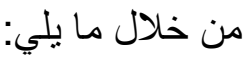
*تحليل المحتوى:- يقصد بتحليل المحتوى به ،وسيلة تستخدم لوصف المحتوى الظاهر للمادة الدراسية وصفا كميا ،وموضو عيا بطريقة منهجية ومنظمة. ( علام، · ( + rم،ص rr) وقد تم تحديد المفاهيم التاريخية المتضمنة ،في المقرر تاريخ الدول العربية والإسلامية كوالتحقق من صدق وثبات التحليل ،وقد تم الاعتماد على المنهج الوصفي في تحليل محتوى الوحدة وفقا للخطوات التالية: *الهدف من التحليل :تم تحديد قائمة بالمفاهيم التاريخية ،المتضمنة في مقرر تاريخ الدول. العربية والإسلامية ،الفرقة الثانية تخصص تاريخ وفق المنهجية الخاصة. * فئة التحليل:تم وحدة تحليل الفقرات، حيث تم تقسيم دروس الوحدة إلى فقرات ثم استخر اج المفاهيم الواردة في كل فقرة، ثم استخر اج نسبة تكرار كل مفهوم في الوحدة ،و تم التحليل في ضوء المحتوى العلمي لدروس المقرر ،وفي ضـوء التعريف الإجرائي للمفهوم التاريخي. * صدق التحليل :تم عرض التحليل الذي قامت به الباحثة على اثثين من أساتذة المادة تخصص تاريخ من ذوي الخبرة و الاختصاص ،لإبداء الر أي في نتائج التحليل ،و قد تم تضمين مبادئ قائمة المفاهيم التاريخية. * ثبات التحليل: تم التحقق مـن ثبـات نتـائج تحليل ،حيث قامـت الباحثـة بتحليل محتوى وحدات مقرر" تاريخ الدولة العربية الإسلامية " ،ثم أعيد التحليل مـرة أخرى مـن قبـل الباحثة ،بعد مرور شهر تقريبا من إجر اء ،التحليل الأول حيث تم حساب معامل الارتباط بين نتائج التحليل الأول ،و الثاني و قد بلغ ( ؟ 9, · ) باستخدام معادلـة كوبر وتم استخدام

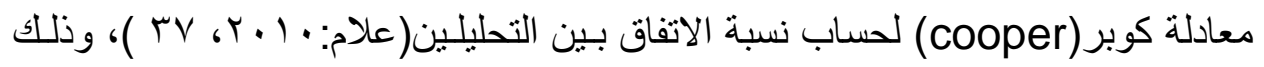
باستخدام المعادلة التالية. 
برنامج مقترح قائم على إستراتيجية التغير المفاهيمي لتصحيح التصورات البايلة للمفاهيم التاريخية

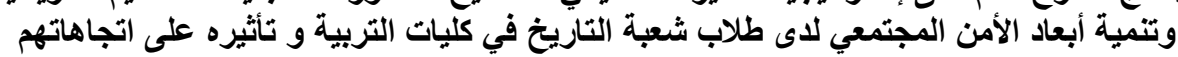

عدد نقاط الاتفاق

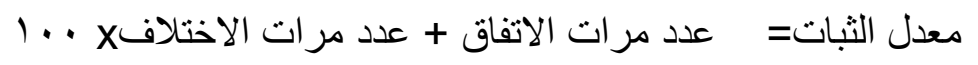

حيث تم حساب مدى الاتفاق نتائج التحليل ،الذي فقامت به الباحثة مع نتائج التحليل الذي هري

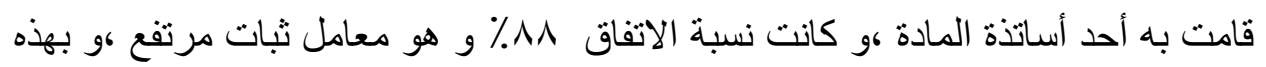
الإجراءات اصبحت قائمة المفاهيم التاريخية ،و بذلك تم التوصل الي المفاهيم مثل: الخلافة ـ الهجرة ـ المهاجرين ـ الأنصار .- الأهرة *تائج التحليل: أسفرت عملية التحليل على تحديد قائمة المفاهيم التاريخية و عددها ( • ( )

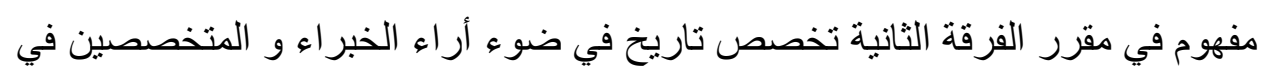

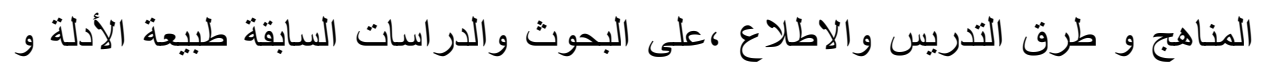
المصادر التاريخية ،و خصائص طلاب كلية التربية ، ثم قامت الباحثة بإعداد قائمة تشتمل على تحديد المعنى ،و المدلول اللفظي لكل مفهوم من المفاهيم التاريخية ،و الخصائص مع توضيح مدى انتمائها أو عدم انتمائها للمفاهيم الأخرى ثم عرض القائمة على خبر اء المناهج وطرق التدريس إلى أن تم وضعها في صورتها النهائية ( ب ).

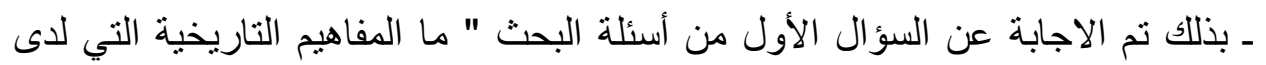

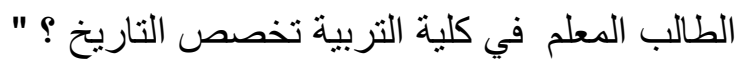
ب ـ بعد تحديد الباحثة المفاهيم التاريخ بمحتوى المقرر ،قامت الباحثة بإعداد قائمة للتصورات البديلة للمفاهيم التاريخية ،التي لها علاقة بالمفاهيم الواردة في الأطر الفكرية، لاى الجماعات المتطرفة و قد قامت الباحثة بتحديد الدلالة اللفظية لكل منها ،و عددها (0) مفاهيم الأكثر تكررا في وحدات مقرر تاريخ الدولة العربية و الإسلامية الفرقة الثانية كوتم ضبطها في صورتها المبئية ،و تحديد الدلالة اللفظية لكل مفهوم وجهة نظر هم ،من خلال در اسة الأدبيات والبحوث و الدراسات السابقةالعربية والاجنبية ،وفي ضوء آراء الخبراء عرضها على السادة المحكمين، في تدريس المناهج وطرائق التدريس مادة التاريخ، و تم إجراء التعديلات اللازمة على القائمة ،ووضعت في

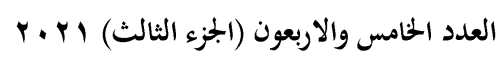

جلة كلية التربية- جامعة عين شمس 
دادة عادة عبد الفتاح زايد

صورتها النهائية ملحق ( ؟ )، ونتنمل على ( 0) مفهوم و أجرت الباحثة التعديلات اللازمة،و بذلك تم الإجابة عن السؤال الثاني من أسئلة البحث " ما التصورات البديلة

للمفاهيم التاريخية التي يجب تصحيحها لدى الطالب المعلم في كليات التربية ؟ " ج ـ قامت الباحثة بإعداد قائمة أبعاد الأمن المجتمعي المناسبة، في صورتها المبدئية وقد عرضت على السادة المحكمين، في تدريس المناهج وطر ائق التدريس مادة التاريخ ،و تم إجر اء التعديلات اللازمة على القائمة ،ووضعت في صورتها النهائية ملحق ( ( ) )، ونتنمل على (ع () بعد فرعي منضمنة في ثلاث أبعاد رئيسية، وهي موضحة في

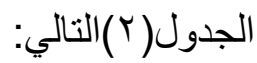

جدول(r) النسبة المئوية متطلبات أبعاد الأمن المجتمي الرئيسية والفرعية

\begin{tabular}{|c|c|c|c|}
\hline النسبة المئوية & الأبعاد الفرعية & أبعاد الأمن المجتمعي & $p$ \\
\hline$\% r \wedge, 0$ & $\varepsilon$ & الأمن السياسي & 1 \\
\hline$\% r \Delta, V$ & 0 & الأمن الاجتماعي & $r$ \\
\hline$\%$ ro,, & 0 & الأمن الفكري & $r$ \\
\hline$\%$ & $1 \leqslant$ & المجموع & \\
\hline
\end{tabular}

و بذلك تمت الإجابة عن السؤال الثالث من أسئلة البحث"ما أبعاد الأمن المجتمعي التي يجب تو افرها لدى الطالب المعلم في كلية التربية تخصص تاريخ ؟ ثانيا ـ إعداد محتوى البرنامج:

ا ـ فلسفة البرنامج :اعتمدت فلسفة تصميم البرنامج الحالي في التاريخ، على الاتجاهات العالمية الحديثة،و نتائج البحوث و الدراسات السابقة و الأدبيات التي تؤكد فاعلية برنامج مقترح قائم على إستراتيجية التغير المفاهيمي لتصحيح التصورات البديلة للمفاهيم التاريخية ،وتتمبة أبعاد الأمن المجتمي لدى طلاب شعبة التاريخ في كليات التربية ،للحفاظ على كيان المجتمع الإنساني و استقراره ورقيه. r ـالأسس التي يقوم عليها البرنامج: روعي عند بناء البرنامج الحالي لتدريس مقرر تاريخ الدولة العربية الإسلامية الفرقة الثانية تاريخ"، لدى الطالب المعلم في كلية التربية تحديد الأسس ،التي يستند عليها البرنامج، عند إعداده ويمكن توضيحها كما يلي: 
برنامج مقترح قائم على إستراتيجية التغير المفاهيمي لتصحيح التصورات البايلة للمفاهيم التاريخية

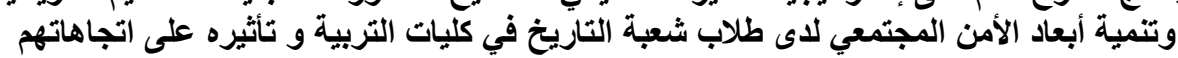

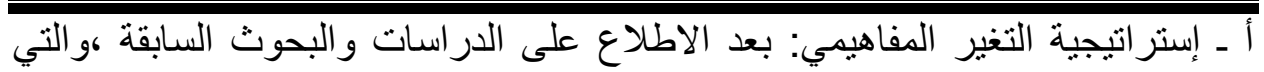
اهتمت بهذا المجال والاطلاع ،على معظم النماذج والاستر اتيجيات المستخدمة ففي تصويب التصورات البديلة للمفاهيم في المجالات المختلفة ،تم اختيار الإستراتيجية

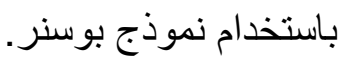
ب ـ تحديد قائمة بالمفاهيم التاريخية :و تم من خلال تحليل محتوى مقرر الدول العربية و الإسلامية ،لدى الطالب المعلم الفرقة الثانية تاريخ في كلية التربية ،لتحديد قائمة المفاهيم التاريخية المتضمنة في المحتوى ،وتحديد مدلولها اللفظي وفق الادلة و المصادر التاريخية الموثقة، واختيار الوحدة المقترحة الواردة بها أكثر عدد من المفاهيم التاريخية. ج ـ تحديد التصورات البديلة للففاهيم التاريخية : نم من خلال تحديد المفاهيم المفاهيم التاريخية الواردة في الأطر الفكرية المتطرفة ،و تخرج عن حيز الاعتدال و الوسطية

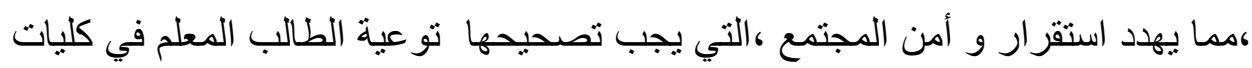
التربية من خلال استقر اء الأدبيات ،و البحوث السابقة العربية والأجنبية . . دـ ـ تحديد أبعاد الأمن المجتمعي التي يحب تو افرها ،لدى الطالب المعلم في كلية التربية،

$$
\text { و تشتمل على بعد الأمن ( الفكري ـ الاجتماعي ـ السياسي) }
$$

ه ـ خصائص الطالب المعلم في كلية التربية : حيث تحرص كلية التربية في هذه

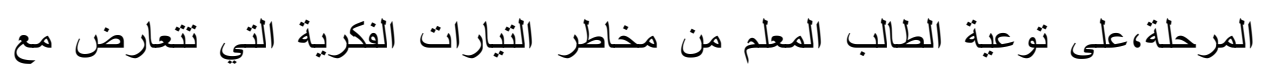
الأهداف التربوية ،و تهدد عقولهم بالفكر المتطرف الذي يحول بين تعايش الفرد داخل

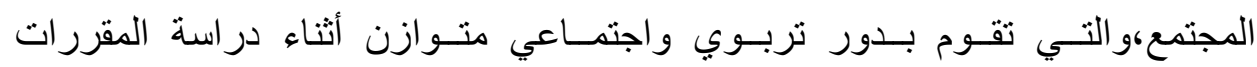
الدراسية ، لكي يتمكن من تتميتها لدى طلابه في المراحل التعليمية المختلفة أثناء التدريس . و ـ طبيعة مادة التاريخ : والتـي تعـد ميـدانا خـصبا للحقائق والمعلومات و الأحداث ،التي تحتوي على عديد من المفاهيم التاريخية الصحيحة، و التي يمكـن مـنـ خلالها بناء بنية معرفية لدى الطالب تساعده على تصحيح المفاهيم التاريخية التصور ات البديلة ،في 
دا غادة عبد الفتاح زايد

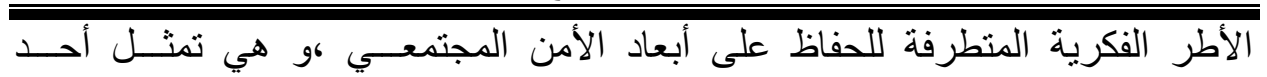

$$
\text { الأهداف الرئيسـسة في تعلــيم المادة. }
$$

ع ـ طبيعة المجتمع المصري و أهم مشكلاته : المجتمع في حاجـة إلى تنمية وعي النشء

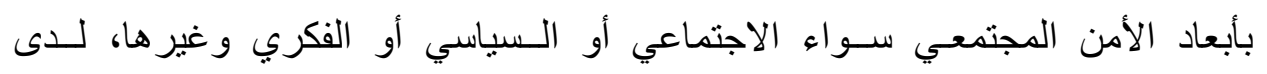

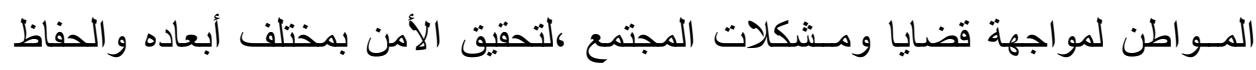
على استقر اره و أمنه. ثالثا ـ خطوات بناء البرنامج : وفيما يلي توضيح لهذه الخطوات: اــ أهداف البرنامج :يستهدف البرنامج قياس فاعلية برنامج مقترح قائم على إستراتيجية

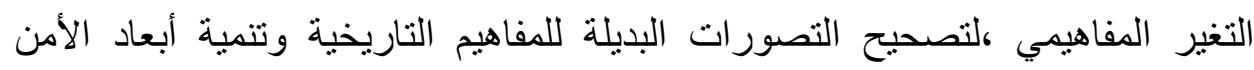
المجتمعي لدى الطالب المعلم شعبة التاريخ في كليات التربية. r- تحديد محتوي البرنامج :- إعداد وحدة مقترحة تطبيقيه معاد صياغتها من مقرر التاريخ " تاريخ الدولة العربية الإسلامية "' باستخدام إستراتيجية التغير المفاهيمي ،لتصحيح التصورات البديلة للمفاهيم التاريخية الواردة في الأطر الفكرية المتطرفة، وتنمية أبعاد الأمن المجتمعي لدى الطالب المعلم شعبة التاريخ في كليات التربية. r ـ تحديد استراتيجيات وطرائق تدريس البرنامج :تناول البحث الحالي عديدا من الاستر اتيجيات، باستخدام إستراتيجية التغير المفاهيمي،مثل إستراتيجية (المناقتنة والحوارـ العصف الذهني ـ التعلم التعاوني ـ حل المشكلات ـ الخرائط معرفيةـ خرائط المفاهيم)من خلال التركيز على نشاط المتعلم .

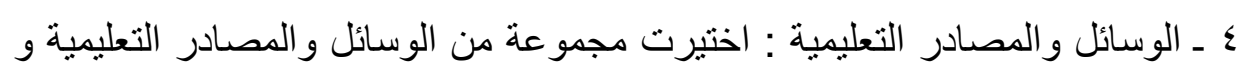
التكنولوجية، أثناء استخدام إستراتيجية التغير المفاهيمي،لتحقيق أهداف كل درس من

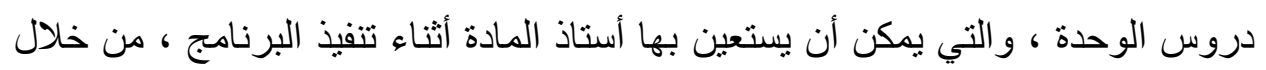
الإنترنت على المستوى الفردي أو التعاوني بين أستاذ المادة و الطالب المعلم. 
برنامج مقترح قائم على إستراتيجية التغير المفاهيمي لتصحيح التصورات البديلة للمفاهيم التاريخية

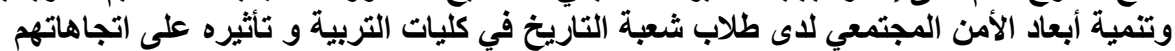
0 ـ الأنشطة التعليمية :يقدم البرنامج مجمو عة من الأنشطة و التكليفات، باستخدام إستر اتيجية التغير المفاهيمي ، التي على الطالب المعلم أدائها و القيام بها أثناء تدريس البرنامج. 7ـ أدوات و أساليب التقويم التي يقدمها البرنامج : :و قد تم إعداد أدوات التقويم لقياس مدى لته تحقن الأهداف، باستخدام إستر اتيجية التغير المفاهيمي وتضمنت : ـ أـ مرحلة التقويم القبلي :ويتم تطبيق ادوات البرنامج قبليا ،و تشتمل على اختبار لقياس مدى قدرة الطالب المعلم على تصحيح التصورات البديلة للمفاهيم التاريخية باستخدام إستراتيجية التغير المفاهيمي ،ثم مقياس لقياس اتجاهاته نحو أبعاد الأمن المجتمي. ب ـ مرحلة التقويم البنائي :أثناء تنفيذ البرنامج واكتشاف الجوانب الإيجابية، ودعمها و الجو انب السلبية ومعالجتها، وتشمل الأسئلة وأداء المهام و التكليفات الخاصة بكل درس. ج - مرحلة التقويم البعدي :وينم تطبيق ادوات البرنامج بعديا و تشتمل على اختبار لقياس مدى قدرة الطالب المعلم وتمكنه من تصحيح التصور ات البديلة للمفاهيم التاريخية باستخدام إستراتيجية التغير الدفاهيمي ،ثم مقياس لقياس اتجاهاته نحو أبعاد الأمن المجنمعي. في ضوء ما سبق تم تحديد توصيف الإطار العام، لبرنامج مقترح قائم على إستراتيجية

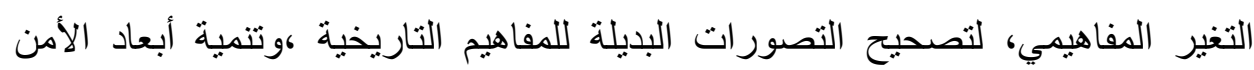
المجتمي لدى الطالب المعلم شعبة التاريخ في كليات التربية ملحق (†) ووضع الإطار

$$
\text { العام لتوصيف البرنامج. }
$$

وتم عقد جلسات في بداية البرنامج لتقديم الإرشادات، لتدريب على كيفية تدريس أستاذ المادة في كلية التربية تخصص التاريخ للبرنامج باستخدام إستر اتيجية التغير المفاهيمي، في توعية الطالب المعلم التصورات البديلة للمفاهيم التاريخية الواردة في الأطر الفكرية

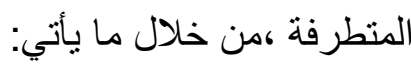

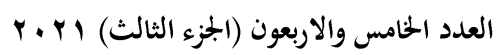

(286)

جلة كلية التربية- جامعة عين شثس 
ـالتهيئة : و تتضمن تحديد أستاذ المادة الأساليب و الطرائق المناسبة، لتطبيق الدرس بحيث تتسم بالإثارة والتشويق ،وتتناسب مع مستوى الطالب المعلم والمحتوى. ـاستخدام إستراتيجية التغير المفاهيمي:اقتصرت الباحثة عند تطبيقها ، إستراتيجية التغير المفاهيمي باستخدام نموذج بوسنر، لتصحيح التصور ات البديلة للمفاهيم التاريخية الواردة في الأطر الفكرية المتطرفة وتنمية أبعاد الأمن المجتمعي، لاى طلاب شعبة التاريخ في كليات التربية، وتتنمل على الأمن (السياسيـ الاجتماعي ـ الفكري) ،ولتحقيق ذلك لابد

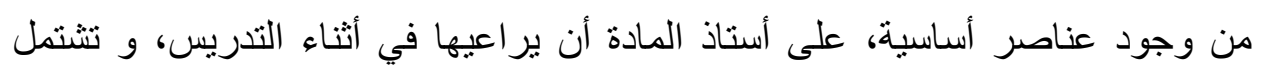

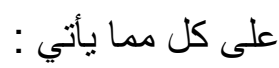
1 ـ منطلبات إجرائية قبل تتفيذ الدرس :و تعني تصميم مواقف التعلم و تحديد المدلول اللفظي ،للمفاهيم التاريخية الصحيحة وفق المصسادر و الادلة ،ثم تحديد التصور ات البديلة للمفاهيم التاريخية المراد تصحيحها ،ثم تحديد أبعاد الأمن المجتمي، قبل البده في في البه استخدامها وتتتوع وفق الأهداف. r ـ في أثناء تتفيذ الدرس : ويعني كيفية تنفيذ أستاذ المادة للموقف التدريسي، من أجل أنجاز أهداف كل مرحلة من مراحل تطبيق إستراتيجية التغير المفاهيمي كيثكل عامل أساسي في تنفيذ كل مرحلة. r ـ التكتيكات التدريسية : وتعني سلسلة من الإجراءات المؤقتة القابلة للتعديل، و التي تساعد أستاذ المادة على استخدامها بنجاح، من خلال تدريب أستاذ المادة على كيفية استخدام إستراتيجية التغير المفاهيمي أثناء التدريس وطرائق تدريس متنوعة، وأداء جميع الأنشطة و المهام.

عـ بيئة التعلم :تتكيل بنية تعلم تتلاءم مع ما تتطلبه كل مرحلة، من مر احل تطبيقها.

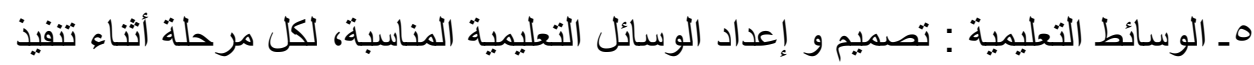
إستراتيجية التغير المفاهيمي. 7 ـ التقويم : قياس ما تم تحقيقه من أهداف قبل و أثناء ونهاية تطبيق البرنامج.

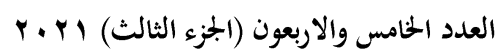

مجلة كلية التربية- جامعة عين شثس 
برنامج مقترح قائم على إستراتيجية التغير المفاهيمي لتصحيح التصورات البايلة للمفاهيم التاريخية

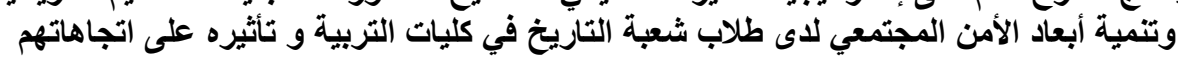

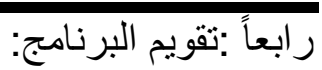

تم إعداد أدوات تقويم البحث وتتشتمل : إعداد اختبار لقياس مدى قدرة الطالب المعلم على تصحيح التصورات البديلة ،للمفاهيم التاريخية الواردة في الأطر الفكرية المتطرفة ،ومقياس لقياس اتجاهاته نحو أبعاد الأمن المجتمعي ،ثم تطبيقها قبليا وبعديا. ـ وقد تم عرض البرنامج على مجموعة من المحكمين، للتحقق من مناسبته من حيث الصياغة كو الأهداف و الوسائل و الأنشطة و المحتوى و أساليب التقويم، وتم التعديل في البرنامج بناء على على على ملاحظات المحكمين، وبذلك أصبح الإطار العام للبرنامج في صورته النهائية. و بذلك تمت الإجابة عن السؤال الرابع " ما البرنامج المقترح القائم على إستراتيجية

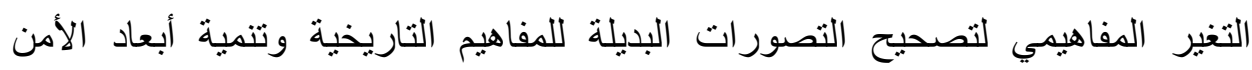
المجتمعي لاى طلاب شعبة التاريخ في كليات التربية؟" التهبر זــ إعداد كتيب الطالب المعلم: تم إعداد كتيب الطالب المعلم يسترشد به "عند دراسته للوحدة المقترحة بحيث يحتوي على المهام والأنشطة المكلف، المطلوب أدائها أثناء التدريس، ثم تم عرضه على مجموعة من السادة المحكمين المختصين ،في مجال المناهج والدراسات اجتماعية و قد أبدى المحكون بعض الملاحظات وضعت في في الاعتبار ،عند إعداد الصورة النهائية لكتيب الطالب المعلم ،طبقا لآر اء السادة المحكمين واصبح الكتيب في صورته النهائية ،صالحا للنطبيق على مجموعة البحث ملحق(V). عـ إعداد دليل أستاذ المادة :تم إعداد دليل استرشادي لأستاذ المادة لتدريس وحدة المقترحة من "تاريخ الدولة العربية الإسلامية" المقرر على الفرقة الثانية تخصص تاريخ ، باستخدام إستر اتيجية التغير المفاهيمي، و هذا الدليل يوضح لأستاذ المادة كيفية تدريس دروس الوحدة المقترحة ،ودوره و مسئولياته أثناء عملية التدريس ،و قد تضمن الدليل مجموعة من العناصر التي تكاد تتقق عليها معظم الدراسات و البحوث السابقة في مجال المناهج و طرق التدريس ،وتم ذلك وفقا للخطو ات التالية:

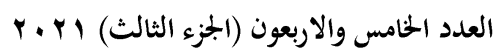

جلة كلية التربية- جامعة عين شمس 


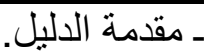

ـ إرشادات و توجيهات عامة لأستاذ المادة يجب أن ير اعيها عند التدريس . ـ ت تحديد أهداف الدليل .

ـ تحديد مكونات الدليل و اشتمل على كل مما يأتي : 1 ـ المقدمة : و اشتملت على التعرف على إستراتيجية التغير المفاهيمي، لتصحيح التصورات البديلة للمفاهيم التاريخية وتتمية أبعاد الأمن المجتمي ،لدى طلاب شعبة التاريخ في كليات التربية. זـ محتوى الدليل : و اشتمل البرنامج على إعداد وحدة معاد صياغتها ،و تضمن عرض عديد من الدروس من مقرر تاريخ الدولة العربية الإسلامية" لدى الطالب المعلم بكلية التربية قائمة على إستراتيجية التغير المفاهيمي، لتصحيح التصورات البديلة للمفاهيم التاريخية ،وتتمية أبعاد الأمن المجتمي ، وأشنتمل كل درس على (أهداف الدرس الزمن المحدد ـ الوسائل و المصادر التعليمية ـ الأنشطة التعليمية ـ إستراتيجيات و طرق التدريس ـ التقويم ـ المراجع التي يمكن الإفادة منها في بناء دليل لأستاذ المادة). rـ تم عرض الدليل على مجموعة من المتخصصين ،للتأكد من المحتويات العلمية، ومدى قابلية أهداف الدليل للتحقيق ،ووضوحها إجرائيا ومناسبة الزمن لتطبيقها ،وبعد الانتهاء من التحكيم تم صياغة فقرات دليل أستاذ المادة في صورته النهائية. ملحق(^) . . خامساً:قياس فاعلية البرنامج وتحديد متغيرات البحث تشتمل ،على متغير مستقل وهو الاستراتيجية المقترحة القائمة على التغير المفاهيمي، ومتغير تابع وهو تصحيح التصورات البديلة للمفاهيم التاريخية تنمية ابعاد الامن المجتمعي وتأثيره على هلى

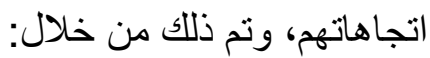


برنامج مقترح قائم على إستراتيجية التغير المفاهيمي لتصحيح التصورات البايلة للمفاهيم التاريخية

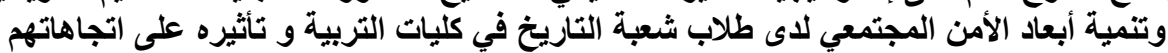

1ـ إعداد اختبار المفاهيم التاريخية:

أـ تحديد هدف الاختبار : فياس قدرة الطالب المعلم على تصحيح التصورات البديلة للمفاهيم التاريخية الواردة في الأطر الفكرية المتطرفة، لدى الطالب المعلم الفرقة الثانية تخصص تاريخ ( مجموعة البحث ) قبل وبعد در استهم للوحدة المقترحة .

ب ـ تحديد جدول المو اصفات :تم صياغتها في عبارات سلوكية، ثم تصميم الاختبار لقياس تلك الأهداف السلوكية، وتم وضع جدول للمو اصفات لتحديد أبعاد اختبار المفاهيم التاريخية ابعاد الاختبار ،ووضع أسئلة تقيس كل منها ملحق ( 9 (9) . ج - صياغة مفردات الاختبار :تم تحديدها من خلال تحليل محتوى ،مقرر تاريخ الدولة العربية و الإسلامية ،التي تم إعدادها و بعد الاطلاع على بعض اختبارات المفاهيم

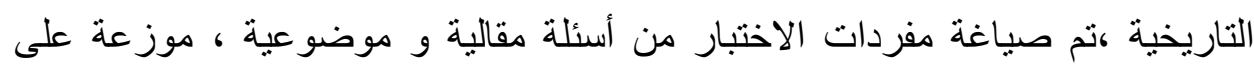
ابعاد الاختبار هي(المدلول اللفظي للمفاهيم التاريخية ـ تصحيح التصورات البديلة للمفاهيم التاريخية ـ التمييز بين المفاهيم التاريخية والتصورات البديلة ـ اثر التصورات البديلة للمفاهيم التاريخية على ابعاد الامن المجتمعي - جهود الدولة في حماية المجتمع من الاثار السلبية للتصورات البديلة للمفاهيم التاريخية ـ المسئولية الفردية و الاجتماعية تجاه تصحيح التصورات البديلة للمفاهيم التاريخية )،و قد عرضت الصورة الأولية لاختبار المفاهيم التاريخية على السادة المحكمين ،بهدف التعرف على آرائهم و ملاحظاتهم حوله ،و تم إجر اء التعديلات اللازمة في ضوء ملاحظات السادة المحكمين ،كما طبق الاختبار على عينة استطلاعية مكونة من ( • ب) طالب معلم بعد استبعاد

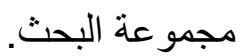

دـ صدق الاختبار :عرض الاختبار علي مجموعة من السادة المحكمين، في مجال المناهج وطرق التدريس مادة التاريخ، وذلك بهدف التأكد من مدي مناسبة الاختبار للأهدافهو التأكد من شمول الاختبار على المفاهيم التاريخية الصحيحة والتصورات 
دادة غادة عبد الفتاح زايد

البديلة للمفاهيم التاريخية، التي تم تحديدها ووضعه في صورته الأولية ، وقد تم الأخذ بالتعديلات و المقترحات التي أثناروا إليها.

و ـ التجربة الاستطلاعية: تم تطبيق الاختبار على عينة استطلاعية، تكونت من (0. (0) طالب معلم الفرقة الثانية تاريخ ،في كلية التربية جامعة عين شمس في الفصل الدراسي

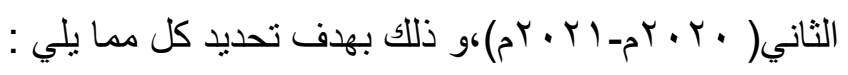
* زمن الاختبار: تم حساب زمن الاختبار من خلال العينة الاستطلاعية، وذلك من خلال تسجيل الزمن الذي أستغرقه كل طالب معلم للإجابة على الاختبار, ثم حساب متوسط الزمن للعينة كلها, وبذلك تم إيجاد زمن الاختبار وهو (• Y I ) دقيقة.

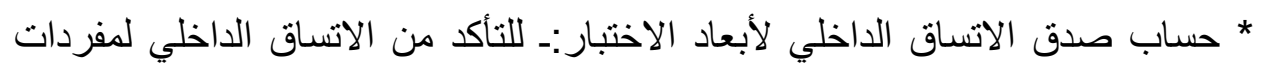
للاختبار , تم حساب معاملات الارتباط بين درجة كل مفردة والدرجة الكلية للاختبار، مما يثير إلي الاتساق الداخلي للاختبار. * ـ حساب ثبات الاختبار: تم تطبيق الاختبار ثم إعادة تطبيقه مرة اخرى، بعد أسبو عين

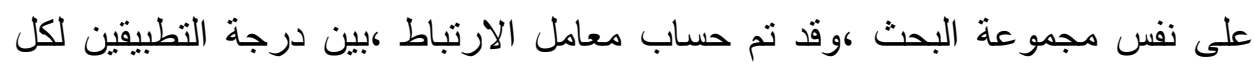

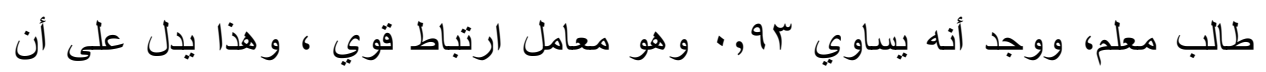
الاختبار يتمتع بدرجة عالية من الثبات، ومن ثم يمكن الاعتماد عليه كوسيلة للقياس.

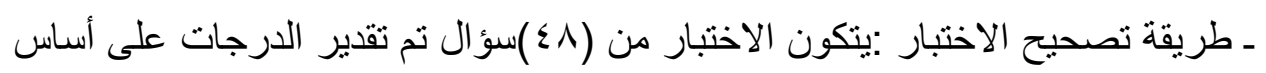

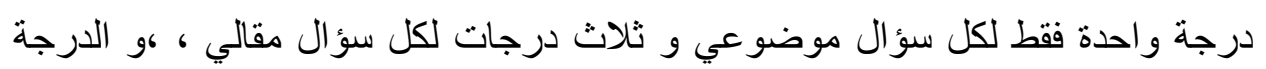

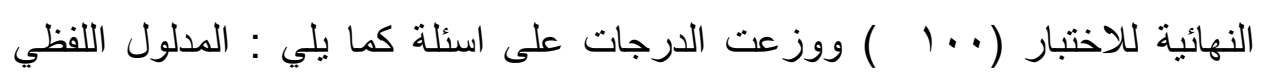
للمفاهيم التاريخية (7 (1) درجة، تصحيح التصورات البديلة للمفاهيم التاريخية بالأدلة

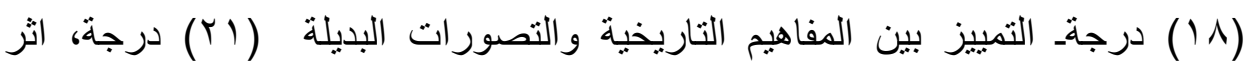

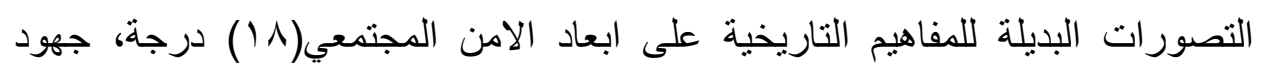
الدولة في حماية المجتمع من الاثار السلبية للتصورات البديلة للمفاهيم التاريخية (10) 
برنامج مقترح قائم على إستراتيجية التغير المفاهيمي لتصحيح التصورات البيلة للتئية المفاهيم التاريخية

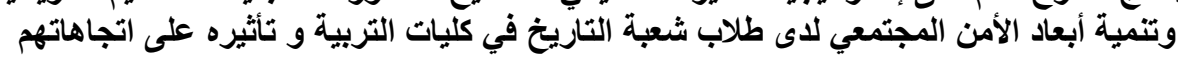

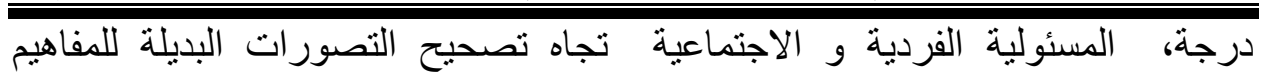
التاريخية( ب ( ) درجة. ـ الصورة النهائية للاختبار: بعد عرض الاختبار علي السادة المحكمين، وبعد إجراء التعديلات على مفردات الاختبار في ضوء آراء السادة المحكمين ،وما أسفرت عنه نتائج التجربة الاستطلاعية، التي أجريت لتحديد زمن وصدق الاختبار ،وبنائه ومعاملات السهولة والصعوبة لمفرداته ،تم صياغة الاختبار في صورته النهائية، و أصبح الاختبار في صورته النهائية ،و اشتمل العدد الإجمالي لأسئلة الاختبار(ی) سؤال استعدادا للانطبيق علي عينة البحث. ملحق ( • (1) ب ـ المقياس أـ تحديد الهذف من المقياس: يهدف المقياس إلى قياس اتجاهات الطالب العلم ،نحو أبعاد الأمن المجتمي فاعلية باستخدام إستر اتيجية التغير المفاهيمي. ب ـ صياغة مفردات المقياس :تم مر اعاة أن تكون العبار ات محددة وغير قابلة، للتأويل و خالية من المصطلحات غير المألوفة ،و استبعاد الالفاظ التي تقود الطالب المعلم، على الاختيار الصحيح بشكل مباشر و توزيع العبار ات عشوائيا. ج - حدود المقياس : يستخدم هذا المقياس قبل و بعد تدريس الوحدة الدراسية المقررة كمن مقرر الفرقة الثانية تاريخ ،لدى الطالب المعلم في كلية التربية و ذلك لمعرفة مدى بـى فعالية تدريس الوحدة في تنمية الاتجاهات نحو أبعاد الأمن المجتمعي ،وتتتمل على أبعاد الأمن( الفكري - السياسي ـالاجتماعي) وفق جدول مو اصفات المقياس ملحق( (1) د ـ صياغة عبار ات المقياس: صيغت عبار ات المقياس في صورتها الأولية على هيئة مو اقف طبقا ،لنموذج ليكرت ذي

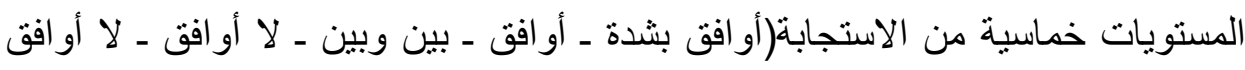
بثدة ) على أن تكون الدرجة المقابلة ،لكل من هذه المستويات على الترتيب كما يلي:

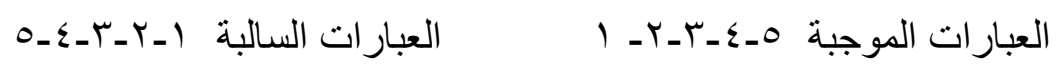

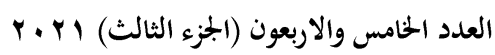

(292)

مجلة كلية التربية- جامعة عين شمس 
داد غادة عبد الفتاح زايد

و أيضا تم مر اعاة بعض المعايير عند صياغة عبار ات المقياس منها، احتواء المقياس غيل على عبار ات موجبة و عبارات سالبة ،وترتيب عبارات المقياس عثوائيا ،يجب أن تكون العبار ات قصيرة ولا تحنوي على أكثر من فكرة واحدة. ه ـ تعليمات المقياس تستهدف تعليمات المقياس، و شرح فكرته و أهدافه و مفرداته و

$$
\text { و ـ التجريبة الاجابة عن العبار ات بدقة. }
$$

-ثبات المقياس يكون المقياس صادقا اذا كأن يقيس ما وضع لقياسه ،و قد تم التأكد من ثبات المقياس باستخدام معامل الارتباط الفا كرونباخ. ل - صدق المقياس : عرض المقياس علي مجموعة من السادة المحكمين، في مجال المناهج وطرق التدريس مادة التاريخهو التأكد من شمول المقياس لجميع الابعاد، التي تم تحديدها ووضعه في صورته الأولية ، وقد تم الأخذ بالتعديلات والمقترحات التي أشاروا إليها. ع - الصورة النهائية للمقياس: تكون المقياس في صورته النهائية ملحق ( Y I ) ،ويحتوي على •0 عبارة موزعة كما هو موضح في الجدول( ا ) التالي:

\begin{tabular}{|c|c|c|c|c|}
\hline المئوية & الكلي & العبارات السلبية & العبارات الايجابية & المجتمعي الامن \\
\hline$\% r \leq$ & IV & 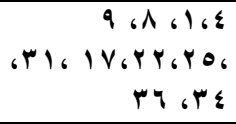 & 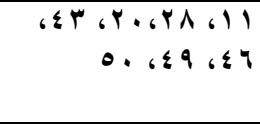 & أولا ـ الأمن \\
\hline$\% \Psi \varepsilon$ & IV & 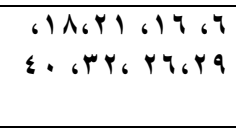 & 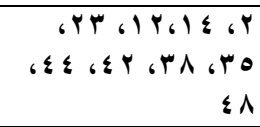 & الاجتيا الأمن \\
\hline$\% r r$ & 17 & $\begin{array}{l}610_{6} 1 q_{6} r \leqslant 6 r \\
\leqslant V ، \leqslant 0, r \cdot 6 \leqslant 1\end{array}$ & 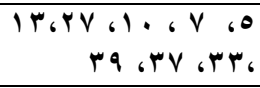 & ثالثيا الأمن \\
\hline$\% 1 \ldots$ & 0 . & ro & ro & المجموع \\
\hline
\end{tabular}

جدول(1 ) مواصفات مقياس اتجاهات الطالب المعلم نحو أبعاد الأمن المجتمعي

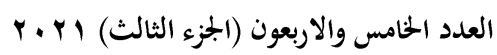

جلة كلية التربية- جامعة عين شثس 
برنامج مقترح قائم على إستراتيجية التغير المفاهيمي لتصحيح التصورات البايلة للمفاهيم التاريخية وتنمية أبعاد الأمن المجتمعي لُّى طلاب شعبة التتاريخ في كليات التربية و تأثيره على اتجاهاتهم

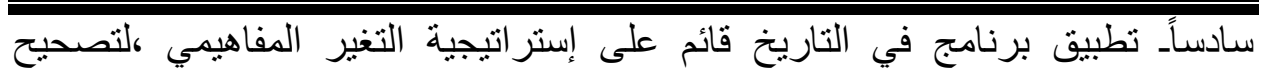
التصورات البديلة للمفاهيم التاريخية وتتمية أبعاد الأمن المجتمعي لدى طلاب شعبة التاريخ في كليات التربية و أثرة على اتجاهاتهم ،وتم ذلك من خلال: اــ التصميم التجريبي للبحث: اعتمد البحث الحالي التصميم التجريبي (المجموعة الو احدة).

rـ التطبيق القبلي لأداة البحث :تم التطبيق القبلي للاختبار لقياس قدرة الطالب المعلم (مجموعة البحث )على تصحيح التصورات البديلة للمفاهيم التاريخية ،ومقياس لقياس لهاب تأثيره على اتجاهاتهم نحو أبعاد الأمن المجتمعي. rـ قامت الباحثة بتدريب أحد أساتذة المادة في قسم التاريخ ، في كلية التربية جامعة عين شمس ،على كيفية استخدام إستراتيجية التغير المفاهيمي ،لتصحيح التصورات البديلة للمفاهيم التاريخية وتنمية أبعاد الأمن المجتمعي ،وتضمن التدريب أربع جلسات استغرقت كل منهما ،ساعتين في نهاية اليوم الدراسي مع المتابعة المستمرة، للتأكد من مدى استيعاب كل أستاذ مادة ، لخطوات تدريس المادة و تسليمه نسخة من دليل أستاذ

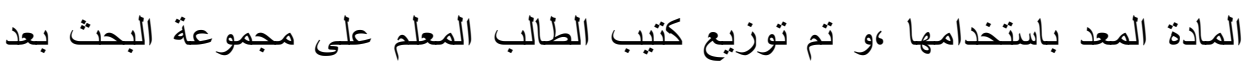
التطبيق القبلي للاختبار. ـ قام بتدريس وحدة البحث أحد أساتذة المادة و تطبيقها ،على الطالب المعلم في الفرقة الثانية قسم التاريخ باستخدام إستراتيجية التغير المفاهيمي ، قامت الباحثة بمتابعة المعلم ، أثناء تدريسه دروس الوحدة بعد إعادة صياغتها. ع -ـ تنفيذ البرنامج القائم على استراتيجية التغير المفاهيمي :استمر تدريس البرنامج،

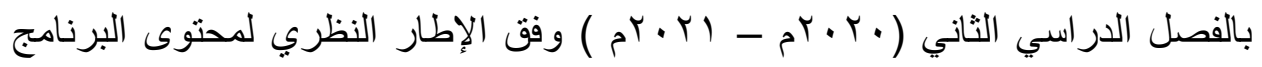
،واستغرق البرنامج أربعة أسابيع ،بما يساوي ست عشرة حصة مقسمة على أربعة محاضرات تدريسية في الاسبوع، مع مراعاة نهاية كل درس الرد، على استفسارات

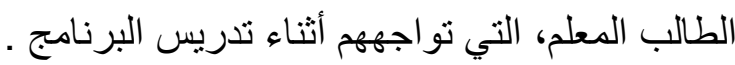

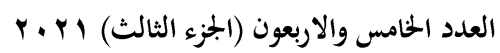
(294)
مجلة كلية التربية- جامعة عين شمس 


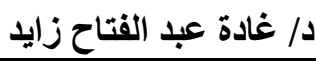

هـالتطبيق البعدي لأدو ات البحث : تم التطبيق البعدي للاختبار لقياس قدرة الطالب المعلم (مجموعة البحث )على تصحيح التصورات البديلة للمفاهيم التاريخية ،ومقياس لقياس تأثيره على اتجاهاتهم نحو أبعاد الأمن المجتمعي. 7ـ التصحيح و رصد النتائج :تم تصحيح نتائج كل من الاختبار بناءً على نموذج

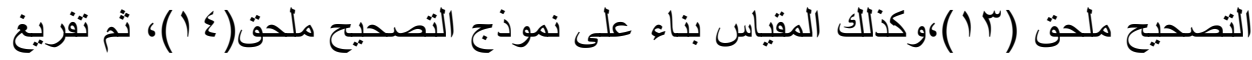
الدرجات الخاصة بكل منهما و إعدادهما للمعالجة الاحصائية. Vـ المعالجة الإحصائية للنتائج: تم حساب قيمة" ت "للمتوسطين المرتبطين؛ لمقارنة نتائج مجموعة البحث قبل تدريس البرنامج وبعده؛ للتأكد من فاعليته في تصحيح التصورات البديلة للمفاهيم التاريخية ،و تأثثره على اتجاهاتهم نحو أبعاد الأمن المتمعي، باستخدام البرنامج الإحصائي SPSS ،لمعالجة جميع البيانات الإحصائية ،للبحث للتأكد من صحة فروض البحث، و فيما يلي عرضا تفصيليا للفروض ونتائجها.

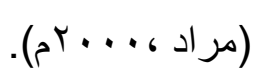

ـ نتائج البحث تفسير ها ومناقتنتها:

و للتحقق من الفرض الأول" يوجد فرق دال إحصائيًا عند مستوى 1 ., • بين متوسطي درجات مجموعة البحث في القياسين القبلي والبعدي ،لاختبار المفاهيم التاريخية ككل لصالح الاختبار البعدي ."للتحقق من هذا الفرض، استخدمت الباحثة اختبار " ت " للعينات المرتبطة ،ويمكن عرض ما توصلت إليه الباحثة من نتائج، من خلال

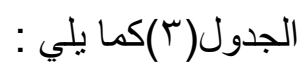

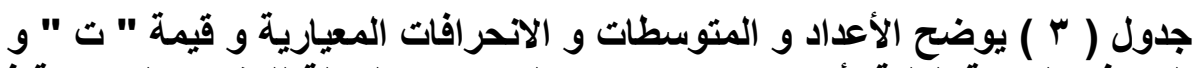

\begin{tabular}{|c|c|c|c|c|c|c|}
\hline \multicolumn{7}{|c|}{ الفياسين الفبلي والبعدي } \\
\hline مستولة الالالة & 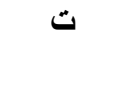 & $\varepsilon$ & b & ن & القياس & 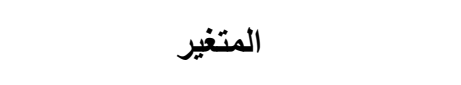 \\
\hline دالةً & & $0, Y \leqslant$ & Y4,70 & o. & قبلي & الارجة الكلية لأبعاد اختبار تصحيح \\
\hline إحصائياً عند & Tr,OY & $r, \cdot \wedge$ & NT,Or & 0 . & 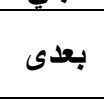 & في القياسين الثبليلة للمفاهيم التاريخية \\
\hline
\end{tabular}

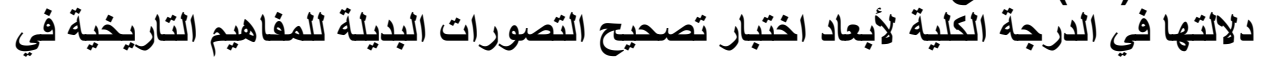

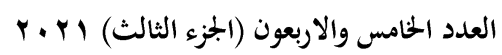

جملة كلية التربية- جامعة عين شثس 
برنامج مقترح قائم على إستراتيجية التغير المفاهيمي لتصحيح التصورات البايلة للمفاهيم التاريخية

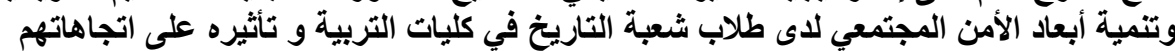

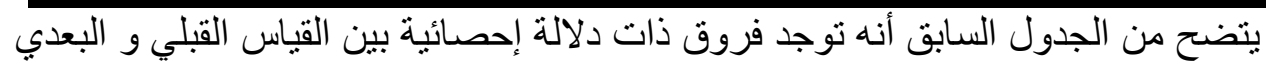

لمجموعة البحث في منوسط الدرجة الكلية لأبعاد اختبار تصحيح التصورات البديلة للمفاهيم التاريخية في القياسين القبلي و البعدي لصالح القياس البعدي حيث كانت قيمة "ت"

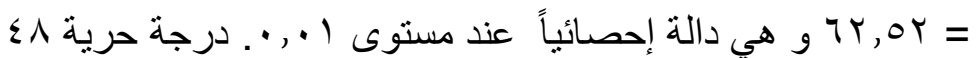
وللتحقق من الفرض الثاني يوجد فرق دال إحصائًًا عند مستوى $\mid$., •بين متوسطي درجات مجموعة البحث في القياسين القبلي والبعدي ،لاختبار المفاهيم التاريخية لكل بعد لصالح الاختبار البعدي." للتحقق من هذا الفرض استخدمت الباحثة اختبار" ت " للعينات المرتبطة ،ويمكن عرض ما توصلت إليه الباحثة من خلال الجدول(ع ) التالي :

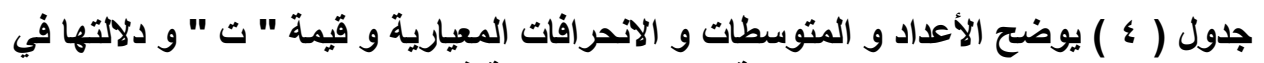
اختبار تصحيح التصورات البديلة للمفاهيم التاريخية في القياسين القبلي والبعدي دئي

\begin{tabular}{|c|c|c|c|c|c|c|c|}
\hline مستوى & ت & $\varepsilon$ & r & $\dot{ن}$ & القياس & ابعاد الاختبار & \\
\hline \multirow{2}{*}{ عند الة إحصائياً } & \multirow{2}{*}{$r \cdot, r q$} & 1,71 & $Y, \wedge \mathrm{T}$ & 0 . & قبلي & \multirow{2}{*}{ التاريخية اللفظي للمفاهيم } & \multirow[t]{2}{*}{1} \\
\hline & & $1,1 \leqslant$ & 7,17 & 0 . & بعدى & & \\
\hline \multirow{2}{*}{ عالة إحصائياً } & \multirow{2}{*}{$\mid r, \wedge \varepsilon$} & .97 & $1, \leqslant 9$ & 0 . & قبلي & \multirow{2}{*}{ للصفاهيح التاريخية بالادلة البديلة } & \multirow[t]{2}{*}{$Y$} \\
\hline & & .891 & $r, r q$ & 0 . & بعدى & & \\
\hline \multirow{2}{*}{ دالة إحصائياً } & \multirow{2}{*}{$\bullet, \Delta r$} & 1,09 & $\Gamma, \Lambda \leq$ & 0 . & قبلي & \multirow{2}{*}{ والتصييز بين المفاهيم التاريخية } & \multirow[t]{2}{*}{$r$} \\
\hline & & $1, V V$ & 0,1 & 0. & بعدى & & \\
\hline \multirow{2}{*}{ عالة إحصائياً } & \multirow[b]{2}{*}{$\varepsilon \varepsilon, Y \leq$} & $r, \varepsilon \wedge$ & $7, \leq \varepsilon$ & 0 . & قبلي & \multirow{2}{*}{ التثاريخية على التصاد الامن البديلة للمفاهيم } & \multirow[t]{2}{*}{$\varepsilon$} \\
\hline & & $1, Y 7$ & $r \leq, q$. & 0 . & بعدى & & \\
\hline \multirow{2}{*}{ عالة إحصائياً } & \multirow[b]{2}{*}{$\varepsilon 1, r}$. & $r, 11$ & 0,1 . & 0. & قبلي & \multirow{2}{*}{ 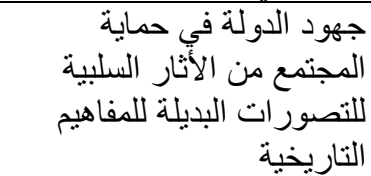 } & \multirow[t]{2}{*}{0} \\
\hline & & .979 & $19, \pi 0$ & 0 . & بعدى & & \\
\hline \multirow[t]{2}{*}{ 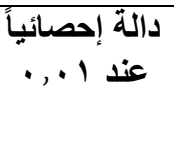 } & \multirow{2}{*}{$\varepsilon \varphi, \mu_{0}$} & $r, r q$ & 7,9 . & 0 . & قبلي & \multirow{2}{*}{ التجاه تصدية الفردية التصو الاجتماعية } & \multirow[t]{2}{*}{7} \\
\hline & & $1, \pi 1$ & $r \leqslant, V q$ & 0. & بعدى & & \\
\hline
\end{tabular}

يتضح من الجدول السابق أنه توجد فروق ذات دلالة إحصائية بين القياس القبلي و البعدي لمجموعة البحث في متوسط البعد الا ول لصالح القياس البعدي حيث كانت قيمة

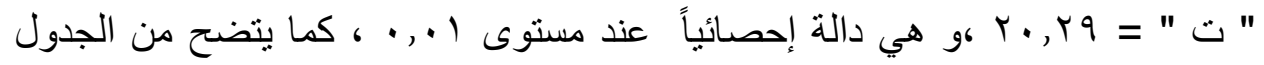


السابق أنه توجد فروق ذات دلالة إحصائية بين القياس القبلي و البعدي لمجموعة البحث

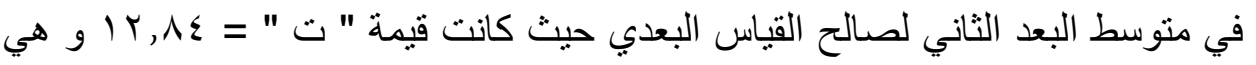
دالة إحصائياً عند مستوى ( . , • و يتضح من الجدول السابق أنه نوجد فروق ذات دلالة إحصائية بين القياس القبلي و البعدي لمجموعة البحث في متوسط البعد الثالث لصالح

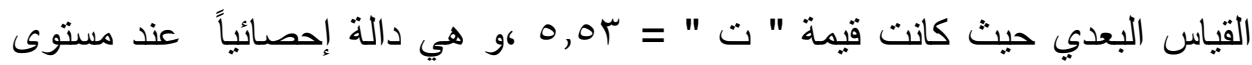
1 . . • . أنه توجد فروق ذات دلالة إحصائية بين القياس القبلي و البعدي لمجمو عة البحث

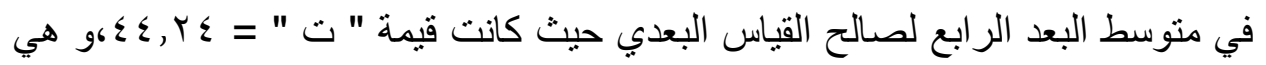

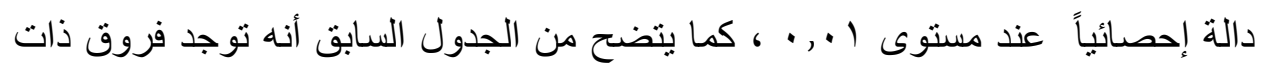
دلالة إحصائية بين القياس القبلي و البعدي لمجموعة البحث في متوسط البعد الخامس

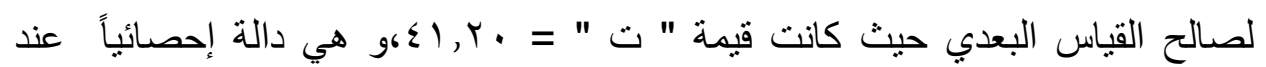
مستوى 1 ., . ، و يتضح من الجدول السابق أنه توجد فروق ذات دلالة إحصائية بين القياس القبلي و البعدي لمجموعة البحث في متوسط البعد السادس لصالح القياس البعدي

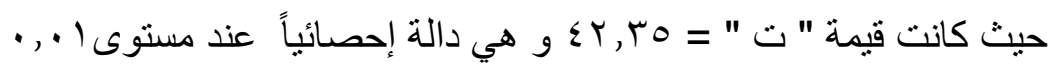

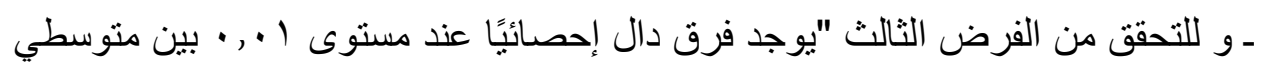

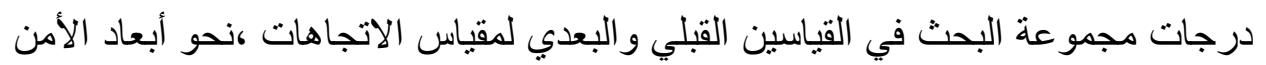
المجتمي ككل لصالح المقياس البعدي للتحقق من هذا الفرض استخدمت الباحثة اختبار " ت " للعينات المرتبطة ،ويمكن عرض ما توصلت إليه الباحثة من نتائج من خلال

$$
\text { الجدول(0) كما يلي : الجيال }
$$

جدول (0 ) يوضح الأعداد و المتوسطات و الانحرافات المعيارية و قيمة " ت ت " و دلالتها في الإئي

\begin{tabular}{|c|c|c|c|c|c|c|}
\hline مستولة الدلالة & ت & $\varepsilon$ & b & ن & القياس & المتغير \\
\hline \multirow{2}{*}{ عند إلـائياً } & \multirow{2}{*}{ אד, 11} & $v, r \wedge$ & $\checkmark V, \wedge \checkmark$ & 0. & قبلي & \multirow{2}{*}{ الالبجتمعي في القياسين القبلية الأبعادي } \\
\hline & & $0, .9$ & צr, & 0. & بعدى & \\
\hline
\end{tabular}

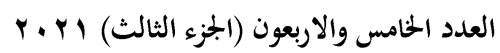

(297)

جلة كلية التربية- جامعة عين شمس 
برنامج مقترح قائم على إستراتيجية التغير المفاهيمي لتصحيح التصورات البايلة للمفاهيم التاريخية

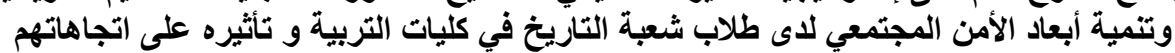

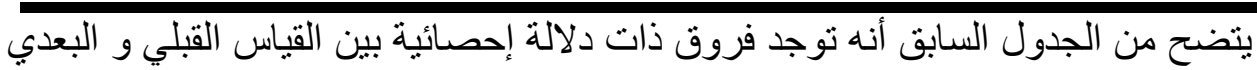

لمجموعة البحث في متوسط الدرجة الكلية لأبعاد اختبار تصحيح التصورات البديلة للمفاهيم التاريخية في القياسين القبلي و البعدي لصالح القياس البعدي حيث كانت قيمة "

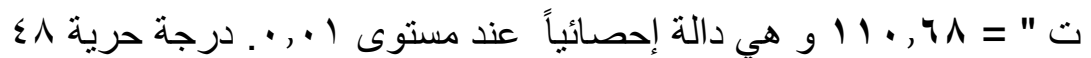
- و للتحقق من الفرض الرابع ". يوجد فرق دال إحصائًا عند مستوى | .,.بين متوسطي درجات مجموعة البحث ،في القياسين القبلي والبعدي ،لمقياس الاتجاهات نحو أبعاد الأمن المجتمعي لكل بعد لصالح المقياس البعدي. وللتحقق من هذا الفرض استخدم الباحثة اختبار " ت " للعينات المرتبطة ،ويمكن عرض ما توصلت إليه الباحثة من نتائج من خلال الجدول( آ) كما يلي : جدول ( 7 ) يوضح الأعداد و المتوسطات و الانحر افات المعيارية و قيمة " ت " و و دلالتها في مقياس ابعاد الامن المجتمعي في القياسين القباتي والئي والبعدي

\begin{tabular}{|c|c|c|c|c|c|c|}
\hline مستوى الدلالة & ت & $\varepsilon$ & p & ن & القياس & أبعاد المقياس \\
\hline \multirow{2}{*}{ دالة إحصائياً عند } & \multirow{2}{*}{$v_{0}, r_{q}$} & $r, V r$ & $r q, r q$ & 0. & قبلي & \multirow[t]{2}{*}{ أولاـ الأمن الفكري } \\
\hline & & $r, \leqslant 0$ & $\vee \vee, \Lambda$. & 0. & بعدى | بع بل & \\
\hline \multirow{2}{*}{ دالة إحصائياً عند } & \multirow{2}{*}{$\Lambda \leqslant, Y \leqslant$} & $\mu, \mu \mu$ & $Y \uparrow, 01$ & 0. & قبلي & \multirow[t]{2}{*}{ ثانياـ الأمن السياسي } \\
\hline & & $r, v q$ & $\vee \vee, \Lambda$. & 0. & بعدى | بع & \\
\hline \multirow{2}{*}{ دالة إحصائياً عذد } & \multirow{2}{*}{ 14,०9 } & r, T & $r \varepsilon, q r$ & 0. & قبلي & \multirow[t]{2}{*}{ ثُالثـــ الأمن الاجتماعي } \\
\hline & & $1, A Y$ & $v \bullet, v$. & o. & 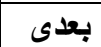 & \\
\hline
\end{tabular}

يتضـح من الجدول السـابق أنـها توجد فـروق ذات دلالــة إحصـائية بـين القياس القبلي و البعدي لمجموعة البحث في متوسط البعد الاولالامن الفكري لصالح القياس البعدي حيث

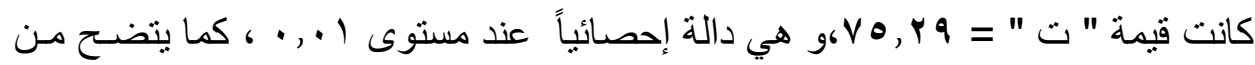
الجدول السابق أنه توجد فروق ذات دلالة إحصائية بين القياس القبلي و البعدي لمجموعـة البحث في متوسط البعد الثاني الامن السياسي لصالح القياس البعدي حيث كانت قيمـة "

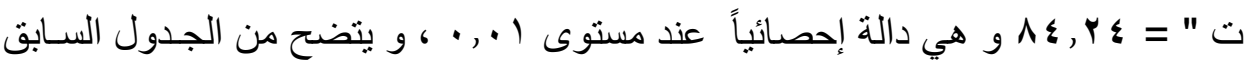


دادة غادة عبد الفتاح زايد

أنها توجد فروق ذات دلالة إحصـائية بين القياس القبلي و البعدي لمجموعـة البحث في في متوسط البعد الثالث الامن الاجتماعي لصالح القيـاس البعدي حيث كانـت قيمـة " ت " =

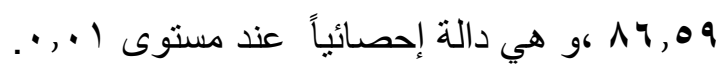

ـ ـ و مما سبق يتضح مدى التأثير الإيجابي للبرنامج على تنمية قدرة الطالب المعلم في كلية التربية لتصحيح التصورات البديلة للمفاهيم التاريخية، وتشتمل على مهارة (T آ) ، وكذلك مدى التأثثر الايجابي للبرنامج على تنمية الاتجاه نحو ابعاد الامن المجتمي،

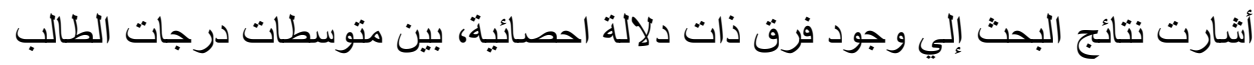
المعلم في كل من الاختبار لتصحيح التصورات البديلة للمفاهيم التاريخية ككل، وفي كل بعد على حدة لصالح التطبيق البعدي ، تأثيره الايجابي على اتجاهاتهم نح ابعاد الامن المجتمعي لدى الطالب المعلم مجموعة البحث ،كما ينضح من النتائج في فاعلية استخدام إستر اتيجية التغير المفاهيمي، في تصحيح التصورات البديلة للمفاهيم التاريخية الواردة ،في الأطر الفكرية المتطرفة لاى مجموعة البحث في الاختبار ،و تأثيره الايجابي تجاه تتمية أبعاد الأمن المجتمعي لما يلي: 1 - عرض المفاهيم التاريخية المتضمنة في البرنامج بأسلوب مشوق باستخدام

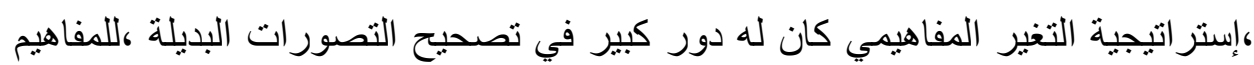
التاريخية الواردة في الأطر الفكرية المتطرفة ،لدى الطالب المعلم في الوحدة فأصبح التعلم اكثر فاعلية وذا معنى. r- أهمية البرنامج وما تضمنه تنوع الأنشطة و المواد التعليمية ،خلال تدريس إستر اتيجية التغير المفاهيمي ،أدى إلى اثارة دافعية الطالب المعلم نحو التعلم ،و تكوين بناء مفاهيمي إيجابي مما ساهم في تصحيح التصور ات البديلة ،للمفاهيم التاريخية الواردة في الأطر الفكرية المنطرفة و تتمية أبعاد الأمن المجتمعي.

rـ المناقتشة و الحوار و التفاعل الايجابي بين الطالب المعلم و أستاذ المادة ،ساعد على تهيئة الفرص لهم للتفكير في مواقف التعلم المختلفة ،باستخدام إستراتيجية التغير

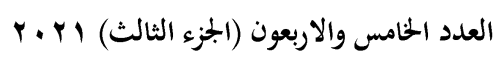

مجلة كلية التربية- جامعة عين شمس لهر 
برنامج مقترح قائم على إستراتيجية التغير المفاهيمي لتصحيح التصورات البيلة للتئية المفاهيم التاريخية

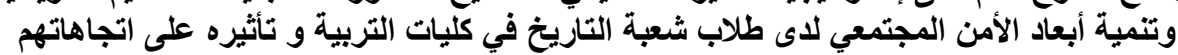

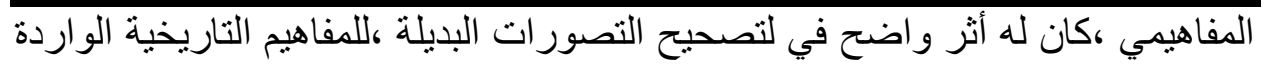
في الأطر الفكرية المتطرفة ،و تنمية أبعاد الأمن المجتمعي. عـ الدور الإيجابي النشط للطالب المعلم في أثناء تعلمه الوحدة المقترحة ،باستخدام إستراتيجية التغير المفاهيمي ،ادى إلى زيادة تركيز هم وفهمه و تحصين عقولهم ،و إدر الك العلاقة بين المفاهيم التاريخية ،و ما تقدمه الجماعات المتطرفة من مفاهيم خاطئة واردة في الأطر الفكرية ،و تتمية اتجاههم نحو تنمية أبعاد الأمن المجتمي.

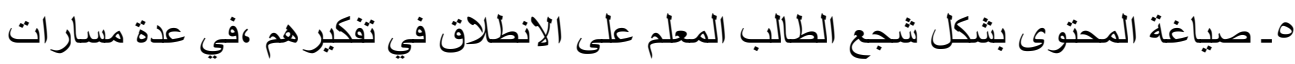
متشعبه لاكتساب المعلومات و اكتشاف الافكار و العلاقات ،و ذلك من خلال التركيز في صياغة المحتوى على بعض المواقف و الأحداث ،التي تتطلب دراستها استخدام و هذا كان لله مردود إيجابي في اكتساب المفاهيم التاريخية بصورة تتسم بالفهم و العمق. 7ـ تطلب در اسة الوحدة المختارة قيام الطالب المعلم ،بالبحث عن المعلومات و الحقائق و القيام بأنشطة البحث و التقصي ،و جمع البيانات و المعلومات عن المفاهيم التاريخية بموضوعية ،مما ساهم في امتلاكهم لقدر كبير المعلومات بدقة ووضوح. وتتفق هذه بهات النتائج مع نتائج بعض الدراسات السابقة ،التي اهتمت لتصحيح للمفاهيم ،لدى الطلاب في استخدمت استراتيجيات مختلف المراحل التعليمية، وأساليب في تدريس الدراسات

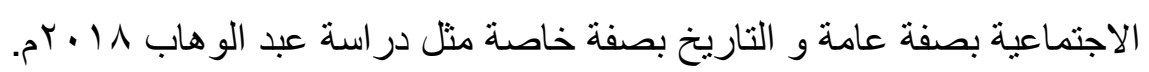
Vـ استهدف دليل أستاذ المادة توجيه الطالب المعلم ،إلى تتفيذ الأنشطة الفردية و الجماعية ،مما شجعهم على المثابرة في العمل و بذل الجهد ،و على التفكير التبادلي من خلال تنفيذ المهام بالتعاون مع زملائه و شجعت على تبادل الآراء و الافكار ،حتى تكتمل المهام

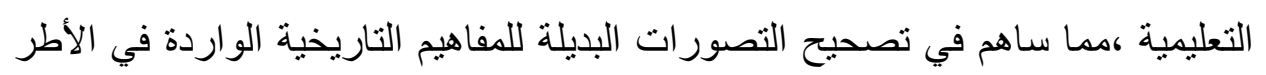

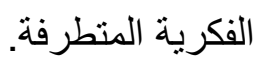


د/ غادة عبد الفتاح زايد

1ـ شجع كتيب الطالب المعلم الإرشادي الطالب المعلم على الانخراط في الأنشطة التعليمية لتقديم مجموعة من الأفكار و الآراء ،و تبادل الحوار مع بعضهم البعض ،و على تقبل الأفكار المختلفة عن أفكار هم و على التحرر من الجمود في التفكير. ـ توصيات البحث : في ضوء نتائج البحث، نوصي الباحثة بما يأتي: اـ توعية الطالب المعلم بكيفية استخدام إستراتيجية التغير المفاهيمي في تصحيح التصورات البديلة للففاهيم التاريخية ،في مادة التاريخ ،حتى يستطيع تنميتها لدى طلابه أنثاء الخدمة. rـ تدريب الطالب المعلم على استخدام إستراتيجية التغير المفاهيمي، كمدخل أساسي في تدريس مادة التاريخ لتصحيح التصورات البديلة ،حتي يستطيع تطبيقها على طلابه أنثاء الخدمة. rـ توجيه أنظار معلمي مادة التاريخ إلى أهمية الكثف عن التصورات البديلة للمفاهيم

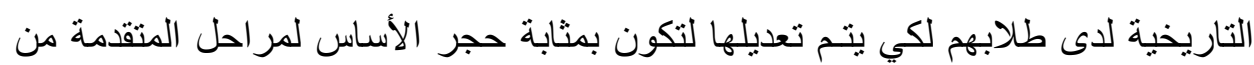
الدر اسة. عـ تضمين محتوى مقررات طرائق التدريس في الكليات ،عن الإستراتيجيات الحديثة التي يمكن استخدامها في تصحيح التصورات البديلة للمفاهيم التاريخية لدى الطالب المعلم. 7ـ تحفيز واضعي المناهج إلى تنظيـم منهج مادة التاريخ وفق أساس مفاهيمي بناء كيتسم بالثراء والعمق ذات معنى لتوعية الطالب المعلم التصورات البديلة للمفاهيم التاريخية وكيفية تصحيحها. V_ـ اهتمام المؤسسات التربوية و التعليمية بالتنسيق مع مؤسسات المجتمع المدني ،ووضع البر امج للحفاظ على استقرار المجتمع كيان ،لوقاية من الانحر اف والتطور لدى الناشئة و معالجتها. 
برنامج مقترح قائم على إستراتيجية التغير المفاهيمي لتصحيح التصورات البيلة للتئية المفاهيم التاريخية

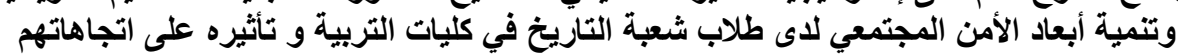

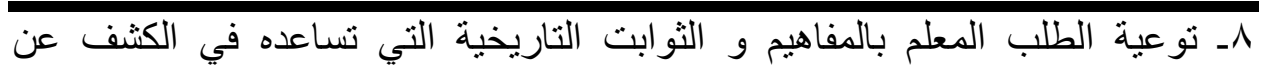
التطرف الفكري ، من أجل الحفاظ على أبعاد الأمن المجمعي والاهتمام، وتتمية الوعي الأمني المجتمعي. 9ـ توفير بر امج و أنشطة لتوعية الطالب المعلم بأهمية تحقيق أبعاد الأمن المجتمعي ،من خلال الندوات و المحاضرات و المسابقات في مراحل التعليم العام. • اـ مر اعاة تنمية أبعاد الأمن المجتمعي عبر المناهج الدراسية المختلفة، وفق متطلبات العصر و تحدياته بحيث يصبح الطالب مشاركا إيجابيا في الحفاظ على كيان و استقرار

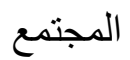
ر ابعاً: المقترحات:تقتر ح نتائج البحث الحالية القيام بالبحث الاتية: اـ تصور مقترح قائم على تصحيح الأخطاء المفاهيمية التاريخية، لاى معلمي مادة التاريخ في المرحلة الثانوية. r ـ فاعلية استخدام متطلبات أبعاد الأمن المجتمعي ،على تتمية مهارات التفكير التاريخي وبقاء أثر التعلم لدى طلاب المرحلة الثانوية. rـ فاعلية استخدام إستراتيجية التغير المفاهيمي في تدريس التاريخ ،على تتمية التفكير المستقبلي لدى طلاب المرحلة الثانوية. عـ برنامج في التاريخ قائم على النظرية البنائية ،لتنمية وعي الطلاب بالتصور ات البديلة و الاتجاه نحو ها بالمر احل المختلفة. ○ـ فاعلية إستراتيجية حل المشكلات تدريسية ،في تنمية المفاهيم التاريخية لتصحيح التصور ات البديلة للمفاهيم التاريخية لاى المتعلمين في المر احل الثانوية. 


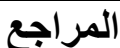

\section{اولا المراجع العربية}

اـ أبو السعيد ،أحمد العبد و حسين، على محمد (9 . . Tم): فاعلية استخدام خرائط المفاهيم و الطريقة الاستقرائية في تنمية التحصيل المعرفي للمفاهيم الجغر افية والاتجاه نحو تعلمها لدى

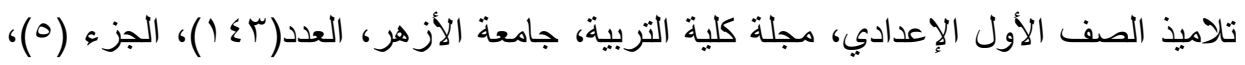
ص ص ص r

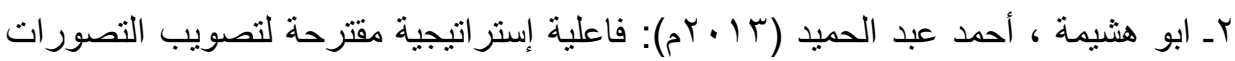
الخطأ في المفاهيم المرتبطة بمقرر المناهج لطلاب كلية التربية بالدمام، مجلة كلية التربية،

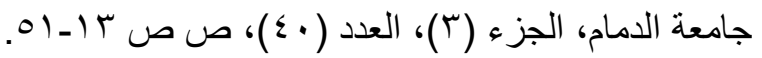

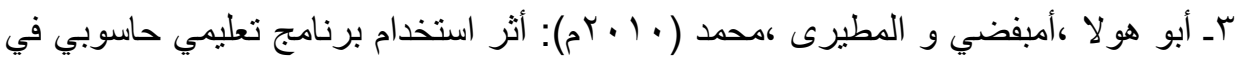
تغير المفاهيم البديلة في العلوم لدى تلاميذ الصف الثاني المتوسط في المملكة العربية السعودية،

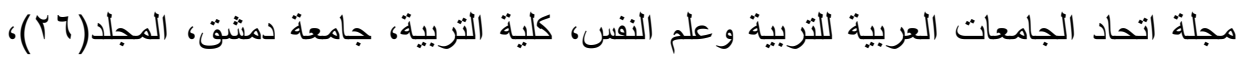

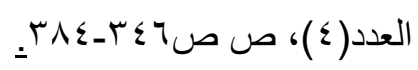

عـأحمد، علاء الدين أحمد عبدالر اضي ( 9 ( • rم): إستر اتيجية قبعات التفكير الست في تدريس الدراسات الاجتماعية لتنمية المفاهيم التاريخية وبعض عادات العقل لاى تلاميذ الصف الأول

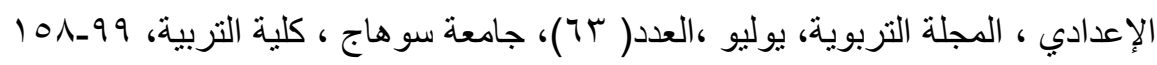

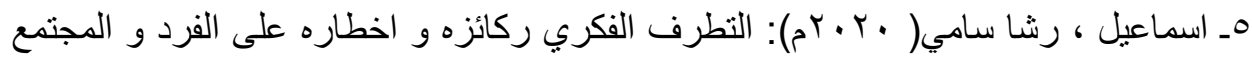

و سبل معالجته من وجهة نظر طالبات جامعة حائل ، مجلة العلوم الإنسانية ، العدد(0)، 99 جـ الأسمر، رائد يوسف (^ . ㄷم): أثر دورة التعلم في تعديل التصورات البديلة للمفاهيم العلمية للى الصف السادس الأساسي واتجاهاتهم نحوها، رسالة ماجستير غير منشورة ، كلية التربية،

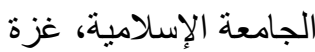
V_ الاشقر ،سماح فاروق المرسي( V V • Yم):استخدام نموذج ستيبانز في تصحيح التصورات البديلة لبعض المفاهيم العلمية و تنمية الاتجاه نحو العمل الجماعي لدى تلاميذ الصف السادس لهاس

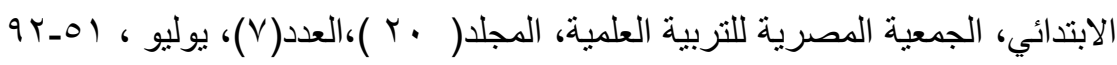


برنامج مقترح قائم على إستراتيجية التغير المفاهيمي لتصحيح التصورات البديلة للمفاهيم التاريخية

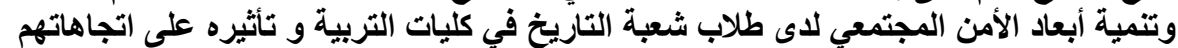

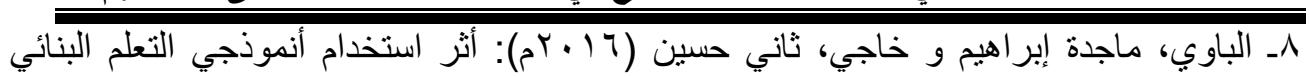
وبوسنر في تعديل التصورات الخاطئة لبعض المفاهيم الفيزيائية لدى طلاب معاهد إعداد المعلمين و اتجاهاتهم نحو المادة، مجلة العلوم الإنسانية، العدد(YV).

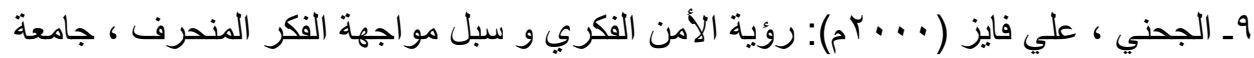
نايق العربية للعلوم الأمنية ، الرياض لايز • ( ـ الجميد ، خديجة فرحان ( • • · r): المناهج و صناعة الأمن الفكري الحاجة و المنطلقات،

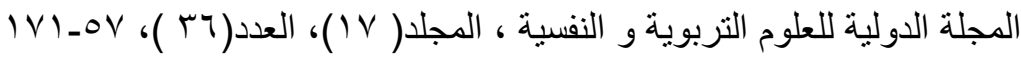

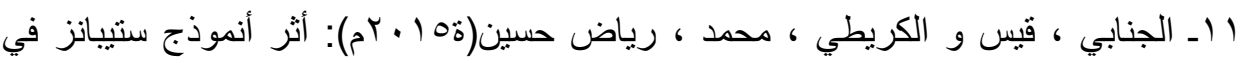
اكتساب المفاهيم التاريخية و استبقائها لدى طلاب الصف الأول المنوسط، مجلو كلية التربية

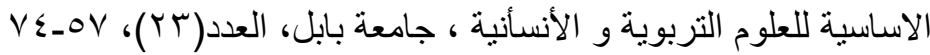
r اـ الجني، فواز بن عقيل ، حسين، محمد فتحي عبد الفتاح (r ا • rم):تصور مقترح لتفعيل دور حامعة تبوك في تعزيز الأمن الفكري لدى الطلاب، دراسات عربية في النربية و علم

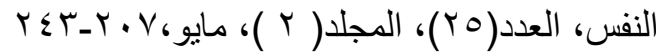

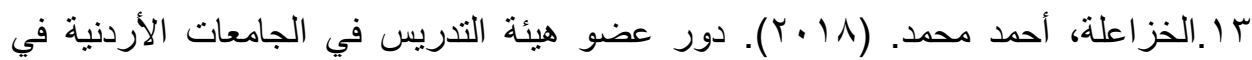
توعية الطلبة بمخاطر الفكر الارهابي والمتطرف وتتمية الحس الوطني لديهم من وجهة نظر لنر طلبتها. المجلة الدولية للبحوث في العلوم التربوية،المجلد (، العدد(ب)، وبr - ع عب.

ع اــ الدليمي ،عصام حسن (ع ( ب)): النظرية البنائية وتطبيقاتها التربوية، دار صفاء للنشر و التوزيع، عمان.

1 ـ الدهمش ،عبد الولي حسين و النعمان، عبد القوي و الفراص ،زكريا (ع ( • ب): أثر استخدام نموذج بايبي في تعديل التصورات البديلة لمادة العلوم لدى تلميذات الصف الثامن الأساسي،

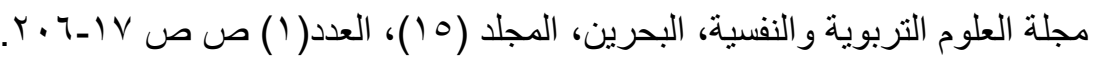
7 ـ الديب، محمد محمود (Y ( Yم):فاعلية استراتيجيات ماور اء المعرفة في تعديل التصور ات البديلة للمفاهيم العلمية في العلوم للى طلاب الصف التاسع رسالة ماجستير ، الجامعة الاسلامية غزة 


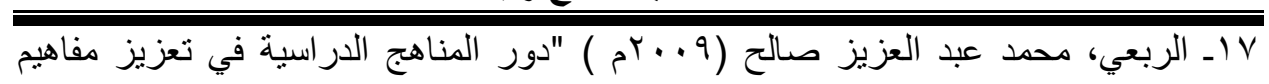
الأمن الفكري و تعزيز الهوية الثقافية لدى طلابها "المؤتمر الوطني الأول للأمن الفكري " المناهج و التحديات "جامعة الملك سعود ، r r ب م مايو. 1 اـ الرفاعي، أحمد محمد رجائي(^ ا • Y: دور إستر اتيجية التغير المفاهيمي عبر أنشطة فن طي الورق وتتمية الثائعة الرياضيات أخطاء تصويب في "Origami"بالنفس لدى تلاميذ المرحلة

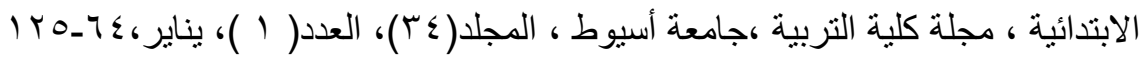
V ا الز هر اني ، محمد سعيد محمود(ع ( Yم): فاعلية إستر اتيجية مقترحة قائمة على التغير المفهومي في تعديل التصورات البديلة عن بعض المفاهيم النحوية لدى طلاب الصف الثأني المتوسط و احتفاظهم بها أطروحة ، دكتور اه غير منشورة،جامعة ام القري 1 اـ الزعانين ،جمال عبد ربه (1 (1)): فعالية نموذج بوسنر في إحداث التغير المفاهيمي لبعض المفاهيم الفيزيائية لدى طلبة الصف السادس بقطاع غزة واحتفاظهم بها، مجلة جامعة مؤتة للبحوث و الدراسات، سلسلة العلوم الإنسانية والاجتماعية، المجلد (Tب)، العدد (T)، ص

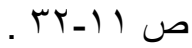

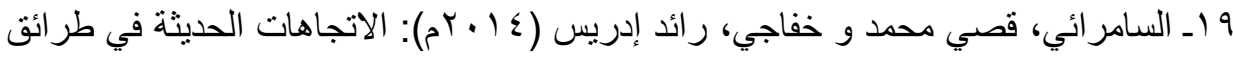
التدريس، طا ، دار دجلة للنشر و التوزيع، عمان، الأردن

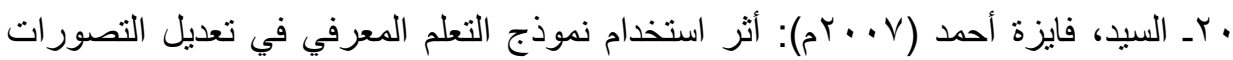
البديلة لبعض المفاهيم السياسية، وتنمية الميل نحو مادة التاريخ لدى تلميذات الصف الثالث الإعدادي في ضوء أنماط تعلمهم المفضلة، مجلة كلية التربية، جامعة أسيوط، المجلد (Yr)،

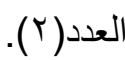

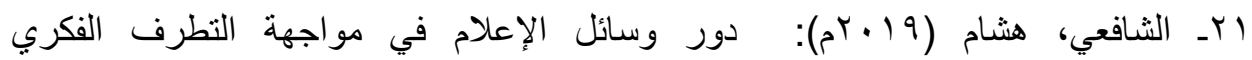
المصدر:مجلة العربي للدراسات الإعلامية،المركز العربي للأبحاث و الدراسات الإعلامية ،

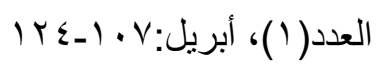

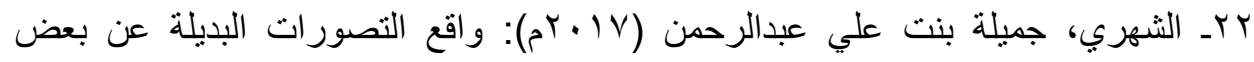
المفاهيم الكيميائية في كتاب الصف الأول المتوسط لدى معلمات علوم المرحلةالمتوسطة، العدد( V V ), المجلد( ) ( ) ، اكتوبر ،جامعة الأزهر ، كلية التربية،694 - 654

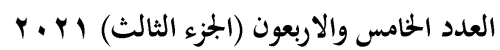
(305)
جلة كلية التربية- جامعة عين شثس 
برنامج مقترح قائم على إستراتيجية التغير المفاهيمي لتصحيح التصورات البديلة للمفاهيم التاريخية

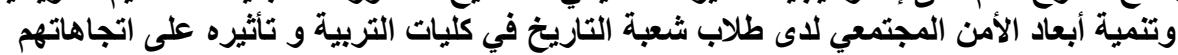

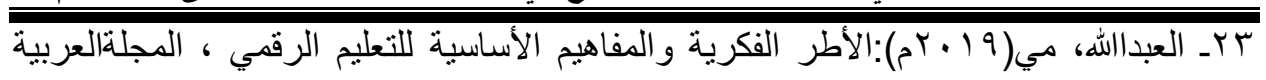

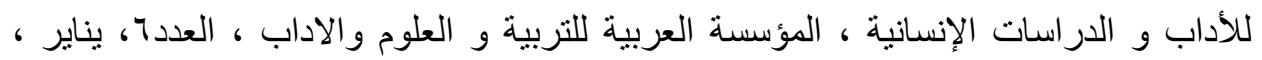
ro.-rma

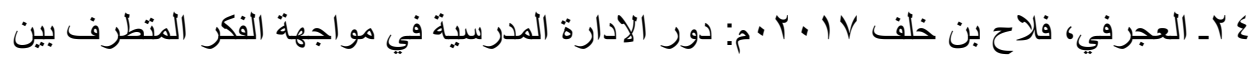

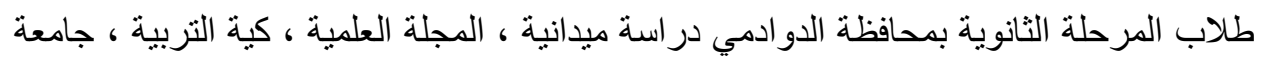

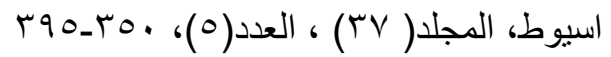

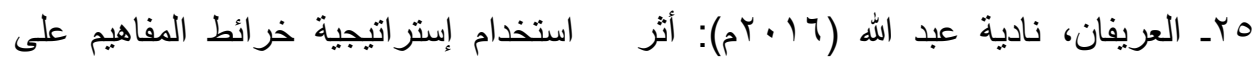

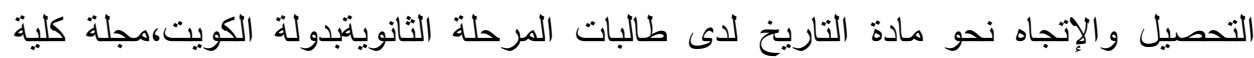

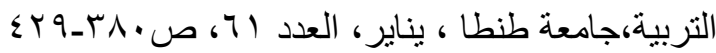

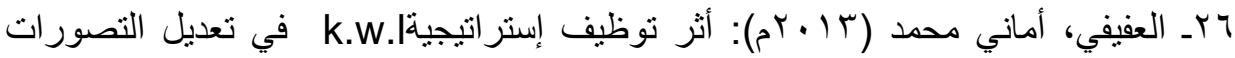

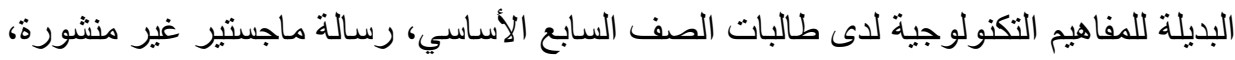
كلية التربية، جامعة الأزهر ، غزة.

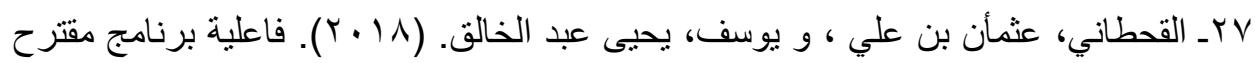
قائم على شبكات التو اصل الاجتماعي ومقومات المو اطنة الرقمية في تنمية مكونات الأمن التقني و الفكري لدى طلبة السنة التحضيرية بجامعة تبوك، مجلة رسالة الخليج العربي، مكتبة التربية

$$
\text { العربية لدول الخليج، العدد( • } 9 \text { (). }
$$

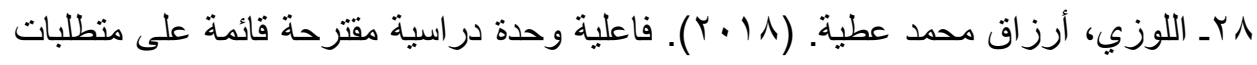
أبعاد التربية المدنية بمنهج التربية الأسرية في تنمية قيم الأمن الفكري ومهار الترات التهات التخاذ القرار

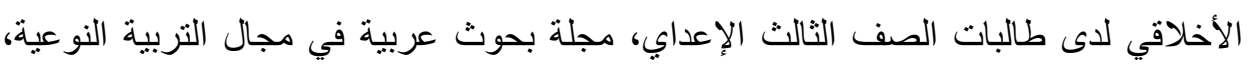
رابطة التربويين العرب، العدد(9)

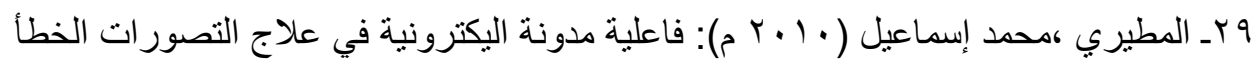
للمفاهيم العلمية لدى طلاب الصف التاسع الأساسي واتجاهاتهم نحوها، رسالة ماجستير غير ماتير

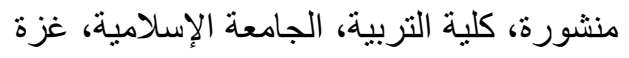


دادة غادة عبد الفتاح زايد

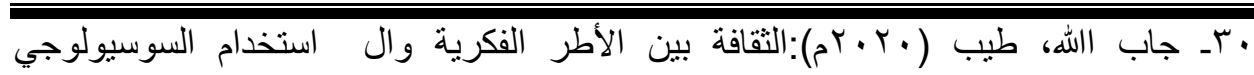
المصدر:المجلة العربية للآداب والدراسات الأنسأنية، المجلة العربية للأداب والداب ولدراسات

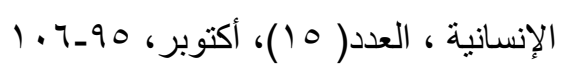

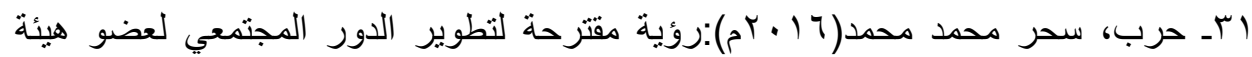
التدريس الجامعى الفلسطينى لتلبية متطلبات مجتمع المعرفة، مجلة القراءة و المعرفة، جامعة عين شمس ، كلية التربية ، الجمعية المصرية للقراءة والمعرفة،،كلية التربية ، جامعة عين

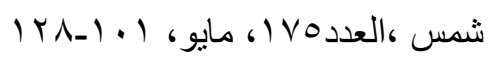

r rـ حسين، آمال اسماعيل ( 9 ( • rم):التطرف الفكري وعلاقته بالقيم الاجتماعية للى طلبة الجامعة ،مجلة أبحاث البصرة للعلوم الأنسأنية ، جامعة البصرة ، كلية التربية للعلوم

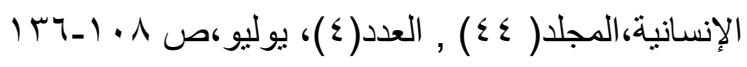

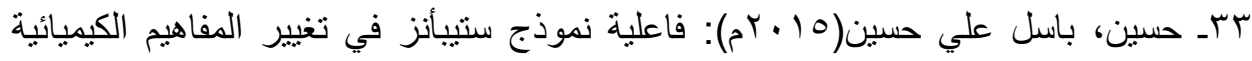

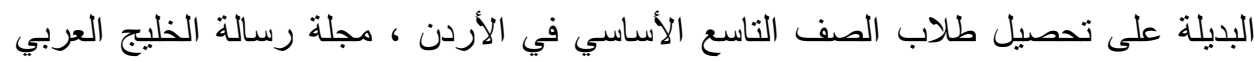

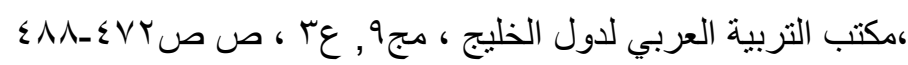

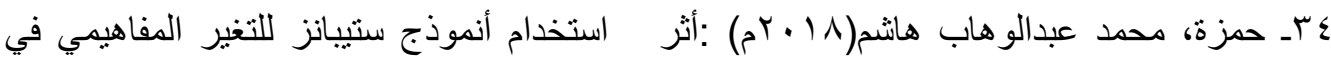
تنمية|المفاهيم الرياضية والاحتفاظ بها لدى طلبة الصف العاثرالأساسي في الأردن المجلة

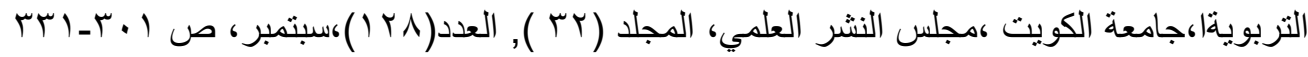

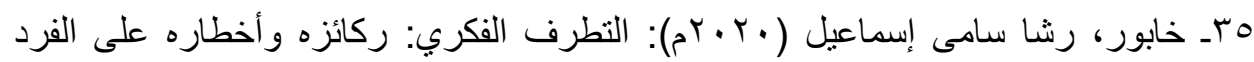

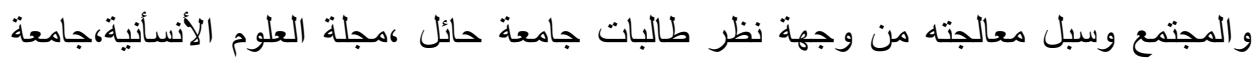

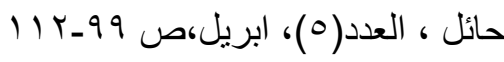

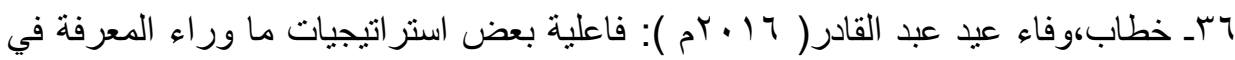
تصويب التصورات الخطأ للمفاهيم الدينية الإسلامية لدى طالبات التعليم الثانويالفني،رسالة

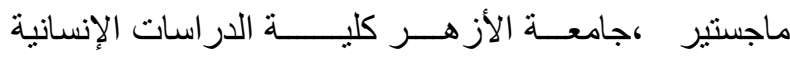

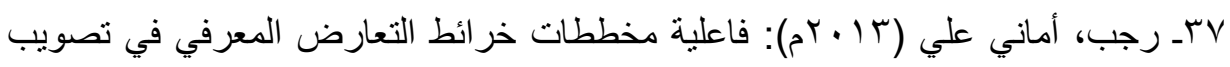
التصورات البديلة للمفاهيم الجغرافية لدى تلاميذ الصف الرابع الابتدائي، مجلة الجمعية التربوية للار اسات الاجتماعية، العدد ع 0).

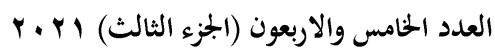

مجلة كلية التببية- جامعة عين شمس 
برنامج مقترح قائم على إستراتيجية التغير المفاهيمي لتصحيح التصورات البيلة للتئية المفاهيم التاريخية

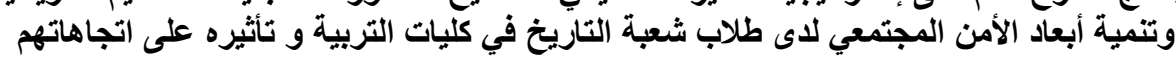

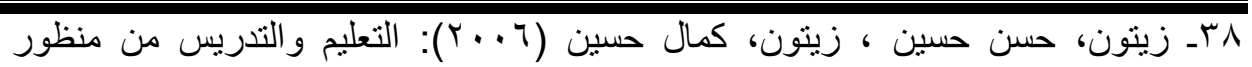
النظرية البنائية، طب، القاهرة، عالم الكتب.

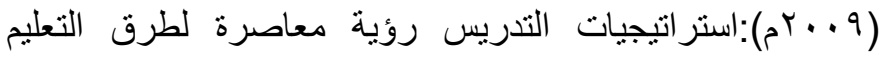
$-49$ و التعلم، طץ، القاهرة، عالم الكتب.

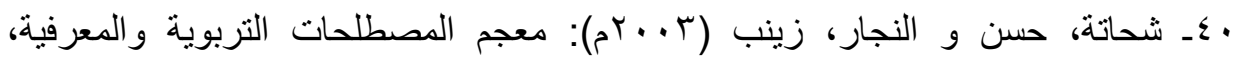

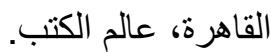

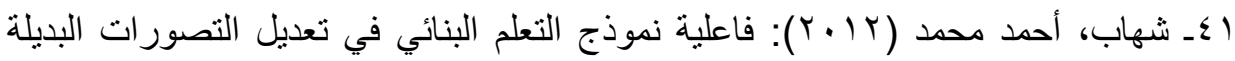
وتتمية القدرات الذهنية في الفيزياء الزراعية، رسالة ماجستير غير منشورة، كلية التربية، جامعة كفر الثيخ

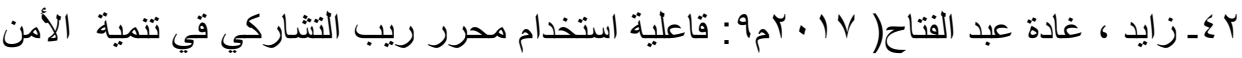
الفكري و التعايش مع الاخر لدى طلاب كلية التربية قسم التاريخ ، مجلة كلية التربية قسم التاريخ ، مجلة الجمعية التربوية للار اسات الاجتماعية ،كلية التربية ، جامعة عين شمس، المجلد

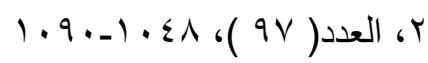
rاءـ عبد الرحمن ، أحمد عبد الرشيد حسين ( 1 ( • بم): فاعلية إستراتيجية المفاهيم الكرنونية في تصويب التصورات البديلة التصورات البديلة للمفاهيم الجغرافية و تتمية الاتجاه نحو المادة

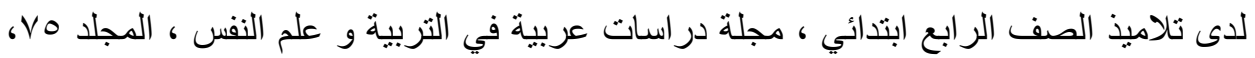
rNTrtra

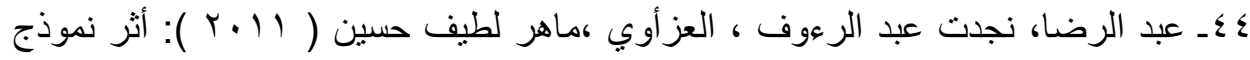
في تصحيح المفاهيم الجغرافية ذات الفهم الخاطئ لاى طلاب الصف الأول المتوسط ، مجلة

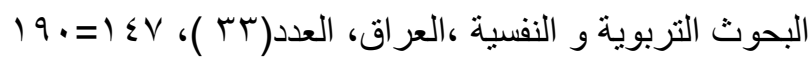

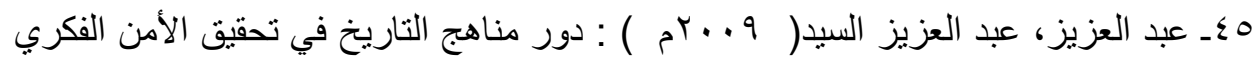

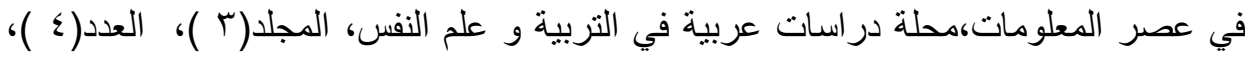

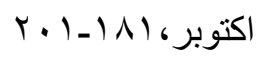

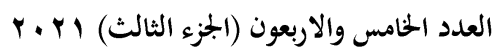

(308)

جلة كلية التربية- جامعة عين شمس 


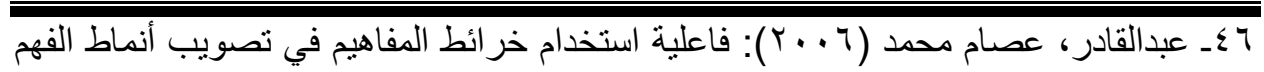

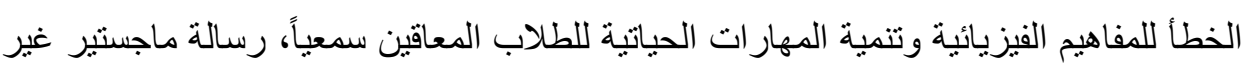
منشورة، كلية التربية، جامعة الاز هر.

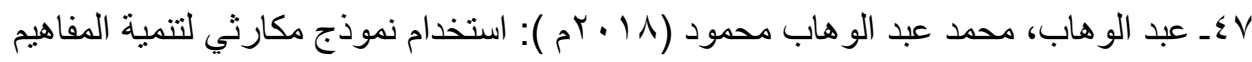
التاريخية و مهارات التفكير التقويمي لدى طلاب الصف التاسع الاساسي بغزة ، رسالة ماجستير غير منشورة ، الجامعة الإسلامية ، غزة.

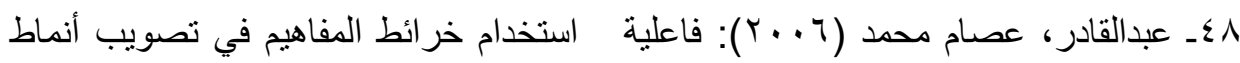
الفهم الخطأ للمفاهيم الفيزيائية وتتمية المهارات الحياتية للطلاب المعاقين سمعياً، رسالة ماجستير غير منشورة، كلية التربية، جامعة الاز هر.

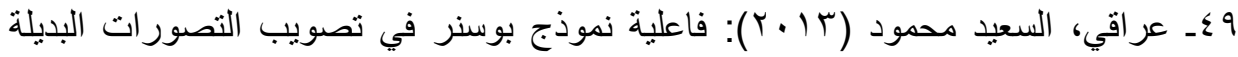
لبعض المفاهيم الرياضية لدى قسم التربية الخاصة بكلية التربية جامعة الطائف، مجلة كلية

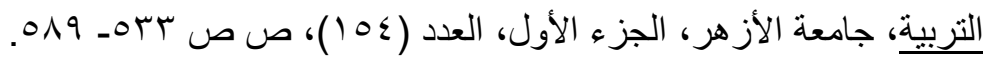

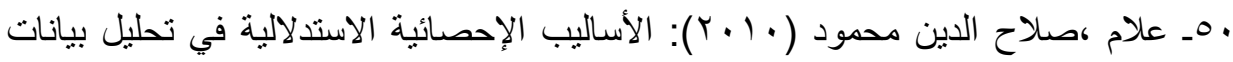
البحوث النفسية و التربوية والاجتماعية البار امتريه و اللابار امتريه، دار الفكر العربي، القاهرة.

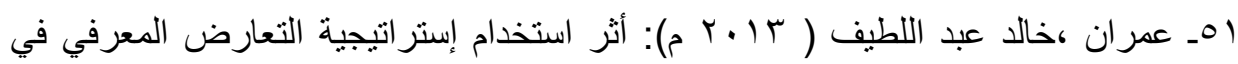
تصويب التصور ات البديلة للمفاهيم الجغر افية لاى طلاب الصف المرحلة الثأنوية، مجلة كلية

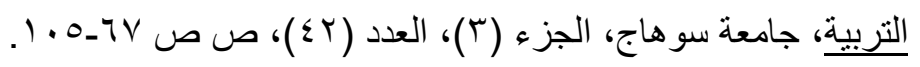

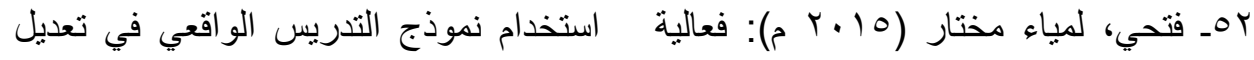
التصورات البديلة لاى تلاميذ الصف الأول الإعدادي في مادة الدراسات الاجتماعية، رسالة

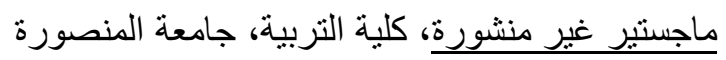

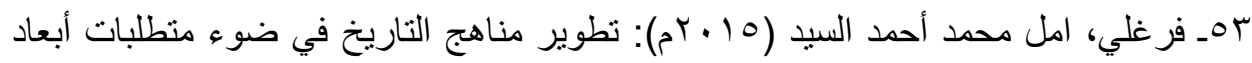

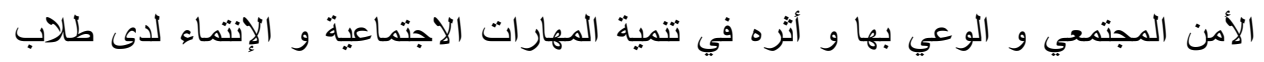

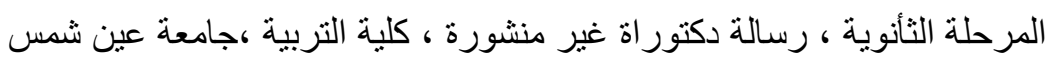


برنامج مقترح قائم على إستراتيجية التغير المفاهيمي لتصحيح التصورات البديلة للمفاهيم التاريخية

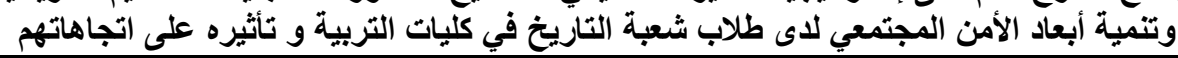

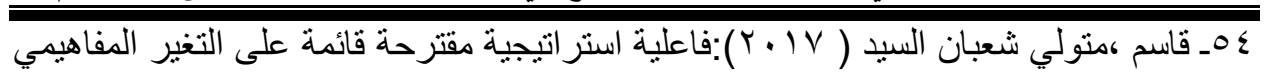
في تصويب التصورات الخطأ للمفاهيم الجغرافية لدى تلاميذ المرحلة الإعدادية الأزهرية،

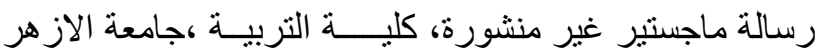

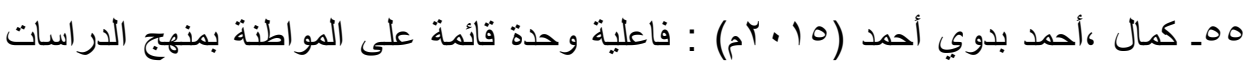

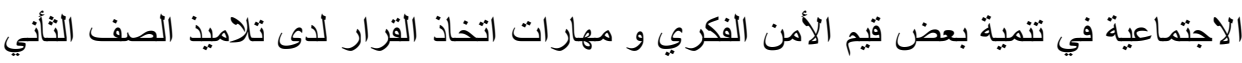

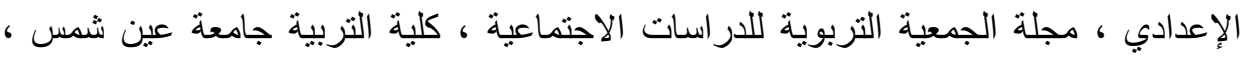

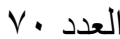

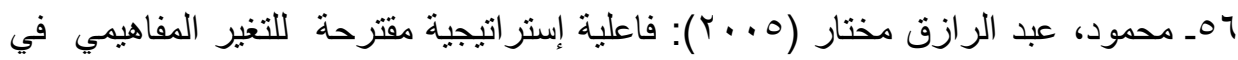
تصويب التصورات الخطأ عن بعض المفاهيم النحوية لدي تلاميذ الصف الثأني المتوسط، مجلة

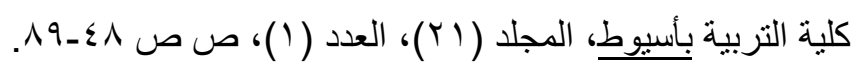

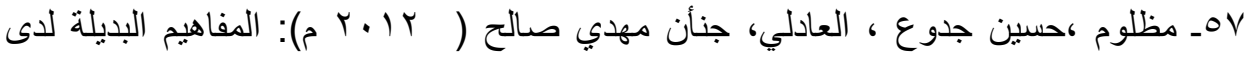

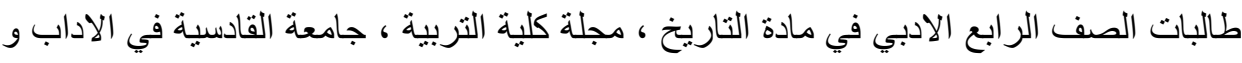

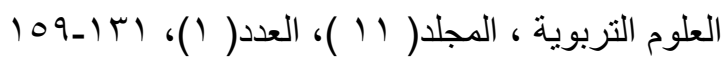

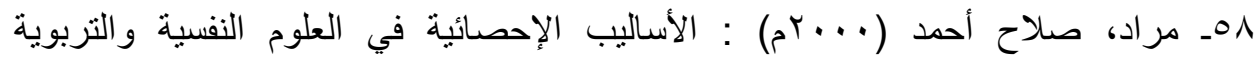

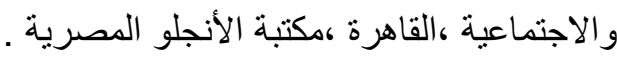
9 همصطفى ،محمد نجيب ومحمود ، عبد الرازق مختار (9 . . Tم): استر اتيجيات تصويب أنماط الفهم الخطأ في العلوم والتربية الإسلامية، طا، القاهرة، دار الفكر العربي.

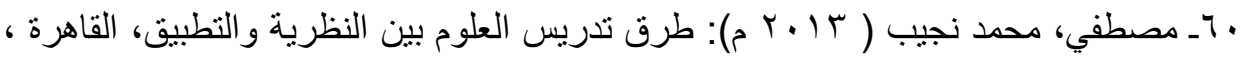
دار الفكر العربي. آTـ مؤتمر الازهر (10 • بم): دليل المسلمين إلى تفنيد افكار المتطرفين ،دار الافتاء المصرية،

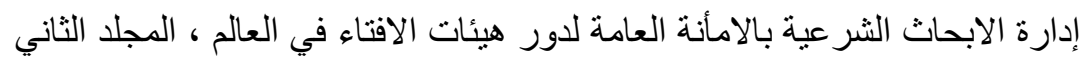

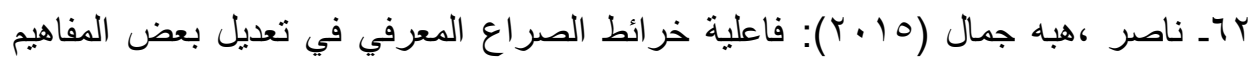

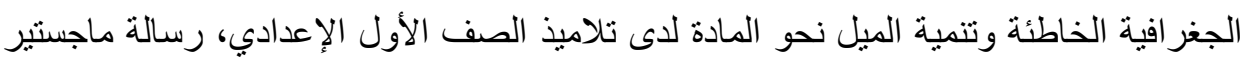
غير منشورة، كلية التربية، جامعة عين شمس.

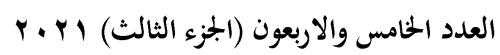

جلة كلية التربية- جامعة عين شمس 


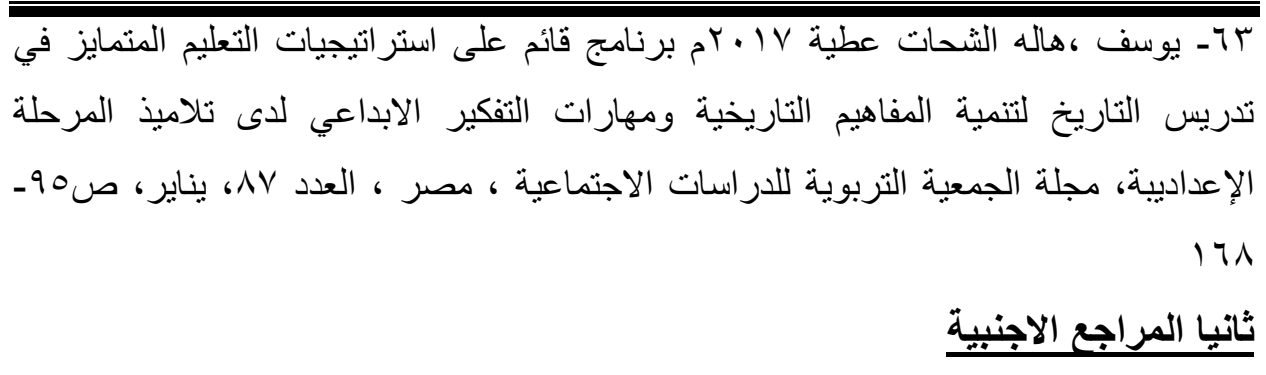

64-Aguilar, Stephen J.; Polikoff, Morgan S.; Sinatra, GalM.(2019):Refutation Texts: A New Approach to Changing Public Misconceptions about Education Policy,Educational Researcher, v48 n5 p263-272 .

65-Clinchm, A. (2011). Community psychology approach to preventing violent extremism: gaining prevention in secondary schools University of Birmingham

66- chi , M \& Roscoe , R (2002) : the process and challenges of conceptual change. In M. limon\& L. Mason(E d s). Reconsidering conceptual change, Issues in theory and practice.

67- Lane, R. (2012). Alternative coneptions of tropical Cylone Causes and proesses. Interntional Research in Geographical and Enironmental Education. 21 (3), 205-222.

68-.Langman, Peter\& Petrosino,Anthony\& Persson, Hannah (2018): Five Misconceptions about School Shootings,Non-Journal,5-1.30

69- Merrill, M. David, and Tennyson, Robert D, (2006). Teaching Concepts, An Instructional Design Guide. New Jersy, Education Technology Publications

70-.Nwafor, Naboth H. -Nwogu, Godpower A. I.(2015):Implication of Radicalisation for Nigerian Education: A Philosophical Analysis, Journal of Education and Practice, vol6 no21 p201-207 31

71-. parker, E. (2010), Therelationship between nature of science understanding and science self -efficacy beliefs of sixth grade students, Georgia State University, Digital Archive @ GSU, Middle-Secondary Education And Instructional Technology Dissertations, Department Of Middle-Secondary Education And Instructional Technology

72-Pinochet, J. (2019). Five Misconceptions about Black Holes, Journal Articles; Reports -Evaluative,vol 54, no(5).32

73-Pitor Razniak (2012): "Influence of the social security level on population migration in Roland" University of Krakow. Poland.

العدد الخامس والاربعون (الجزء الثالث) ا ب r r

مجلة كلية التربية- جامعة عين شمس 


\section{برنامج مقترح قائم على إستراتيجية التغير المفاهيمي لتصحيح التصورات البديلة للمفاهيم التاريخية

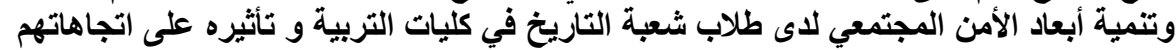

74-Schmidt,D .Saigo.B.and Stepans, J.(2006). Conceptual Change Model: The CCM Hand book. Saiwood Publications, Minnesota, USA..

.74-Stepans, J. \& Schmidt, D. (2009). From Wyoming to Florida, They ask, "Why was not I taught this way?" In: R. Yager (Ed.), Inquiry: The key to exemplary science(pp.70-75. Arlington, Virginia: National Science Teachers Association press

75-Thabet, I.M)2012 (: The Effectiveness of the Respect and Discipline Initiative Program in Modifying the Behavior of the Students of UNRWA Schools in the Gaza Governorates and Ways of Development .Faculty of Education, 254.33

76-Thomas, Christopher L.; Kirby, Lauren A. J.(2020):Situational Interest Helps Correct Misconceptions: An Investigation of Conceptual Change in University Students,Instructional Science: An International Journal of theLearningSciences, vol 48 no 3 p223-241 